\title{
Resisting the Pied Piper: Colorful Defense Mechanisms in Insect Eggs, With a Focus on Stink Bugs (Heteroptera: Pentatomidae)
}

\author{
by \\ Eric Guerra-Grenier
}

\begin{abstract}
A thesis submitted to
the Faculty of Graduate and Postdoctoral Affairs

in partial fulfillment of the requirements for the degree of
\end{abstract}

Master of Science

in

Biology

Carleton University

Ottawa, Ontario

(C) 2018, Eric Guerra-Grenier 


\begin{abstract}
How can immobile life stages such as eggs protect themselves against physical and biological threats? One protective adaptation that has evolved to help them survive is egg coloration. In this thesis, I begin by reviewing the studies looking at the adaptive insect egg coloration and distinguish what is known based on scientific evidence versus untested hypotheses. I then move on to testing whether the eggs of the Harlequin cabbage bug are chemically defended, in an attempt to link glucosinolate sequestration to possible aposematic egg coloration. I argue that the nymphs are not only chemically defended, but also use tonic immobility as an alternative antipredation strategy until sufficient compound sequestration is achieved. Finally, I assess the selective pressures behind the evolution of egg color polymorphism in the Spined soldier bug. I demonstrate that frequency-dependent predation is necessary to select for approximately equal frequencies of the two main morphs observed in nature.
\end{abstract}




\section{ACKNOWLEDGEMENTS}

First of all, I would like to dedicate this Master's thes is to Dr. Paul K. Abram. Although Paul is now a successful researcher at Agriculture Canada, I first met him when he was a $\mathrm{PhD}$ student at the University of Montreal. Back then, I was a first year undergraduate student beginning an internship in Dr. Jacques Brodeur's lab, where I was assigned to work on two of Paul's many side projects. It was then that I was first introduced to the joy of doing research, but also to the magical world of adaptive egg coloration. I can safely say that on that day, my life changed and I began walking on a path that led me to where I am today. Paul, I owe you many thanks for the time you spent answering all of my many questions and the valuable opportunities you gave me. Go team Podisus!

It was also Paul who suggested that I reach out to Dr. Tom Sherratt, my thesis supervisor to whom I also owe a great debt of gratitude. I decided to move to Ottawa specifically to work with Tom and I must say that I never regretted my decision. I got to learn a great deal from him, whether it was about adaptive coloration, statistical analyses and mathematical modelling, or simply how to deal with very energetic twins. I am very thankful for his patience, of which he never ran out of even when things were tough in the lab. I will always cherish my fruitful time at Carleton University, thanks to him.

Many thanks go to my thesis advisory committee for their advice and feedback during committee meetings, especially when Skype connections were horrible. I also wish to thank Rui Liu, because without his brilliant input and technical assistance I could never have completed any biochemical analyses. I am grateful for Dr. Don Weber and the 35 
eggs clutches he sent me in order to build an efficient insect colony. When it came to learning how to be a good teaching assistant, Dr. Andrew Simons and Dr. Mark Forbes gave me fantastic advice and were always patient with me. Dr. Changku Kang was particularly helpful during my first year at Carleton, doing everything he could to make me feel welcome. I also owe many thanks to Dr. Felipe Dargent for several hours chatting about my current and future research; I learned a great deal from him. I also wish to thank the other members of the Sherratt lab, past and present. In particular, Sophie Potter always did everything she could to make me feel like I was part of the gang. Her emotional support, sometimes in the form of Oreo cookies, Squash games and Firefly DVDs allowed me to complete this thesis without going mad. Along with other colleagues like Lauren Efford and Ian Dewan, we went through many lab crises and complaining about "the thing" was always very comforting. I would also like to thank Casey Peet-Paré and Tammy Duong for fun times in the lab and very helpful discussions.

Finally, I need to thank my friends and family for helping me out during a tough situation I found myself into while being at Carleton. To my friends, I want to say that I am very grateful you never gave up on me and were always there when I needed you. To my mother Marie Guerra and grandparents Joey Guerra and Nicole Piché, I cannot begin to tell you how lucky I am that you are my family; many thanks for everything you did to make sure that I became the best version of myself. Last but not least, I need to thank my lovely partner, Alexandra Angers, for being my sunshine during rainy days. You always know exactly what I need, whether it is a hug of a push in the right direction. Writing this thesis simply could not have been possible without you. You really are my sheep. 


\section{TABLE OF CONTENTS}

ACKNTRACT

CHAPTER 1: EVOLUTIONARY ECOLOGY OF INSECT EGG COLORATION - A REVIEW

CHAPTER 2: CHEMICAL DEFENSES AND TONIC IMMOBILITY IN EARLY LIFE STAGES OF THE HARLEQUIN CABBAGE BUG....................................................... 35

CHAPTER 3: UNDERSTANDING THE ROLE OF FREQUENCY-DEPENDENT PREDATION ON THE EVOLUTION OF SELECTIVE EGG PIGMENTATION .................61

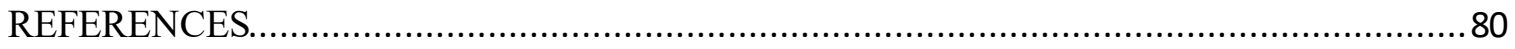




\section{LIST OF TABLES}

Table 1. Non-exhaustive list of species with known egg chemical defenses. For each species listed, mentions of egg coloration and aposematism in the original research papers are reported when existent. The symbol "-“" is used when studies lacked experimental evidence testing for the aposematism hypothesis.

Table 2. Comparison of the fit of the models testing for the effects of fixed and random factors on A) the presence and B) duration of TI displayed by nymphs. Rows in bold indicate which models best fitted the data based on AIC values. If two or more models shared the lowest AIC $( \pm 0.1)$, the one with the most degrees of freedom was chosen. ...53 


\section{LIST OF FIGURES}

Figure 1. Eggs of Manduca sexta laid on a green leaf. The greenish color of the eggs may have evolved for background matching cryps is. Photo by the Insect Zoo of the Smithsonian National Museum of Natural History (CC BY-NC 2.0).

Figure 2. Egg clutch of the ladybug Coccinella septempunctata. The orange eggs contrast with the green background, and their color hue and saturation positively correlate with their concentration in defensive a kaloids (Winters et al., 2014). Photo by Gilles San Martin (CC BYSA 2.0).

Figure 3. Two days old eggs of the saturniid moth Automeris io. These white eggs possess a dark spot on the top as well as a transparent segment on the side of the shell, show ing the yellowishorange color of the developing embryo. Photo by Gary Foster (CC BY-SA 3.0)...... 25

Figure 4. Eggs of the stink bug Podisus maculiventris. Pale eggs (left) are laid on leaf undersides while dark eggs (right) are laid on leaf tops. Photos by Leslie Abram (with permissions)...... 29

Figure 5. A) Adults (photo by Judy Gallagher (CC BY 2.0)) and B) eggs (Public Domain Mark 1.0) of Murgantia histrionica.. 39

Figure 6. Postures adopted by $M$. histrionica nymphs during behavioral assays. Nymphs could be active (A) or display tonic immobility when on their ventral (B) or dorsal (C) side. The pictures shown here are of an individual in its first instar. Photo credit: Eric Guerra-Grenier.

Figure 7. Pictures of eggs and adults taken in the visual (left panels) and ultraviolet (right panels) spectra. Eggs are seen from their top (A-B) and external sides (C-D). The female is seen from her ventral (E-F) and dorsal (G-H) sides. The male is seen from his ventral (I-J) and dorsal (K-L) sides. UV pictures were converted in black and white images so that UV light could be perceived by human eyes on a luminance scale (the brighter the markings, the more UV-reflecting they are). Photo credit: Eric Guerra-Grenier. 48 
Figure 8. UPLC-ESI/MS negative extracted ion chromatogram of glucoraphanin ( $\mathrm{m} / \mathrm{z}=436$ (MH)-). A) Glucoraphanin commercial standard; B) Broccoli flowerets; C) Whole eggs; D) First instars (hatchlings).

Figure 9. Boxplot representations of glucoraphanin concentrations in various life stages. A) The concentrations of glucoraphanin $(\mu \mathrm{g} / \mathrm{mg})$ in whole eggs, first, second and third nymphal instars chemical defenses. The blue dotted lines represent concentrations of glucoraphanin in broccoli (reported by Florkiewicz et al. 2017; Song and Thornalley, 2007) as a means of comparison. B) The concentrations of glucoraphanin $(\mu \mathrm{g} / \mathrm{mg})$ in hatchlings and their shells. 50

Figure 10. The effects of A) nymphal instars and B) prodding order within a clutch on an individual's probability of entering tonic immobility. 52

Figure 11. A simulation of frequency-dependent predation on Podisus maculiventris eggs, where predators can either forage on leaf tops (LT) or on leaf bottoms (LB). Proportions of eggs laid or attacked on LB are equal to 1- proportion of eggs laid or attacked on LT respectively. A) FDS using the parameter values in Figure 2 of van Leeuwen et al. (2013): predators are equally likely to keep foraging on leaf tops $\left(S_{t t}=1\right)$ or on leaf bottoms $\left(S_{b b}=1\right)$. B) FDS using parameter values optimized using experimental data (Abram et al., 2015b): predators have a preference for leaf bottoms and are more likely to stay under a leaf $\left(S_{b b}=2.5\right)$ than to stay on a leaf top $\left(S_{t t}=1\right)$. For both panels, $\mathrm{S}_{\mathrm{tb}}=0.05$. Dashed lines highlight the proportion of eggs attacked on leaf tops when eggs are laid at a 50:50 top to bottom ratio.

Figure 12. Graphical representation of the variation in frequencies of $\mathrm{PT}, \mathrm{PB}, \mathrm{NT}$ and NB over evolutionary time in a context of frequency-dependent predation $\left(\mathrm{S}_{\mathrm{tt}}=1, \mathrm{~S}_{\mathrm{bb}}=2.5, \mathrm{~S}_{\mathrm{tb}}=0.05\right)$. A) Predation pressure is relatively high $(\mathrm{Q}=0.5)$, leading to an equilibrium between $\mathrm{PT}$ and $\mathrm{NB}$ at approximately a 50:50 ratio. B) Predation pressure is low $(\mathrm{Q}=0.05)$, leading to a rapid extinction of PT, PB and NB and a domination of the ancestral NB strategy. .71

Figure 13. Graphical representation of the variation in frequencies of PT, PB, NT and NB over evolutionary time in a context of frequency-independent predation $\left(\mathrm{S}_{\mathrm{tt}}=\mathrm{S}_{\mathrm{bb}}=\mathrm{S}_{\mathrm{tb}}=1\right)$. Even under very high predation pressure $(\mathrm{Q}=0.99), \mathrm{PT}$ and $\mathrm{NB}$ never reach a 50:50 ratio. 72 
Figure 14. Contour plots showing the effect of the interactions between leaf bottom bias $\left(\mathrm{S}_{\mathrm{bb}}\right)$ and predation intensity (Q) on the proportions of PT (upper left), NB (upper right), NT (lower left) and PB (lower right) eggs within a population. For both panels, $\mathrm{V}_{\mathrm{pt}}=0.80 ; \mathrm{V}_{\mathrm{pb}}=0.98 ; \mathrm{V}_{\mathrm{nb}}=1.00$; $\mathrm{V}_{\mathrm{nt}}=0.05 ; \mathrm{S}_{\mathrm{tt}}=1 ; \mathrm{S}_{\mathrm{tb}}=0.05$. As the value of $\mathrm{Q}$ increases, the proportion of NB eggs decreases. The NB eggs lost are effectively replaced by PT eggs. An increase in the value of $\mathrm{S}_{\mathrm{bb}}$ has a similar effect and leads to an increase in the proportion of PT and a decrease in the proportion of NB, but only when the value of $\mathrm{Q}$ is high enough. The proportions of PB and NT eggs never significantly increase above zero. 74

Figure 15. Contour plots showing the effect of the interactions between payoff values of pigmented eggs on leaf bottoms $\left(\mathrm{V}_{\mathrm{pb}}\right)$ and on leaf tops $\left(\mathrm{V}_{\mathrm{pt}}\right)$ on the proportions of NB (upper panel), and PB (lower panel) eggs within a population. For both panels, $\mathrm{V}_{\mathrm{nb}}=1.00 ; \mathrm{V}_{\mathrm{nt}}=0.05 ; \mathrm{S}_{\mathrm{tt}}$ $=1 ; \mathrm{S}_{\mathrm{bb}}=2.5 ; \mathrm{S}_{\mathrm{tb}}=0.05 ; \mathrm{Q}=0.5$. The proportion of NB eggs is unaffected by the value of $\mathrm{V}_{\mathrm{pb}}$ and remaining at 1.0 in any case. NB eggs do decrease in proportion when $V_{p t}$ is high enough $\left(\mathrm{V}_{\mathrm{pt}}\right.$ $>0.5$ ), but they are never replaced by PB eggs .75 


\section{INTRODUCTION}

The Pied Piper is a legendary figure that dates back to the 1200's. According to German folklore, he was a man known for his multicolored clothes and his magical flute that allowed him to attract whatever creature heard its song. He used it to lure rats away from the town of Hamelin, but when the town refused to pay him for his services he swore he would get his revenge. One day, while the adults were in church, the Pied Piper lured away the town's children, never to be seen again. In my opinion, the legend of the Pied Piper illustrates well the benefits of parental care. In nature, many animals take care of their brood in order to protect their offspring against multiple sources of danger. Although some species of non-social insects engage in egg attendance or brooding (Wong et al., 2013), parental care is not always present and juveniles often have to survive on their own from the moment the egg is laid. Without proper parental care, how do they resist their pied pipers?

My thesis aims at elucidating how insect eggs have adapted to biotic and abiotic selection pressures, with a focus on defensive egg coloration. I chose to work mostly with stink bugs (Heteroptera: Pentatomidae) as they are an ecologically diverse group that is well suited to help answer my research questions. This introduction is divided into three sections. The first section reviews known threats to insect eggs. The second section is an overview of defense mechanisms that have evolved in response to threats against eggs. The last section summarises the objectives of this thesis. 


\section{Threats to insect eggs}

Selective pressures can be split into two major categories: biotic and abiotic pressures. When one thinks of biotic pressures, the first thing that comes to mind is natural enemies. Indeed, insect eggs are attacked by all kinds of organisms, such as predators, parasitoids and pathogens. Predators attacking eggs are quite common in nature (Orians and Janzen, 1974), which makes a lot of sense considering their high nutritional value (they have to contain enough resources to ensure successful embryo growth) and lack of ability to flee unlike most prey types. Egg parasitoids are however probably the most studied natural enemies of insect eggs, given their economical importance as biological control agents. Contrary to egg predators, which are usually generalists, parasitoids are more hostspecific and can target eggs of pest species while leaving beneficial species and crops unharmed. Most of the egg parasitoids that have been described are hymenopterans (Hinton, 1981), although some Diptera like tachinid and sarcophagid flies can use insect eggs as hosts (Jones, 1988). Entomopathogens including viruses, bacteria and fungi are also frequent threats to eggs (Hinton, 1981). Among those, fungi like Beauveria spp. and Metarhizium anisopliae (Li et al., 2013; Mochi et al., 2010) are also used as biological control agents given their high virulence. Plants used for oviposition can also harm or destroy eggs through mechanisms such as egg desiccation, dropping and crushing (Hilker and Fatouros, 2015).

In addition to biotic pressures, abiotic components of the environment can also strongly affect egg survival. These include dry environments, rainfall and solar radiation. If the eggs are placed in a dry environment, they often suffer from severe water loss leading to 
desiccation and death (Clark and Faeth, 1998; Farnesi et al., 2017; Jacobs et al., 2013). Excess exposure to water can however be just as deadly, as is the case for rainfall-related mortality in mosquito eggs (Frank and Curtis, 1977). Yet, the abiotic stressor that probably has the highest impact on egg survival is solar radiation, as prolonged exposure to sunlight can cause overheating (Hinton, 1981) and ultraviolet irradiation (Abram et al., 2015b; Gaudreau et al., 2017).

\section{Defense mechanis ms of insect eggs}

Considering the threats mentioned above, it is obvious that insect eggs need to possess defense mechanisms in order to survive until hatching. These are as diverse as the dangers they were selected to protect against. First, mothers often apply secretions to the eggs during oviposition. These commonly serve as glue to fix the eggs to the substrate (Voigt and Gorb, 2009) and can provide hatchlings with endosymbiotic bacteria (Fukatsu and Hosokawa, 2002). Yet, they can also have several defensive functions as pointed out by Hilker and Fatouros (2015) and help the eggs fight off attacks from pathogens (Marchini et al., 1997), predators and parasitoids (Blum and Hilker, 2002; Eisner et al., 1996) and abiotic stressors like desiccation and rainfall (Jacobs et al., 2013). Maternal secretions on mosquito egg rafts, in addition to being good ant predator repellants, are also known to reduce the risk of eggs overturning on the water (Hinton, 1981). While faeces are not secretions per se, they are however often used to cover the eggs and/or juveniles and ensure that predators and parasitoids will not come near them (Damman and Cappuccino, 1991; Schaffner and Müller, 2001). 
Hiding the eggs is also a very efficient way to ensure their safety: they have a reduced exposure to environmental stressors and are harder to find by natural enemies. Classic hiding options include laying eggs inside plant tissues, within the leaf litter or in the soil (Birchard, 1991; Hilker, 1992; Hinton, 1981). More specialized adaptations for hiding the eggs include the oothecae in which mantids place their clutch to protect it against both predation and desiccation (Birchard, 1991). Lacewings are also well known for placing their eggs at the end of long stalks to reduce the risk of detection by natural enemies (Eisner et al., 1996). Some species of Lepidoptera use their scales or setae to cover and hide their eggs, or even to create a defensive wall surrounding their clutch (Hinton, 1981).

\section{Thesis objectives and predictions}

Another key feature used for defense against both biotic and abiotic threats by animals is body (or egg) coloration. In nature, colors can be used to hide a prey in plain sight through various forms of crypsis (Stevens, 2007) or to become conspicuous to potential predators in order to advertise (honestly or not) physical, behavioral or chemical defenses (Mappes et al., 2005; Ruxton et al., 2004). Pigments like melanin can also have defensive properties including water retention (Välimäki et al., 2015) and photoprotection (Jablonski and Chaplin, 2000). The general objective of this thesis was to investigate how insect eggs can use adaptive coloration as an efficient defensive mechanism against various threats from their ecosystems. I was interested in finding out to what extent evolutionary ecologists are currently aware of the use of adaptive egg coloration in insects, but was also keen on filling knowledge gaps myself. Therefore, my thesis is 
divided into three chapters: a review of the evolutionary ecology of insect egg coloration, an experimental study of chemical defenses in a phytophagous stink bug and a theoretical study of the evolution of photo-protective egg pigmentation in a predaceous stink bug.

First, I conducted a literature review of the known adaptive functions of coloration in insect eggs. During the first few months of my Master's, I realized that very few studies had been published on the subject and that, of those studies, even fewer arrived to conclusions based on experimental data and not only on the likelihood of their hypotheses being true. I hoped that gathering all of those conclusions into a single paper would help shed light on how diverse adaptive egg coloration is, but also on how much work effort is still needed in this field of study.

Second, I sought to experimentally investigate the adaptive significance of the complex and conspicuous egg color pattern of Murgantia histrionica (Hahn 1834) (Heteroptera: Pentatomidae), a recognized pest of multiple cruciferous crops. I used biochemical techniques to assess whether eggs and early nymphal instars contained sequestered defensive glucosinolates, supporting the hypothesis of a warning (aposematic) egg coloration. I also used behavioral experiments to test for the use by nymphs of an alternative defense strategy: tonic immobility (also known as death feigning). I predicted that there was a negative relationship between glucosinolate concentrations and the use of tonic immobility, allowing for the latter strategy to decrease while sequestration of defensive chemicals increased. 
Third, I expanded on previous work I had done as an undergraduate student and looked at the selective pressures affecting the evolution of photoprotective egg pigmentation in Podisus maculiventris (Say 1832) (Heteroptera: Pentatomidae), a frequently used biological control agent. Specifically, I used a mathematical model to investigate whether selection by frequency-dependent predation is sufficient to explain the polymorphic egg coloration of this species, in which pale eggs are laid under leaves while dark pigmented eggs are laid on leaf tops. I predicted that the low probability of predators switching between leaf sides while foraging would lead to the evolution of a balanced polymorphism in egg pigmentation, with the frequency of specialist strategies for topand bottom- laid eggs dictated by predation intensity, leaf side biases and morph payoffs. 


\title{
CHAP TER 1: EVOLUTIONARY ECOLOGY OF INSECT EGG COLORATION - A REVIEW
}

\begin{abstract}
Body coloration in animals is often adaptive and used for defensive "purposes" against biotic (e.g. predators, competitors) and abiotic (e.g. solar radiation, desiccation) threats. The study of adaptive coloration in insects usually favors obvious model species such as vespid wasps and heliconid butterflies, partly because they actively interact with their environment. Yet, one life stage has received less attention because of its immobility: the egg. So far, vertebrate eggs, especially avian eggs, have held the "big end of the stick" when it comes to research effort on adaptive egg coloration. In species where eggs are not provided with parental care and left to survive on their own until hatching, studying the defensive roles played by their colors is imperative to understand their evolutionary ecology. Adaptive functions provided by egg coloration such as crypsis, aposematism and photoprotection against ultraviolet radiation potentially have huge fitness impacts and deserve more attention. We here review the current literature on the subject and report the known adaptive significance of insect egg coloration. Clear distinctions are made between functions tested empirically and functions that remain hypothetical despite often being treated as facts. We also describe what we think to be the best avenues for future work in the field.
\end{abstract}

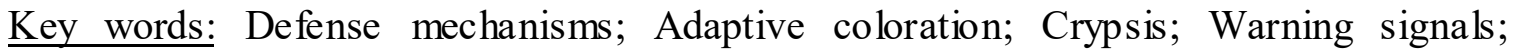
Photoprotection; Insect eggs 


\section{Introduction}

Since the publication of The Colors of Animals (Poulton, 1890), evolutionary biologists have studied and significantly improved our understanding of animal coloration and its "purpose" in nature (Cuthill et al., 2017). We now know that colors are used by a plethora of taxa in various ways. In many species, body coloration is sexually selected to communicate mate quality between sexes, usually from the male to the female (Endler, 1983; Hill, 1991; Maan and Cummings, 2009). Colors are also frequently integrated in defensive strategies against predators, either to conceal the prey (e.g. backgroundmatching camouflage) or to advertise its unprofitability, whether the signal is honest (e.g. aposematism, Müllerian mimicry) or not (e.g. Batesian mimicry) (Ruxton et al., 2004). Furthermore, coloration can allow animals to interact with their abiotic environment and confer fitness benefits through thermoregulation (Forsman, 2000), photoprotection against ultraviolet radiation (Jablonski and Chaplin, 2000) and water retention (Välimäki et al., 2015).

When we think of adaptive coloration, especially in the context of predator-prey relationships, we tend to picture free-living, mobile organisms such as adult peacocks, chameleons, skunks and bees. Yet, eggs are also often very colorful. It can be argued that color-related defenses in eggs are potentially more important than in mobile life stages, as the former are fixed in space until hatching and cannot flee like the latter if discovered by predators. A considerable amount of work has been done on vertebrate egg coloration in taxa such as ascidians (Young and Bingham, 1987) and amphibians (Altig and McDiarmid, 2007; Petranka et al., 1998; Pintar and Resetarits, 2017), but especially in 
birds. Kilner (2006) reviewed the adaptive significance of bird egg coloration and listed multiple functions such as camouflage and thermoregulation. Blues in egg shells are of particular interest, as they are used for their photoprotective properties (Bakken et al., 1978) or to signal maternal investment in egg nutrients as a way to elicit parental care from sires (Moreno and Osorno, 2003; Soler et al., 2005). The interest for blue shell coloration even led to recent discoveries on its presence in dinosaur lineages (Wiemann et al., 2015, 2017). Egg color is also used for mimicry in brood parasites such as cuckoos, as a way to reduce the host's ability to discriminate between the parasite's eggs and its own (Brooke and Davies, 1988; Stoddard and Stevens, 2011).

Compared to vertebrates, we know a lot less about the adaptive significance of invertebrate egg coloration. Yet, the latter group largely outnumber the former in terms of biodiversity, with around 7 million species worldwide just for terrestrial arthropods (Stork, 2017). Among what can only be described as a small fraction of the species diversity in which egg coloration has been studied, a few examples of aposematic eggs have been reported in aquatic invertebrates. For example, the pink-red egg ribbons of the Spanish dancer nudibranch, Hexabranchus sanguineus, contain toxic macrolides sequestered from their sponge-rich diet (Pawlik et al., 1988). Apple snails of the genus Pomacea also produce pink eggs using carotenoids, which are defended thanks to a proteinase inhibitor called ovorubin (Dreon et al., 2010). As far as insect eggs go, not much is known about the fitness benefits of their coloration, regardless of how morphologically diverse they are. 
The aim of this chapter is to review our current state of knowledge regarding the adaptive significance of insect egg coloration. Reviews on insect egg defenses (Blum and Hilker, 2002; Hinton, 1981) and parental care (Wong et al., 2013) have been published in the past, but there remains a significant gap in the literature that needs to be filled regarding color-related defensive strategies. Although we wish to acknowledge that work has been done on non-adaptive physiological color change during development (Bernhardt, 2009; Peterson, 1962) and on the use of colors by egg parasitoids as a foraging cue (Lobdell et al., 2005), the focus of this review will be solely on adaptive egg coloration. This paper is therefore divided into multiple categories, each one reviewing a given adaptive function such as crypsis, warning signals and photoprotection. Where necessary, distinctions were made between conclusions based on experimentation versus on educated guesses.

\section{Crypsis}

Hiding their eggs is a very efficient way for parents to protect their offspring against natural enemies. A common strategy is to physically hide the offspring, using scales or setae (in Lepidoptera; Hinton (1981)), or even sticky spumaline that accumulates dust particles (Peterson, 1962). The present section of this review will however focus on ways to hide eggs in plain sight, using only coloration.

\section{Background-matching camouflage}

First of all, crypsis does not always have to be achieved through applying colors on the eggs. Background matching can indeed occur simply through transparency. If eggs or egg clutches are transparent, their perceived coloration will be that of the underlying substrate 
(e.g. a leaf, a twig, bark, etc.) as reflected light from the background around the eggs will presumably be the same as the reflected light coming through the eggs. Several moth species of the Pyralidae and Olethreutidae families have been reported to have transparent shells that make them look like they have the same color as the background (Peterson, 1962). Whether this provides a fitness benefit, by making the eggs hard to find by predators, remains untested.

Many insect eggs on plant leaves do however have an intrinsic green or yellowish-green coloration. The most probable explanation for these phenotypes is that green eggs match the color of the substrate they were oviposited on, reducing the risk of being found by natural enemies foraging using visual cues, again through background-matching camouflage. Although this hypothesis is straightforward, it has seldom been tested. For example, the hawkmoth Manduca sexta is known for its green coloration in eggs (Figure 1) and caterpillars (Kawooya et .al. 1985, Kang et al. 1995). Biochemical assays revealed that the green color is achieved through a mix of yellow carotenoids and insecticyanin, a blue biliprotein sequestered from the hemolymph (Kang et al., 1995). Although this coloration pathway has been hypothesized to create a cryptic effect through background matching, research effort never reached the testing phase.

Yellow-green polymorphisms in eggs laid on more than one type of substrate would also make sense in a background-matching camouflage paradigm. Such polymorphism has thus far been identified in at least two species of Lepidoptera, Agathymus estelleae (Stallings and Stallings, 1986) and Heraclides aristodemus ponceanus 


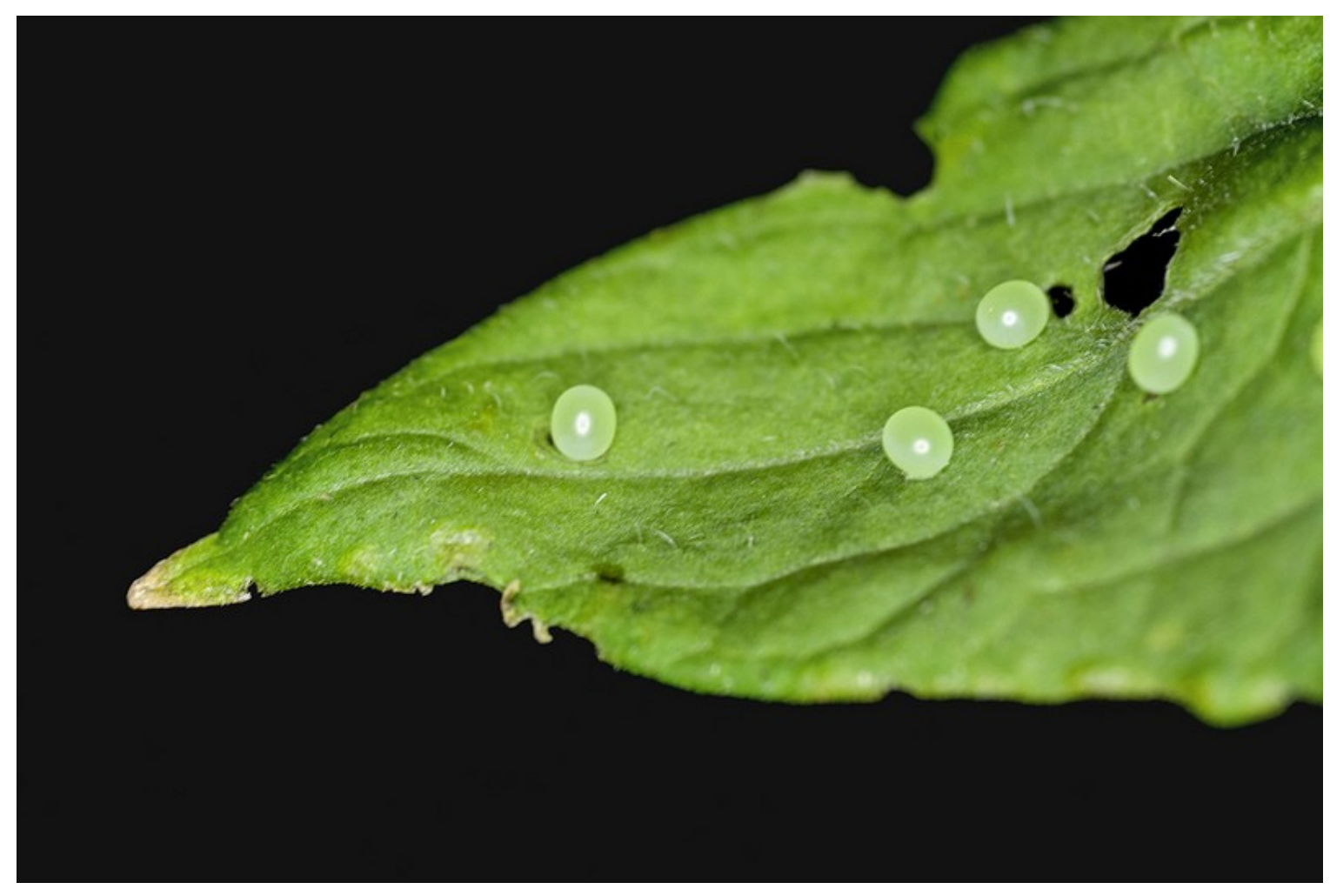

Figure 1. Eggs of Manduca sexta laid on a green leaf. The greenish color of the eggs may have evolved for background matching crypsis. Photo by the Insect Zoo of the Smithsonian National Museum of Natural History (CC BY-NC 2.0). 
(Daniels et al., 1993). In the former case, females lay eggs that are either green or beige. Glueless eggs are dropped on host plants and some of them fall on the ground while others get lodged on the plants. Stallings and Stallings (1986) reported that green eggs appeared cryptic on the plant while beige eggs were cryptic on the ground, and suggested that egg color dimorphism was used in order to always have a proportion of eggs camouflaged, regardless of where they fall. As for the latter case, Daniels et al. (1993) reported that $H$. aristodemus can lay either yellow or green eggs on either yellowish or greenish leaves, also as a way to ensure that at least some of the eggs were protected through background-matching camouflage.

The issue with both studies mentioned above is that neither one of them actually tested whether the egg colorations they observed were cryptic or not. We are here not questioning the validity of their hypotheses, but rather stressing the problem with confusing hypothesis and fact. Although both papers are interesting and provide promising observations, none of them can conclusively say that egg color in those species is used for background-matching camouflage. Their explanations for the evolution of dimorphic egg coloration are also hypothetical and do not consider alternative hypotheses such as the exploitation of search images by predators to reduce the efficacy of predator foraging (Bond, 2007). Furthermore, as is the case for other adaptive functions of coloration, camouflage is not selected for by humans, but rather by ecologically relevant predators (Bennett et al., 1994). Quantifying camouflage according to predator color vision and acuity is necessary in order to fully test whether a prey is cryptic or not. 


\section{Disruptive camouflage}

Contrarily to background matching camouflage, disruptive camouflage allows a prey to go unrecognized, not because it blends with the substrate it is on, but rather thanks to conspicuous markings that either disrupt its edges or create false boundaries, making it difficult to detect as suitable prey (Stevens and Merilaita, 2009). Such markings, usually in the form of spots or stripes, are not uncommon in insect eggs. Hinton (1981) argued that the very bold markings on the eggs of the lappet moths Gastropacha quercifolia and Epicnaptera americana are excellent examples of cryptic eggs that have a disruptive color pattern. Although this hypothesis is likely, it was reported as being the "clear" explanation without ever being tested empirically. It is thus our opinion that, although disruptive coloration in eggs is likely to have evolved in many taxa, concrete evidence of its existence is to our knowled ge still missing.

\section{Warning signals}

Inter-specific (aposematic) signals

Poulton originally defined the term aposematism as the use of colors to "warn an enemy off' (Poulton, 1890), usually about antipredation strategies like toxicity (Skelhorn et al., 2016). Such is the case with the yellow-and-black body coloration of venomous wasps or the orange-and-black colors of poisonous Monarch butterflies. Yet, description of aposematic colors in egg entomology is not always adequate. For example, Hinton (1981) used the term to refer to conspicuous colors in general, regardless of their functions. He wrote about color changes from cryptic to aposematic when the process in question was 
simply caused by the formation of the not yet sclerotized embryo and had nothing to do with the advertisement of secondary defenses.

Orians and Janzen (1974) stated that "insect eggs are almost invariably white or cryptically colored", yet it is well known among entomologists and naturalists that brightly colored eggs are far from anecdotal in several orders (F igure 2). Multiple studies, reviewed by Blum \& Hilker (2002) or published afterwards, have looked at insect egg chemical defense, but only a handful of them reported egg coloration (28.6\%), fewer hypothesized aposematism (17.1\%) and only one (Winters et al. 2014) tested for it (Table 1). Based on what has been reported on insect egg chemical defenses, we can state that there is a missing link between color and toxicity or unpalatability in the literature. This knowledge gap could be explained by the fact that, so far, egg chemical defense has mostly been of interest to chemical ecologists rather than to evolutionary bio logists.

Much like with studies on background-matching camouflage, colorful and toxic eggs are sometimes reported as being aposematic even without empirical data in favor of the hypothesis. For example, Rothschild (1992) stated that the bright yellow eggs of three given insect species "must be deemed aposematic" since they are both conspicuous and toxic. Although this statement was appropriate in the sense that it did not contradict Poulton's definition of aposematism, we argue that the warning function of conspicuous colors should be tested experimentally and not simply assumed. Certain colours that appear conspicuous against their background may not be conspicuous to their predators 


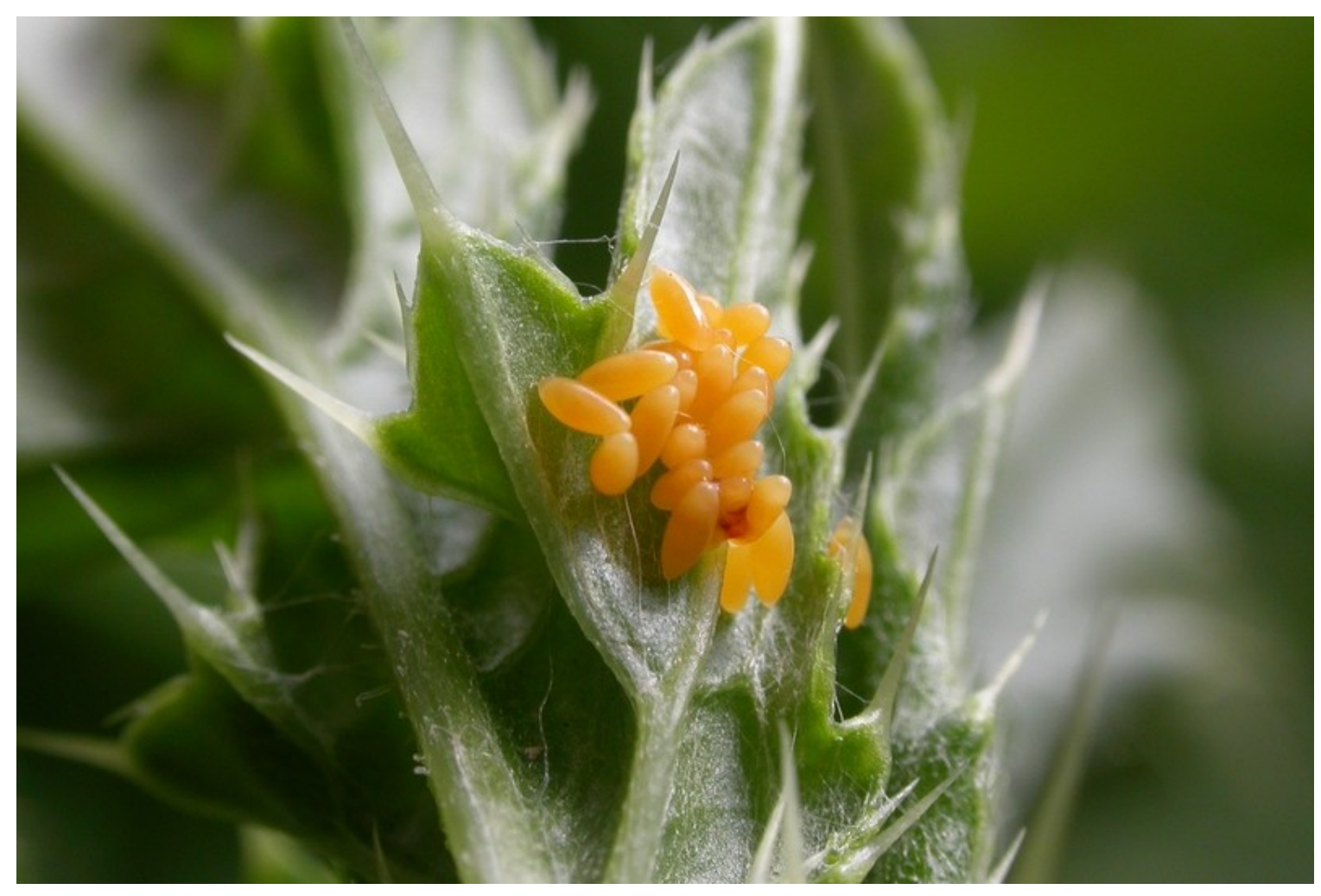

Figure 2. Egg clutch of the ladybug Coccinella septempunctata. The orange eggs contrast with the green background, and their color hue and saturation positively correlate with their concentration in defensive alkaloids (Winters et al., 2014). Photo by Gilles San Martin (CC BY-SA 2.0). 
Table 1. Non-exhaustive list of species with known egg chemical defenses. For each species listed, mentions of egg coloration and aposematism in the original research papers are reported when existent. The symbol “_“ is used when studies lacked experimental evidence testing for the aposematism hypothesis.

\begin{tabular}{|c|c|c|c|c|c|c|c|c|}
\hline Order & Family & Species & $\begin{array}{c}\text { Defensive } \\
\text { compound(s) }\end{array}$ & $\begin{array}{l}\text { Egg color } \\
\text { reported? }\end{array}$ & $\begin{array}{c}\text { Aposematis } \\
m \\
\text { hypothesize } \\
\text { d? }\end{array}$ & $\begin{array}{c}\text { Indirect } \\
\text { evidence of } \\
\text { aposematism } \\
\text { ? }\end{array}$ & $\begin{array}{c}\text { Direct } \\
\text { evidence of } \\
\text { aposematism } \\
\text { ? }\end{array}$ & Reference \\
\hline \multirow[t]{9}{*}{ Coleoptera } & Chrysomelidae & $\begin{array}{c}\text { Acalymma } \\
\text { vittatum }\end{array}$ & Cucurbitacins & No & No & - & - & $\begin{array}{c}\text { Ferguson et } \\
\text { al. } 1985\end{array}$ \\
\hline & & $\begin{array}{l}\text { Chrysolina } \\
\text { coerulans }\end{array}$ & Cardenolides & No & No & - & - & $\begin{array}{c}\text { Daloze and } \\
\text { Pasteels } \\
1979\end{array}$ \\
\hline & & $\begin{array}{l}\text { Chrysolina } \\
\text { fuliginosa }\end{array}$ & Cardenolides & No & No & - & - & $\begin{array}{c}\text { Hilker et al. } \\
1992\end{array}$ \\
\hline & & $\begin{array}{c}\text { Chrysolina } \\
\text { polita }\end{array}$ & Cardenolides & No & No & - & - & $\begin{array}{c}\text { Daloze and } \\
\text { Pasteels } \\
1979\end{array}$ \\
\hline & & $\begin{array}{c}\text { Chrysomela } \\
\text { spp. }\end{array}$ & $\begin{array}{l}\text { Isoxazolinone } \\
\text { glucosides and } \\
\text { salicin }\end{array}$ & $\begin{array}{l}\text { Brightly } \\
\text { colored }\end{array}$ & No & - & - & $\begin{array}{c}\text { Pasteels et } \\
\text { al. } 1986\end{array}$ \\
\hline & & Dibrotica spp. & Cucurbitacins & No & No & - & - & $\begin{array}{c}\text { Ferguson et } \\
\text { al. } 1985 \\
\end{array}$ \\
\hline & & $\begin{array}{l}\text { Galeruca } \\
\text { tanaceti }\end{array}$ & Anthraquinones & No & No & - & - & $\begin{array}{c}\text { Hilker and } \\
\text { Schulz } 1991\end{array}$ \\
\hline & & $\begin{array}{c}\text { Gastrophysa } \\
\text { cyanea }\end{array}$ & Oleic acid & Yellow & Yes & - & - & $\begin{array}{c}\text { Howard et } \\
\text { al. } 1982\end{array}$ \\
\hline & & Oreina & Cardenolides & No & No & - & - & Pasteels et \\
\hline
\end{tabular}




\begin{tabular}{|c|c|c|c|c|c|c|c|}
\hline & elongata & $\begin{array}{c}\text { and } \\
\text { pyrrolizidine } \\
\text { alkaloids }\end{array}$ & & & & & al. 1996 \\
\hline & $\begin{array}{l}\text { Paropsis } \\
\text { atomaria }\end{array}$ & $\begin{array}{l}\text { Cyanogenic } \\
\text { glycosides }\end{array}$ & No & No & - & - & $\begin{array}{c}\text { Nahrstedt } \\
\text { and Davis } \\
1986\end{array}$ \\
\hline & Phratora spp. & $\begin{array}{l}\text { Isoxazolinone } \\
\text { glucosides and } \\
\text { salicin }\end{array}$ & $\begin{array}{l}\text { Brightly } \\
\text { colored }\end{array}$ & No & - & - & $\begin{array}{c}\text { Pasteels et } \\
\text { al. } 1986\end{array}$ \\
\hline & $\begin{array}{l}\text { Plagiodera } \\
\text { versicolora }\end{array}$ & $\begin{array}{l}\text { Isoxazolinone } \\
\text { glucosides and } \\
\text { salicin }\end{array}$ & $\begin{array}{l}\text { Brightly } \\
\text { colored }\end{array}$ & No & - & - & $\begin{array}{c}\text { Pasteels et } \\
\text { al. } 1986\end{array}$ \\
\hline & $\begin{array}{c}\text { Pyrrhalta } \\
\text { luteola }\end{array}$ & $\begin{array}{l}\text { Anthraquinones } \\
\text { and Anthrones }\end{array}$ & No & No & - & - & $\begin{array}{l}\text { Howard, } \\
\text { Phillips, et } \\
\text { al. } 1982\end{array}$ \\
\hline Coccinellidae & $\begin{array}{c}\text { Adalia } \\
\text { bipunctata }\end{array}$ & Alkaloids & No & No & - & - & $\begin{array}{c}\text { Lognay et } \\
\text { al. } 1996\end{array}$ \\
\hline & $\begin{array}{c}\text { Adalia } \\
\text { decempunctat } \\
a\end{array}$ & Alkaloids & No & No & - & - & $\begin{array}{l}\text { Lognay et } \\
\text { al. } 1996\end{array}$ \\
\hline & $\begin{array}{c}\text { Coccinella } \\
\text { septempuncta }\end{array}$ & Alkaloids & $\begin{array}{l}\text { Yellow/ } \\
\text { Orange }\end{array}$ & Yes & $\begin{array}{c}\text { Positive } \\
\text { correlations } \\
\text { between egg } \\
\text { color metrics } \\
\text { and toxicity }\end{array}$ & - & $\begin{array}{c}\text { Winters et } \\
\text { al. } 2014\end{array}$ \\
\hline & $\begin{array}{c}\text { Exochomus } \\
\text { quadripustulat } \\
\text { us }\end{array}$ & Alkaloids & No & No & - & - & $\begin{array}{l}\text { Daloze et } \\
\text { al. } 1994\end{array}$ \\
\hline & $\begin{array}{c}\text { Exochomus } \\
\text { varivestis }\end{array}$ & Alkaloids & No & No & - & - & $\begin{array}{l}\text { Daloze et } \\
\text { al. } 1994\end{array}$ \\
\hline
\end{tabular}




\begin{tabular}{|c|c|c|c|c|c|c|c|c|}
\hline & Lampyridae & $\begin{array}{l}\text { Ellychnia } \\
\text { corrusca }\end{array}$ & Lucibufagins & No & $\begin{array}{l}\text { Mentioned } \\
\text { for free living } \\
\text { stages only }\end{array}$ & - & - & $\begin{array}{l}\text { Smedley et } \\
\text { al. } 2017\end{array}$ \\
\hline & & Photuris spp. & $\begin{array}{c}\text { Betaine and } \\
\text { Lucibufagins }\end{array}$ & No & No & - & - & $\begin{array}{c}\text { González et } \\
\text { al. } 1999 \\
\end{array}$ \\
\hline \multirow[t]{3}{*}{ Hemiptera } & Dactylopiidae & $\begin{array}{l}\text { Dactylopius } \\
\text { confusus }\end{array}$ & $\begin{array}{l}\text { Anthraquinines } \\
\text { (carminic acid) }\end{array}$ & $\begin{array}{l}\text { No, but } \\
\text { hinted that } \\
\text { they are } \\
\text { red }\end{array}$ & $\begin{array}{l}\text { Mentioned } \\
\text { for free living } \\
\text { stages only }\end{array}$ & - & - & $\begin{array}{c}\text { Eisner et al. } \\
1980\end{array}$ \\
\hline & \multirow[t]{2}{*}{ Lygaeidae } & $\begin{array}{c}\text { Caenocoris } \\
\text { nerii }\end{array}$ & Cardenolides & $\begin{array}{l}\text { Buttercup- } \\
\text { yellow }\end{array}$ & Yes & - & - & $\begin{array}{l}\text { (von Euw et } \\
\text { al., 1971) }\end{array}$ \\
\hline & & $\begin{array}{l}\text { Oncopeltus } \\
\text { fasciatus }\end{array}$ & Cardenolides & No & $\begin{array}{l}\text { Mentioned } \\
\text { for free living } \\
\text { stages only }\end{array}$ & - & - & $\begin{array}{c}\text { Duffey and } \\
\text { Scudder } \\
1974 \\
\end{array}$ \\
\hline \multirow[t]{4}{*}{$\begin{array}{c}\text { Lepidopter } \\
\text { a }\end{array}$} & \multirow[t]{3}{*}{ Erebidae } & $\begin{array}{l}\text { Cosmosoma } \\
\text { myrodora }\end{array}$ & $\begin{array}{l}\text { Pyrrolizidine } \\
\text { alkaloids }\end{array}$ & No & $\begin{array}{l}\text { Mentioned } \\
\text { for free living } \\
\text { stages only }\end{array}$ & - & - & $\begin{array}{l}\text { Conner et } \\
\text { al. } 2000\end{array}$ \\
\hline & & $\begin{array}{c}\text { Creatonotos } \\
\text { transiens }\end{array}$ & $\begin{array}{l}\text { Pyrrolizidine } \\
\text { alkal oids }\end{array}$ & No & No & - & - & $\begin{array}{c}\text { von } \\
\text { Nickisch- } \\
\text { Rosenegk } \\
\text { et al. } 1990\end{array}$ \\
\hline & & $\begin{array}{c}\text { Utetheisa } \\
\text { ornatrix }\end{array}$ & $\begin{array}{l}\text { Pyrrolizidine } \\
\text { alkal oids }\end{array}$ & No & No & - & - & $\begin{array}{c}\text { Dussourd } \\
\text { et al. 1988, } \\
\text { Eisner et al. } \\
2000 \\
\end{array}$ \\
\hline & Lycaenidae & $\begin{array}{c}\text { Eumaeus atala } \\
\text { florida }\end{array}$ & Cycasin & $\begin{array}{l}\text { Whitish/ } \\
\text { beige with } \\
\text { a bright }\end{array}$ & Yes & - & - & $\begin{array}{c}\text { Rothschild } \\
1992\end{array}$ \\
\hline
\end{tabular}




\begin{tabular}{|c|c|c|c|c|c|c|c|c|}
\hline & & & & $\begin{array}{l}\text { orange/red } \\
\text { scale cover }\end{array}$ & & & & \\
\hline & \multirow[t]{3}{*}{ Nymphalidae } & Actinote spp. & $\begin{array}{l}\text { Cyanogenic } \\
\text { components }\end{array}$ & $\begin{array}{l}\text { Brightly } \\
\text { colored }\end{array}$ & $\begin{array}{l}\text { Mentioned } \\
\text { that eggs are } \\
\text { colorful and } \\
\text { rarely preyed } \\
\text { upon }\end{array}$ & - & - & $\begin{array}{c}\text { Brown and } \\
\text { Francini } \\
1990\end{array}$ \\
\hline & & $\begin{array}{l}\text { Danaus } \\
\text { gilippus }\end{array}$ & $\begin{array}{c}\text { Pyrrolizidine } \\
\text { alkaloids }\end{array}$ & No & $\begin{array}{l}\text { Mentioned } \\
\text { for free living } \\
\text { stages only }\end{array}$ & - & - & $\begin{array}{c}\text { Dussourd } \\
\text { et al. } 1989\end{array}$ \\
\hline & & $\begin{array}{c}\text { Danaus } \\
\text { plexippus }\end{array}$ & Cardenolides & No & $\begin{array}{l}\text { Mentioned } \\
\text { for free living } \\
\text { stages only }\end{array}$ & - & - & $\begin{array}{l}\text { Reichstein } \\
\text { et al. } 1968\end{array}$ \\
\hline & \multirow[t]{2}{*}{ Papilionidae } & $\begin{array}{l}\text { Atrophaneura } \\
\text { alcinous }\end{array}$ & $\begin{array}{l}\text { Aristolochic } \\
\text { acids }\end{array}$ & $\begin{array}{l}\text { Reddish } \\
\text { orange }\end{array}$ & Yes & - & - & $\begin{array}{c}\text { Nishida and } \\
\text { Fukami } \\
1989\end{array}$ \\
\hline & & $\begin{array}{l}\text { Parnassius } \\
\text { phoebus }\end{array}$ & $\begin{array}{c}\text { Sarmentosin } \\
\text { (cyanoglucoside } \\
\text { ) }\end{array}$ & No & $\begin{array}{l}\text { Mentioned } \\
\text { for free living } \\
\text { stages only }\end{array}$ & - & - & $\begin{array}{c}\text { Nishida and } \\
\text { Rothschild } \\
1995\end{array}$ \\
\hline & Various & Various & Various & Various & Yes & - & - & $\begin{array}{c}\text { Marsh and } \\
\text { Rothschild } \\
1974\end{array}$ \\
\hline \multirow[t]{2}{*}{ Orthoptera } & \multirow[t]{2}{*}{ Pyrgomorphidae } & $\begin{array}{c}\text { Poekilocerus } \\
\text { bufonius }\end{array}$ & Cardenolides & No & $\begin{array}{l}\text { Mentioned } \\
\text { for free living } \\
\text { stages only }\end{array}$ & - & - & $\begin{array}{l}\text { von Euw et } \\
\text { al. } 1967\end{array}$ \\
\hline & & $\begin{array}{l}\text { Poekilocerus } \\
\text { pictus }\end{array}$ & Cardenolides & No & $\begin{array}{l}\text { Mentioned } \\
\text { for free living } \\
\text { stages only }\end{array}$ & - & - & $\begin{array}{l}\text { Pugalenthi } \\
\text { and } \\
\text { Livingstone } \\
1995\end{array}$ \\
\hline
\end{tabular}


and parasitoids. Indirect evidence of aposematism can include, for example, correlational data between color and defensive compounds, such as those found between color metrics and alkaloid concentrations in the ladybug Coccinella septempunctata (Winters et al., 2014). Direct evidence of aposematism however requires data on associative learning between color and toxicity by predators. To our knowledge, no study to date has provided this kind of evidence. Associative learning by insect predators should not be underestimated, as insects have been shown to learn on several occasions (Dukas, 2008) and could therefore realistically associate colors and toxicity or unpalatability.

Assuming that aposematic displays are the only possible explanation for the presence of both conspicuous egg colors and defensive compounds is also a trap that should be avoided. An alternative hypothesis for their simultaneous presence is the idea that eggs with transparent shells contain pigments, usually carotenoids that cannot be synthesized by the insect, to be used by free-living life stages for warning signals before dietary sequestration of further pigments is available. In such a scenario where predators do not learn to associate color and unprofitability, laying eggs in clutches can instead allow for the protection of some of the offspring (Stamp, 1980). Sampling only a fraction of a toxic clutch would be sufficient to deter predation on the rest of it; no need for learning as predation reduction is achieved through safety in numbers instead. Evidence in favor of this hypothesis has been provided by a study describing the foraging behavior of a lacewing larva attacking the eggs of Utetheisa ornatrix (Lepidoptera, Arctiidae) (Eisner et al., 2000). The authors showed that the proportion of eggs within a clutch eaten by the 
predators was significantly higher in alkaloid free clutches than in alkaloid-laden clutches.

\section{Intra-specific warning signals and egg load assessment}

Warning signals do not necessarily target other species such as predators or inter-specific competitors; they can also be directed towards conspecifics (Sherratt and Forbes, 2001). In insects, coloration can be used to allow gravid females to assess the degree of colonization of an individual host plant by conspecifics. Such is the case in the pipevine swallowtail butterfly Battus philenor, in which the conspicuous coloration of the caterpillars, in addition to being an aposematic signal, deters adult females from ovipositing on the same host (Papaj and Newsom, 2005). This is thought to reduce intraspecific competition. As for insect eggs, Shapiro (1981a) reported a similar function for the orange-red egg coloration of some species of Pierinae and Euchloinae (Lepidoptera: Pieridae). He carried out a field experiment in which he removed freshly laid eggs from host leaves, four to five times per day. The results showed that "cleaned" plants were used for oviposition significantly more frequently than control plants in which eggs were never removed. In other words, gravid females use the presence of conspecific eggs as a visual cue to determine whether a host plant is suitable or not. The experiment did not control for egg color and could thus not tease apart the effect the red color from the effects of egg shape or smell. However, Shapiro (1981a) also reported that only species that lay red eggs, as opposed to those with yellowish-white eggs, engage in egg-load assessment, which would suggest (but not confirm) that the red coloration of the eggs functions as an intra-specific warning signal advertising a risk of competition. 
Egg-load assessment using egg morphological traits, coloration or otherwise, has sometimes selected for spectacular counter-adaptations in host plants. Indeed, some plants have evolved egg mimicry to reduce the risk of oviposition by their herbivores. Such a trait has been described in Passiflora spp. attacked by Heliconius butterflies (Gilbert, 1975) as well as in Streptanthus spp. attacked by Pierines (Shapiro, 1981a). In all reported cases, leaves develop callosities with shapes and sizes consistent with the morphological features of the eggs laid by their associated herbivores. In the PassifloraHeliconius system specifically, Gilbert (1975) reported that the egg mimics found on the leaves are closer in coloration to old Heliconius eggs than they are to fresh eggs. He argued that this deterred females from laying on the leaves since the caterpillars are cannibalistic and therefore the fake "old" eggs would hatch before and prey upon the real eggs. The adaptive significance of egg mimicry by plants has been confirmed experimentally: artificial removal of egg mimics lead to an increase in oviposition by female butterflies (Shapiro, 1981b; Williams and Gilbert, 1981). In other words, females maladaptively use the presence of egg mimics to assess the suitability of a host plant.

\section{Mimicry}

Mimicking leftover shells post-parasitism

The most common forms of protective mimicry encountered in nature are Batesian and Müllerian mimicry, in which an unprofitable model is mimicked by a profitable or unprofitable organism respectively. To our knowledge, neither of these types of mimicry has been reported in insect eggs. One type of egg mimicry that has however been argued 
to exist in species of several families of Lepidoptera (e.g. Notodontidae, Lymantriidae, Saturniidae, etc.) is one where they look like eggs from which parasitoids have emerged (Hinton, 1981). Hinton mentioned that he neglected to collect eggs of Automeris moths in the field because he confused the dark spot on the top of the eggs for emergence holes left by hymenopteran wasps. However, the hypothesis was never tested further with relevant natural enemies, meaning that the existence of such type of mimicry is still debatable, at least in insect eggs. In our opinion, at least in the case or Automeris eggs (Figure 3), emerged parasitoid mimicry is unlikely given that the sides of the eggs are transparent. This allows observers to see the orange embryos still developing in the eggs and confirm that they have in fact not been parasitized.

\section{Masquerade}

In contrast to background-matching camouflage, where a prey is concealed by looking like the substrate it is on, masquerade allows organisms to remain undetected by morphologically and behaviorally mimicking objects found in the environment. However, masquerade differs from mimicry sensu stricto in the sense that the aim of the former is to copy cues while the latter's is to copy signals (Jamie, 2017). Classic examples of masquerade include stick insects looking like twigs, or caterpillars looking like bird feces.

\section{Masquerading as a dew drop}

Masquerade has been described in insect eggs, although infrequently. One example comes from a book chapter by (Eisner et al., 2002), in which they provided a picture of 


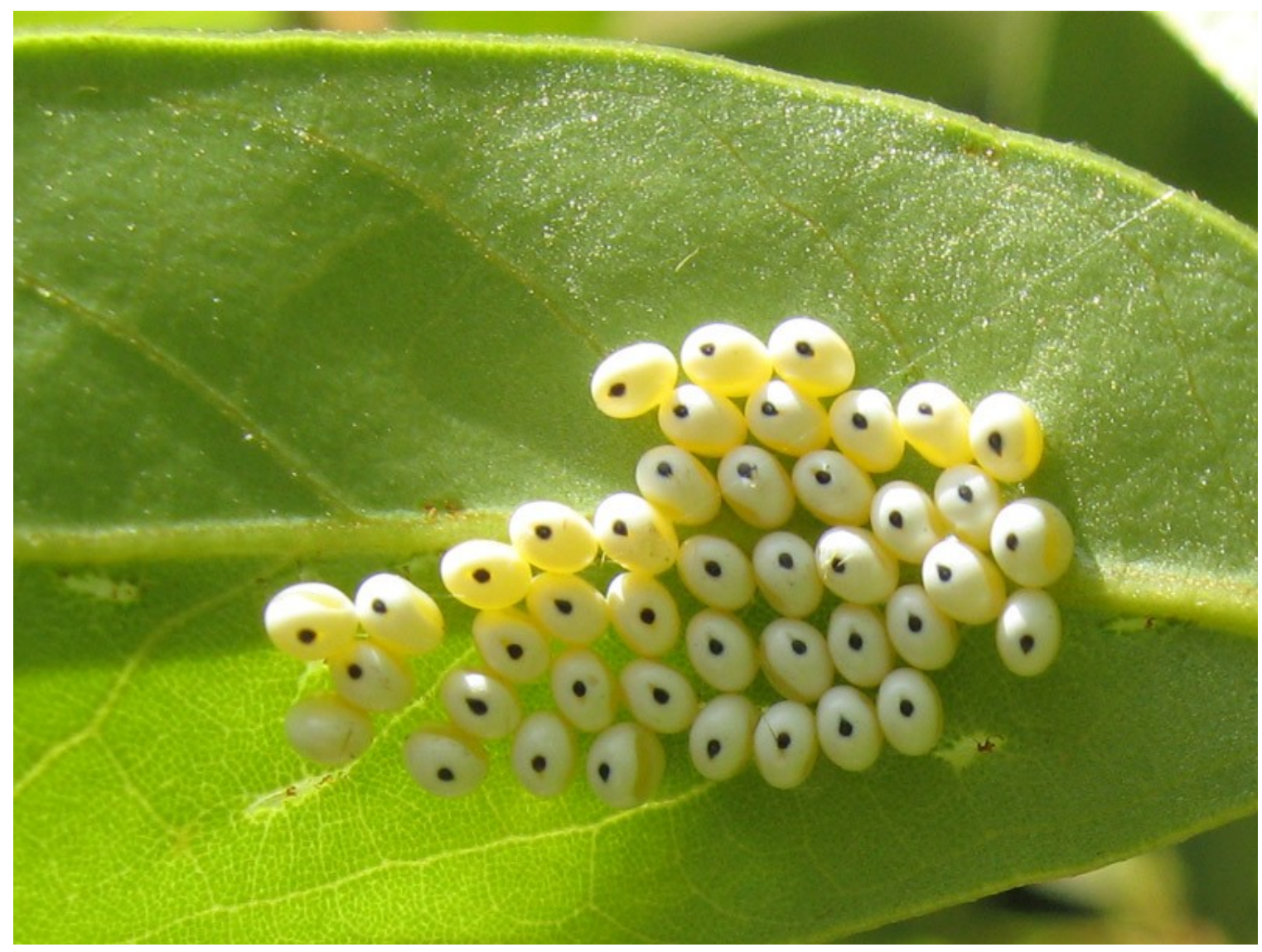

Figure 3. Two days old eggs of the saturniid moth Automeris io. These white eggs possess a dark spot on the top as well as a transparent segment on the side of the shell, showing the yellowish-orange color of the developing embryo. Photo by Gary Foster (CC BY-SA 3.0). 
an "egg of an unidentified coreid bug [...] imitative of a dew drop". From a qualitative stand point, the egg depicted does look like the dew drops next to it, both in terms of shape and color. However, evidence that egg predators would be fooled by the masquerade is not reported in the text, and no study was cited along with the picture. Thus, conclusions regarding the adaptive significance of this bug's egg coloration may be somewhat premature.

\section{Masquerading as a seed}

Another type of masquerade thought to frequently occur in taxa like moths, stick insects and katydids is seed mimicry (Carlberg, 1986; Compton and Ware, 1991; Hinton, 1981). Insects thought to engage in egg-seed masquerade produce shells that share not only the color, shape and texture, but also special features of the seeds produced by their host plants (Hinton, 1981). By looking like seeds, eggs seem to evade predation by insectivorous predators (Carlberg, 1986). Yet, seeds are rich in nutrients and are integrated in the diet of numerous herbivorous taxa, both vertebrate and invertebrate. It seems counterintuitive that there is an advantage for eggs to look like an alternative palatable food source: they should be eaten by phytophagous instead of zoophagous organisms. This however may be the key to understand seed masquerade. Hoffmeyer (1970) showed that not only are eggs unharmed by the digestive system of birds feeding on them, their ingestion also allows for dispersal of the offspring. Thus, seed masquerade provides protection against insectivorous predators and allows for distribution throughout the environment by granivorous herbivores. 
Birds are not the only organisms allowing for egg dispersion: ants do it too (Compton and Ware, 1991). Multiple species of Formicidae feed on seeds, and are attracted to them thanks to special structures called elaiosomes (Beattie 1985, cited in Compton and Ware 1991). As far as we know, close to half of all subfamilies of Phasmatidae produce eggs that look like plant seeds, but also harbor a capitulum (Clark, 1976). These capitula look very much like elaiosomes, and evidence suggests that their presence allows for egg capture by ants and later their dispersal (Compton and Ware, 1991). The eggs are brought to the ant nest where the capitula will be fed upon, benefiting the ant and leaving the egg themselves intact and safe until hatching. Once hatched, the nymphs are left alo ne by the ants (Compton and Ware, 1991) thanks to various adaptations such as ant "mimicry" (Carlberg, 1986). It is unclear whether the seed-like color pattern on the eggs plays a role in eliciting myrmecochory, or if ants are only attracted to them by the capitula. The egg coloration itself may only allow for reduction of attacks by natural enemies; future work is required to tease apart the roles of colors and capitula in ant attraction.

\section{Masquerading as a plant organ}

Aside from seeds, the eggs of several species from various Lepidopteran taxa tend to resemble other plant organs (Hinton, 1981). Some geometrid and nymphalid species lay their eggs on top of each other as to form egg strings, reminiscent of broken tendrils from their host plant. No hypotheses regarding the adaptive significance of this egg-tendril comparison was provided, but a valid one would be that predators confuse the eggs as unpalatable plant material and do not attack them. This remains to be tested. Hinton (1981) also mentioned the eggs of Cerura spp. (Notodontidae) that closely resemble the 
galls formed by other insects on their shared willow and poplar host plants. In addition to their visual similarities, both eggs and galls are found on the upper surface of leaves. It has been hinted that the eggs avoid predation by looking like the galls, but also are probably safe from gall-feeding organisms by possessing spots mimicking exit holes left by gall-producing parasites. However, experimental data are still required to confirm or reject the masquerade hypothesis.

\section{Photoprotection}

The reason why some pigments appear black to our eyes is that they absorb most of the wavelengths of the visible spectrum. Those pigments, such as melanin, tend to also absorb wavelengths in the ultraviolet range of the spectrum, which can cause damage to DNA (Cadet et al., 2005). To our knowledge, UV-protecting egg pigmentation has only been investigated in one insect species: the predacious stink bug Podisus maculiventris. This species is known to produce polymorphic eggs; each female can selectively apply pigment to the eggs, which can range from pale yellowish-white to dark-brown/black (Abram et al., 2015b). Interestingly, pale eggs are usually laid on the underside of leaves while dark eggs tend to be found on leaf tops (Figure 4). This dichotomy has been hypothesized to be because of heterogeneous solar radiation intensities in the environment. In other words, UV-absorbing pigmentation is necessary on leaf tops as eggs laid there would be exposed to harmful solar radiation, while pale eggs would be safe on the bottom because of UV-absorbent pigments in leaves (Gutschick, 1999). Abram et al. (2015b) sought to test that hypothesis and found that darker eggs had a higher probability of surviving prolonged exposure to UV radiation than pale eggs, 


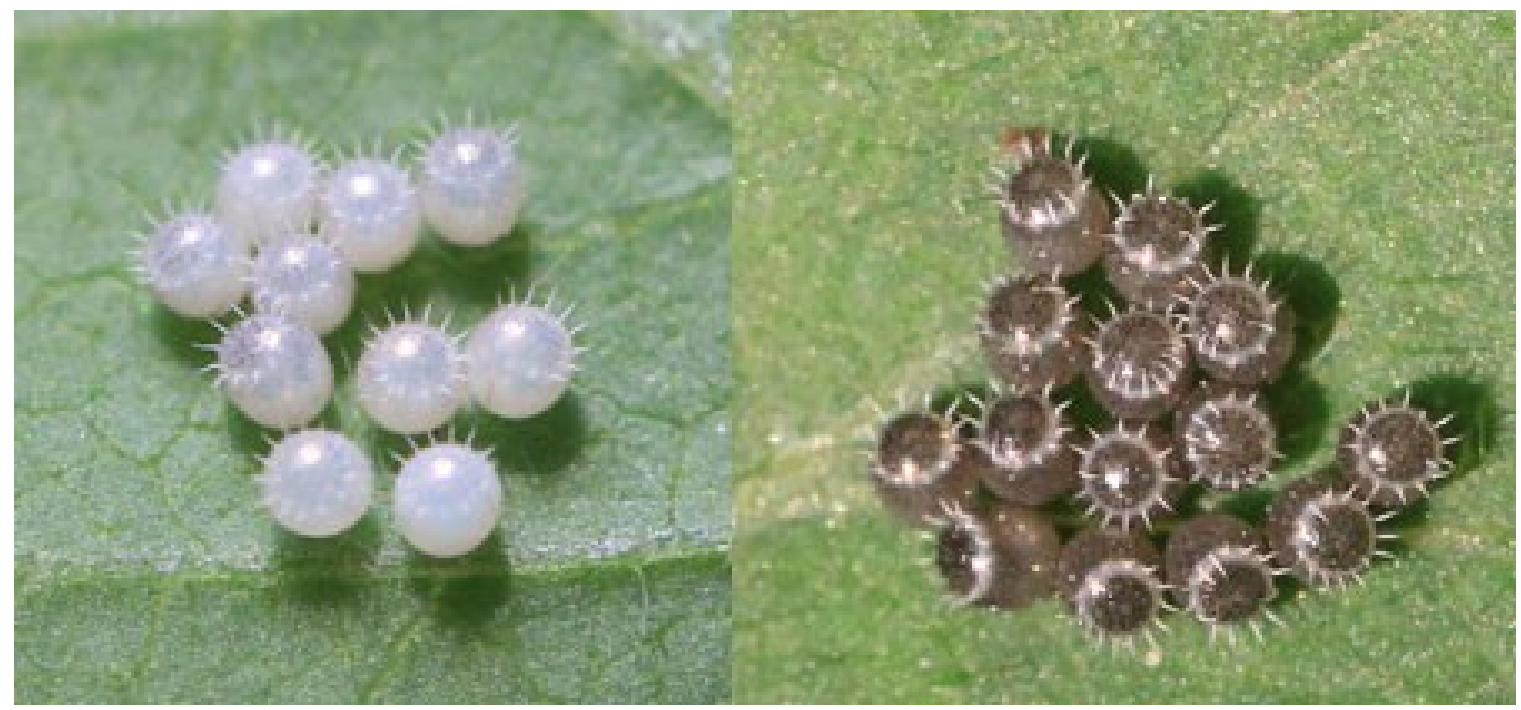

Figure 4. Eggs of the stink bug Podisus maculiventris. Pale eggs (left) are laid on leaf undersides while dark eggs (right) are laid on leaf tops. Photos by Leslie Abram (with permissions). 
especially at higher intensities. As a case of extended phenotype, parasitoid wasps attacking $P$. maculiventris eggs also benefit from the photoprotective pigment in question (Gaudreau et al., 2017), which surprisingly is not melanin and has yet to be identified (Abram et al., 2015b).

The obvious question left unanswered was: why evolve egg pigmentation in the first place? Why not always lay pale eggs on leaf undersides, thus reducing the risk of UV exposure to a maximum while avoiding a potential cost of egg pigmentation? In a followup study, Torres-Campos et al. (2016) carried out a field experiment to look at the fate of eggs displaying the whole range of pigmentation, artificially placed on either sides of leaves. Their main finding was that eggs were attacked significantly more often on leaf undersides by predators (but not parasitoids) than on leaf tops, regardless of egg color. In addition, the researchers also found that egg pigmentation does not provide camouflage, but can slightly reduce development time through thermoregulation. Altogether, these results suggest that female stink bugs first oviposited on leaf tops as a way to reduce predation risk, leading to the evolution of egg pigmentation in order to survive higher UV radiation intensities on the new laying substrate. Torres-Campos and collaborators (2016) also hypothesized that the selectivity of egg pigmentation is a way to optimize the degree of pigment application and avoid wasting resources to pigment eggs in microenvironments where protection is not required, but their results on resource-limited pigment production were not conclusive. It should be noted that, although $P$. maculiventris was the only species studied for its selective egg pigmentation, other 
species from various genera of the Asopinae (e.g. Stiretrus, Zicrona) also seem to possess selective egg pigmentation (Guerra-Grenier, personal observations).

\section{Wate $r$ retention}

Aside from its well-known properties for thermoregulation and photoprotection, melanin can also play a role in water retention. For example, the caterpillars of a geometrid moth vary in their degree of body melanization in response to risk of desiccation in the environment, where melanic larvae develop better in dry environments than non-melanic conspecifics (Välimäki et al., 2015). Such a function for egg melanism has also been described in mosquitoes (Farnesi et al., 2017). In their recent paper, Farnesi et al. (2017) discuss the relationship between eggshell melanization degree and resistance to desiccation. They used three species of Culicidae from three different genera, producing pale, grayish and dark eggs respectively. They showed that the probability of hatching increased with denser melanin cover, more so in dryer vs. humid environments. Their next step was to measure the effect of melanin on desiccation of eggs of Anopheles quadrimaculatus using two different strains: a wild, dark-brown type and a mutant, gold type (GORO). Eggs of the wild type were more viable in a dry environment than eggs of the mutant type, providing evidence that melanization plays a key role in water balance by eggshells.

\section{Areas of future work}

After a review of the existing literature on adaptive coloration in insect eggs, two conclusions can be made: 1- the diversity of defensive functions played by egg color, 
both against biotic and abiotic threats, seems high and is probably underestimated, but 2many of these functions are still hypothetical and have not yet been experimentally tested. There is a need for empirical studies across the board, especially for cryptic and aposematic egg colorations. Green eggs laid on leaves are common in several orders of insects such as Lepidoptera and Hemiptera, and background-matching camouflage is the most likely explanation for such phenotypes. Toxic eggs with conspicuous orange-red colorations might on the other hand be aposematic, but associative learning between color and toxicity by predators should be established before concluding so.

Future studies should therefore aim at quantifying whether relevant egg predators (e.g. ladybugs, lacewing larvae, ants, etc.) and parasito ids can perceive a contrast bet ween egg colors and background colors, using common vision modeling protocols established by other studies in the field of adaptive coloration (Troscianko et al, 2017; Troscianko and Stevens, 2015). Manipulation of egg coloration, using dyes or pastry-based fake eggs can also allow to test the effect of specific color phenotypes on predatory responses such as latency before detection (for studies on crypsis and masquerade) and associative learning (for studies on aposematic displays and mimicry). In any case, it is of the utmost importance to consider the color vision of the relevant natural enemies and not just that of humans. Birds and insects can frequently perceive ultraviolet wavelengths as colors while humans can't, meaning that an organism can appear cryptic to us but conspicuous to nonhuman animals (Briscoe and Chittka, 2001; Cronin and Bok, 2016). 
In the case of mimicry, the ubiquity of Batesian and Müllerian strategies in other life stages makes it unlikely that such types of mimicry are seldom used by insect eggs. We therefore suggest that future work effort should try to uncover the use of such strategies in model systems. For example, Table 1 shows that several chysomelid and coccinellid beetles lay toxic, brightly colored eggs, often yellow-orange. If two or more species cooccur in a given community, it is likely that predators learning to avoid the toxic orange eggs of one species would also be deterred by the similar egg colorations of the other toxic species. This can be true for species co-occurring within a given field, but also on a same host plant (e.g. for eggs of the Müllerian ring found on milkweed plants).

Future studies on the evolutionary ecology of insect egg coloration should make sure to test for multiple functions provided by the same phenotype. Indeed, color patterns, especially complex ones, often defend organisms against multiple threats. Such is the case for the orange/green markings on the caterpillar of the swallowtail butterfly Papilio machaon, cryptic at long range but aposematic at short range (Tullberg et al., 2005), or for the blue/yellow markings on reef fishes used for intra-specific communication at short range but for camouflage at long range (Marshall, 2000). Testing for multiple functions of egg color is also important even if some of them are just context-dependent secondary benefits provided by the main adaptive function, like the slight thermoregulatory properties of the photoprotective pigment in P. maculiventris eggs (Torres-Campos et al., 2016). Additionally, phylogenetic analyses would provide us with a better understanding of the evolution of egg coloration in various taxa, by testing whether related species are more likely to have similarly colored eggs. Correlates of egg coloration can also tell us a 
lot about reproductive strategies and investments. For example, females laying conspicuously colored eggs are more likely aggregate their offspring than those laying eggs that seem to blend in with the background (Stamp, 1980). Egg color can also be correlated to egg weight (Wickman and Karlsson, 1987) and viability (Merle and Brunet, 1991), depending on the age of the mother at the time of oviposition. 


\title{
CHAP TER 2: CHEMICAL DEFENSES AND TONIC IMMOB ILITY IN EARLY LIFE STAGES OF THE HARLEQUIN CABBAGE BUG
}

\begin{abstract}
Antipredation strategies are important for the survival and fitness of animals, especially in more vulnerable life stages. In insects, eggs and early juvenile stages are often either immobile or unable to rapidly flee and hide when facing predators. Unders tanding what alternative antipredation strategies they use, but also how those change over development time, is required to fully appreciate how species have adapted to biotic threats. Murgantia histrionica is a stink bug, conspicuously colored from egg to adult, known to sequester defensive glucosinolates from its cruciferous hosts. We sought to assess whether this chemical defense is also present in its eggs and early nymphal instars and quantified how it fluctuates among life stages. In parallel, we looked at an alternative anti-predator strategy, described for the first time in this species: tonic immobility. Our results show that the eggs are significantly more chemically defended than the first two mobile life stages, but not than the third instar. Tonic immobility is also favored by hatchlings, but less so by subsequent instars. We argue the case that over development time, tonic immobility is a useful defensive strategy until adequate chemical protection is achieved over an extended feeding period.
\end{abstract}

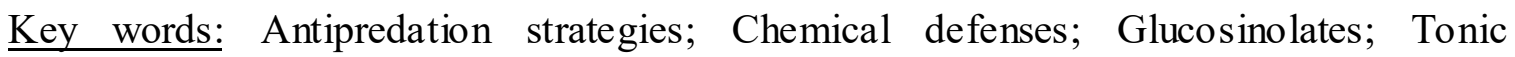
immobility; Egg coloration; Pentatomidae; Murgantia histrionica 


\section{Introduction}

Animals are faced with constant threats, such as predation and parasitism, and have to overcome them in order to survive and reproduce. Several antipredation strategies have evolved in numerous taxa in order to minimize predation pressures. One of them is the use of chemical compounds to deter predators through their unpalatability or toxicity. Species using such chemical defenses frequently advertise their unprofitability through warning signals (e.g. conspicuous body coloration), allowing predators to learn to avoid the former when exposed to the latter through associative learning: a phenomenon called aposematism (Skelhorn et al, 2016). Although usually studied in active life stages, chemical defenses in insects are also known to occur in eggs. In their excellent book chapter on the subject, Blum and Hilker (2002) distinguish between two types of chemical protection in insect eggs: the defensive compounds can either be produced autogenously by the parents (intrinsic origin) or can be sequestered from their diet (extrinsic origin), although some species are known to do both such as Photuris fireflies (González et al., 1999). An example of eggs protected by de novo chemicals is found in the Australian chrysomelid Paropsis atomaria Olivier 1807 (Blum and Hilker, 2002; Nahrstedt and Davis, 1986). All life stages of these beetles possess cyanoglygosides which, when under attack, can be modified to release hydrogen cyanide (HCN), a known respiratory inhibitor. As their Eucalyptus host plants are free of cyanoglycosides, it is believed that the chemical defense is produced by the insects themselves and then transferred into the eggs. Eggs protected through sequestration can be found for example in two orthopteran species of the genus Poecilocerus feeding on milkweed plants: $P$. bufonius (Klug 1832) and P. pictus (F. 1775) (Blum and Hilker, 2002; Fishelson et al., 
1967; Pugalenthi and Livingstone, 1995). Milkweeds are famous for their poisonous cardenolides, which are sequestered by the aposematic Poecilocerus and later incorporated in their eggs. Furthermore, whether they are of intrinsic or extrinsic origin, chemical defenses can sometimes be provided to the eggs by the fathers (Eisner et al., 2002). This is advantageous to both parents since females only partially have to pay the metabolic costs for synthesis and/or sequestration while males with lots of toxins are favored during mate choices and have presumably increased reproductive success.

Aside from chemical protection, tonic immobility (TI) is another common antipredation strategy. Individuals engaging in tonic immobility enter a completely motionless state after physical contact with potential predators. TI is also referred to thanatosis or death feigning in the literature, because immobile prey are reminiscent of deceased individuals (Ruxton, 2006). However, as pointed out by Humphreys and Ruxton (2018, and references therein) in their recent review, death feigning individuals often adopt postures that are dissimilar to those of dead individuals of the same species. We agree with them that the term death feigning is misleading and therefore will use the term tonic immobility. TI has been hypothesized to be an efficient anti-predation strategy through various mechanisms (not necessarily mutually exclusive) including mimicking death but also the signaling of chemical defenses (Miyatake et al., 2009, 2004; Ruxton, 2006) and the reduction of attack rates by motion-oriented predators (Edmunds, 1974; Miyatake, 2001; Prohammer and Wade, 1981). Although it is well known, tonic immobility is still relatively understudied and its use is most likely under-reported (Humphreys and Ruxton, 2018). 
A good candidate for the study of anti-predation strategies is the Harlequin cabbage bug, Murgantia histrionica (Hahn 1834) (Heteroptera: Pentatomidae). This species of stink bug feeds mainly on cruciferous plants (Brassicaceae), but is known to have over 50 possible host plants (McPherson, 1982). Native to Mexico, it is established in several U.S. states and is occasionally observed in Canada (McPherson, 1982; Paiero et al., 2013). It is a recognized pest of economically important crops such as cabbage, collard, kale and broccoli (Ludwig and Kok, 2001; Wallingford et al., 2011) and is thus studied for its management, more recently in a semiochemical context (Conti et al, 2003; Peri et al., 2016). Part of what explains the success of these bugs is their low number of natural enemies; they have a few parasitoids and virtually no predators or competitors (Amarasekare, 2000; McPherson, 1982), suggesting efficient anti-predation strategies. Contrary to most North American pentatomids, which are cryptic brown or green, Murgantia histrionica is easily recognizable through its orange, white and black markings (Figure 5a). Aliabadi et al. (2002) suggested that this conspicuous color pattern acts as a warning signal to reduce predation by birds. Indeed, they showed that, much like some other species feeding on cruciferous plants such as aphids and sawflies (Opitz and Müller, 2009), adult Harlequin bugs can sequester glucosinolates from their host plant into their body tissues. Glucosinolates (mustard oil glycosides) are secondary metabolites produced by cruciferous plants and their hydrolysis products (isothiocyanates, nitriles, etc.) are toxic and used as antiherbivory defenses (Louda and Mole, 1991; Opitz and Müller, 2009). Although only described in Murgantia histrionica, this chemical defense 


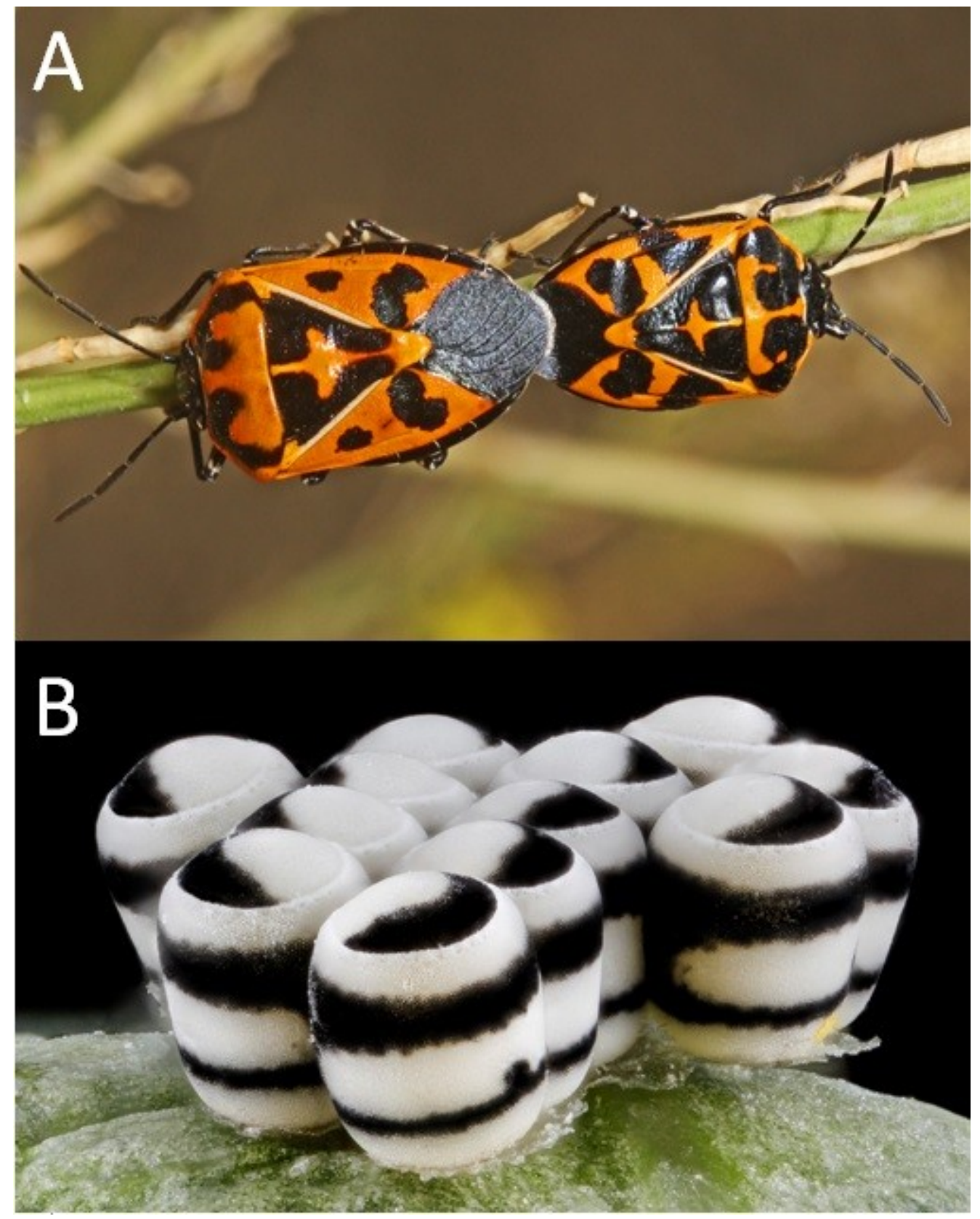

Figure 5. A) Adults (photo by Judy Gallagher (CC BY 2.0)) and B) eggs (Public Domain Mark 1.0) of Murgantia histrionica. 
could potentially be present in other members of the Strachini tribe (i.e. other Murgantia spp., Eurydema spp., Stenozygum spp., etc.) given their shared body coloration (orange, white and black markings) and use of glucosinolate-producing host plants (i.e. Brassicaceae, Capparaceae, etc.) (Exnerová et al., 2008; Samra et al., 2015).

Much like the adults of the species, M. histrionica eggs and nymphs are also quite colorful. The eggs (Figure 5b), usually laid in clutches of 12 (two rows of six eggs) are white with two black bands and a black spot on the external side. The operculum is also black and white, and the black portion can either form a ring or be shaped as to resemble the Yin-Yang symbol. Much like in the adults, the egg color pattern is generally conserved throughout the Strachini tribe (Kalender, 1999; Samra et al., 2015). Nymphal coloration is somewhat similar to that of the adults in term of hues and pattern complexity, but white markings are also found on their dorsal side. Although sequestration of glucosinolates presumably starts during juvenile stages, it is currently unknown whether nymphs and eggs are actually chemically defended against vertebrate and invertebrate predators. Furthermore, tonic immobility has been observed in hatchlings that were physically disturbed (Guerra-Grenier, personal observations). This is interesting because, like in other stink bug species, this life stage does not feed (Canerday, 1965; Zahn et al., 2008), meaning that if glucosinolates are not vertically obtained through parental bestowal, chemical defense cannot be achieved until later on in their development. TI could thus be an alternative line of defense, possibly used to deter motion-oriented predators. 
The aim of the present study was to assess the extent of antipredation defenses in eggs and early nymphal instars of the Harlequin cabbage bug. First, we asked if the white portion of the egg color pattern, already thought to be conspicuous against a green crucifer leaf background, allows for an increased contrast (i.e. more intense warning signal) by also reflecting wavelengths in the ultraviolet (UV) part of the electromagnetic spectrum. Indeed, several insect species can perceive UV light and incorporate ultraviolet coloration in their signals (Cronin and Bok, 2016) and leaves are known to absorb ultraviolet radiation from the sun (Gutschick, 1999). Secondly, we wanted to assess whether eggs and nymphs have glucosinolates and, if so, whether concentrations are different among life stages. We predicted that concentrations in nymphs increase over successive molts, reflecting an increased sequestration over feeding time. Finally, we wanted to investigate the use of TI in nymphs by looking at its frequency and duration, predicting that it is used by the insects in order to compensate for lower chemical defenses and that TI use decreases as glucosinolate sequestration increases.

\section{Materials and Methods}

\section{Insect colony}

M. histrionica individuals were collected in the Beltsville area (Maryland, USA) in 2016 and subsequently cultured at $28 \pm 1{ }^{\circ} \mathrm{C}$ and a 16L: $8 \mathrm{D}$ light cycle in an incubator (VWR Chamber Diurna Growth 115V, Cornelius, USA) supplied with a jar of water for added moisture. Adults were reared continuously in $30 \mathrm{~cm}^{3}$ ventilated polyester cages (BugDorm, Taichung, Taiwan) while nymphal instars were kept in ventilated plastic containers (length: $22 \mathrm{~cm}$; width: $15 \mathrm{~cm}$; height: $5 \mathrm{~cm}$; Rubbermaid, USA). All were fed 
with rinsed fresh store-bought broccoli (Brassica oleracea var. italica), replaced three times per week. Eggs were collected three times per week from the sides of the cages and broccoli and put into Petri dishes (diameter: $9 \mathrm{~cm}$ ) lined with a filter paper until hatching, at which point they were transferred to the plastic containers.

\section{Ultraviolet photography}

Ten clutches (totaling 106 eggs), one adult male and one adult female were photographed under both ultraviolet and visible light using a Nikon D70 camera with an El-Nikkor 80mm lens and a Baader U UV filter (Baader Planetarium, Germany: 310-390nm UV transmission). The El-Nikkor lens is sensitive to wavelengths $320 \mathrm{~nm}$ and higher (Verhoeven and Schmitt, 2010). A MTD70 EYE color arc bulb (70W, 1.0A power source, www.eyelighting.co.uk) was used as the only light source and was chosen for its D65 spectrum (the same spectrum as sunlight). Eggs were glued on double sided tape on a Petri dish (diameter: 9cm) and pictures were taken from above and from the external (banded) side. Adults were photo graphed on their ventral and dorsal sides.

\section{Biochemical assays}

A total of 301 individual Harlequin cabbage bugs were sampled from the lab colony for glucosinolate extractions, following an adapted version of the protocol established by Doheny-Adams et al. (2017). Individuals were first separated into life stages (whole eggs, first instars, second instars and third instars), subsequently split into triplicates of equivalent mass $(3 \mathrm{x} \sim 18.00 \mathrm{mg}$ for eggs; $3 \mathrm{x} \sim 13.00 \mathrm{mg}$ for first instars; $3 \mathrm{x} \sim 40.00 \mathrm{mg}$ for second and third instars) and finally macerated in a solution of $70 \%$ methanol at a 
dilution ratio of $1 \mathrm{ml}$ of solution per $4 \mathrm{mg}$ of insect mass. The shells left behind by the first instars, which were collected before they started feeding, were also pooled ( $\sim 3.00 \mathrm{mg}$ per replicate) and treated the same way. Flowerets of broccoli $(440.45 \mathrm{mg})$ bought from the same batch the insects fed on were ground with liquid nitrogen and then transferred into $70 \%$ methanol at the same dilution ratio mentioned above. Once prepared, samples were put into a water bath at $70^{\circ} \mathrm{C}$ for 30 minutes for extraction.

The resulting extracts were filtered and analyzed on a Shimadzu UPLC-MS system (Mandel scientific company Inc, Guelph, Canada) which contains LC30AD pumps, a CTO20A column oven, a SIL-30AC autosampler and a LCMS-2020 mass spectrometer. Briefly, $1 \mu 1$ of each fraction was injected through the autosampler to a Luna omega polar C18 column (100 x $2.1 \mathrm{~mm}, 1.6 \mu \mathrm{m}$ particle size, Phenomenex, Torrance, USA). Mobile phases were $\mathrm{H}_{2} \mathrm{O}$ and acetonitrile, with $0.1 \%$ formic acid in both. The isocratic elution method was initialed with $2 \%$ acetonitrile for 5 minutes. The column was then washed with $100 \%$ acetonitrile for $3 \mathrm{~min}$ and re-equilibrated for 5 minutes before the next injection. The flow rate was set at $0.5 \mathrm{ml} / \mathrm{min}$ with the column tempered at $50^{\circ} \mathrm{C}$.

The mass spectrometer with electrospary ionization (ESI) interface operated in negative selective ion monitoring (SIM) mode, the nebulizing gas flow was set at $1.5 \mathrm{~L} / \mathrm{min}$ and drying gas flow was at $10 \mathrm{~L} / \mathrm{min}$. The desolvation line temperature and heat block temperature were set at $250^{\circ} \mathrm{C}$ and $400^{\circ} \mathrm{C}$ respectively. The detector was monitoring at $436[\mathrm{M}-\mathrm{H}]^{-}$with $938 \mathrm{u} / \mathrm{sec}$ scan speed. Linear calibration curves were built by injecting dilutions of glucoraphanin (Cayman chemicals, Ann Arbor, USA) which bracket the 
compound concentration in the samples. Calibration curves were prepared at five concentration levels (0.2-10 ng on column) and $\mathrm{R}^{2}$ values obtained.

\section{Behavioral assays}

Eggs were sampled from the lab colony and put in clutch-specific Petri dishes (diameter $=9 \mathrm{~cm})$. Individuals that hatched from those eggs were reared in the same environmental condition as the general rearing until they reached the first ( 86 from 8 clutches), second (81 from 10 clutches) and third instars (97 from 14 clutches). The number of clutches used increased with increasing instar as to obtain similar sample sizes while compensating for the baseline mortality rate. One at a time, every individual went through the following protocol. Bugs were first placed on a filter paper (diameter: 12.5 $\mathrm{cm})$. They were then prodded by an observer using a paint brush. Each trial consisted of up to five sessions of five prods (25 in total), with each session separated by one minute. The presence of TI and its duration (if present) was recorded. Trials ended when individuals either displayed TI postures (Figure 6) for 5 seconds or more, or if all 25 prods unsuccessfully elicited the behavior. TI postures kept for less than 5 seconds were not considered given that such a short duration could be due to sensory overload or to a period of physiological recovery from impact. The clutch of origin of each individual, as well as the order at which they were taken from their clutch-specific container and prodded, were also recorded. A Petri dish lid of the same size as the filter paper was placed onto the arena between prodding sessions in order to stop the bugs from escaping. The soft hair of the brush was frequently moistened, twisted to gether and then dried by 


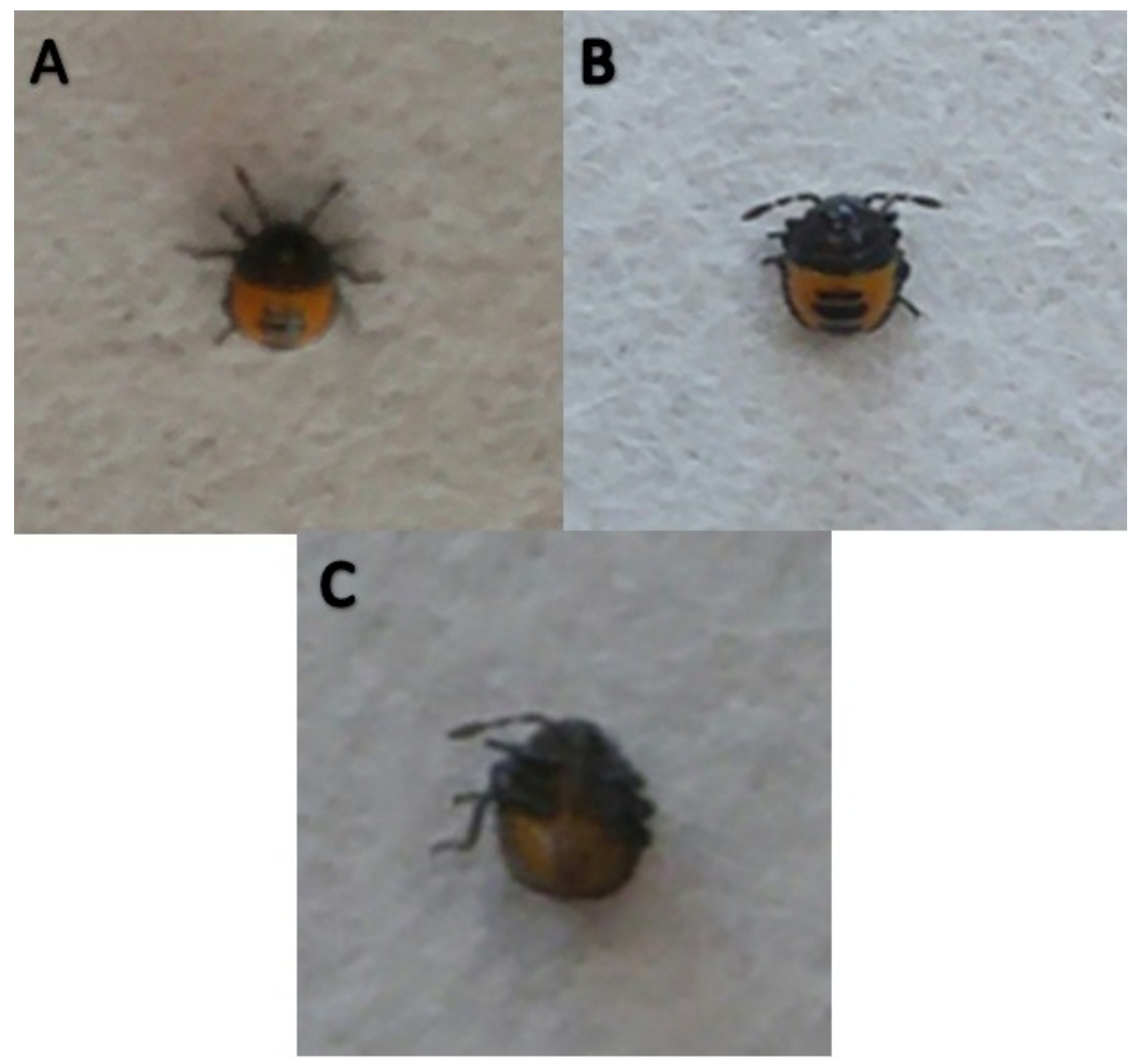

Figure 6. Postures adopted by $M$. histrionica nymphs during behavioral assays. Nymphs could be active (A) or display tonic immobility when on their ventral (B) or dorsal (C) side. The pictures shown here are of an individual in its first instar. Photo credit: Eric Guerra-Grenier. 
contact with another filter paper in order to reduce the risk of trapping the bugs among the brush hair. All trials were carried out by the same observer.

\section{Statistical analyses}

All analyses were conducted with $\mathrm{R}$ version 3.3.3 (R Core Team, 2017). A KruskalWallis rank sum test allowed for the comparisons of glucoraphanin concentrations among eggs and the three nymphal instars. Dunn's tests were subsequently used for post-hoc pairwise comparisons between life stages using the "dunn.test" package in R (Dinno, 2017). Differences in concentrations between hatchlings and their eggshells were analyzed by fitting a linear model following a square root transformation of the concentration data to successfully ensure homogeneity and normality.

Generalized linear mixed models (GLMMs) and generalized linear models (GLMs) with binomial error distributions were used to regress the probability of tonic immobility as a function of instar and prodding order within clutch as fixed factors, and clutch of origin as a random factor. These models were fit using the "lme4" package in R (Bates et al., 2014). General linear mixed models (LMERs) and linear models (LMs) were fitted to test for the effect of the same factors on the duration of tonic immobility, assuming normally distributed error. For all statistical models that we fit to the TI data, the significance of each of the fixed factors was determined by using Wald chi-square tests using the "car" package in R (Fox and Weisberg, 2011). AIC values finally determined which models among those based on all or a subset of the factors best fitted the data. Simultaneous tests for general linear hypotheses with Tukey contrasts were subsequently used for post-hoc 
pairwise comparisons between nymphal instars using the "multcomp" package in $\mathrm{R}$ (Hothorn et al., 2008).

\section{Results}

$U V$ reflectance in eggs and adults

Eggs exposed to ultraviolet light (Figure $7 b, d$ ) showed high reflectivity in the pale, but not dark markings of the color pattern in all ten clutches photographed. The same level of contrast was present under visible light only (Figure 7a, c). This implies that the pale markings of the eggs are perceived as true white to UV-sensitive animals as well as to those who are not (e.g. humans). Unlike the eggs, both the male and the female adults showed almost no reflection of wavelengths between 320-390nm (Figure 7e-1). This suggests that the features (i.e. pigments and/or refracting nanostructures) responsible for the white coloration perceived by humans in adults and eggs are different to some extent.

\section{Chemical defenses in eggs and nymphs}

Glucoraphanin was detected in broccoli as expected, but also in the eggs and hatchlings (first instars) (Figure 8). Simple qualitative (presence/absence) detection of the compound was irrelevant for second and third instars as its presence in the gut from previous feeding events make it impossible to know if glucoraphanin is also present in body tissues. Concentrations of glucoraphanin were subsequently evaluated in eggs and all three instars (Figure $9 \mathrm{a})$ and were shown to differ among life stages $(\mathrm{H}=8.7436, \mathrm{df}=3, \mathrm{p}$-value $=$ 


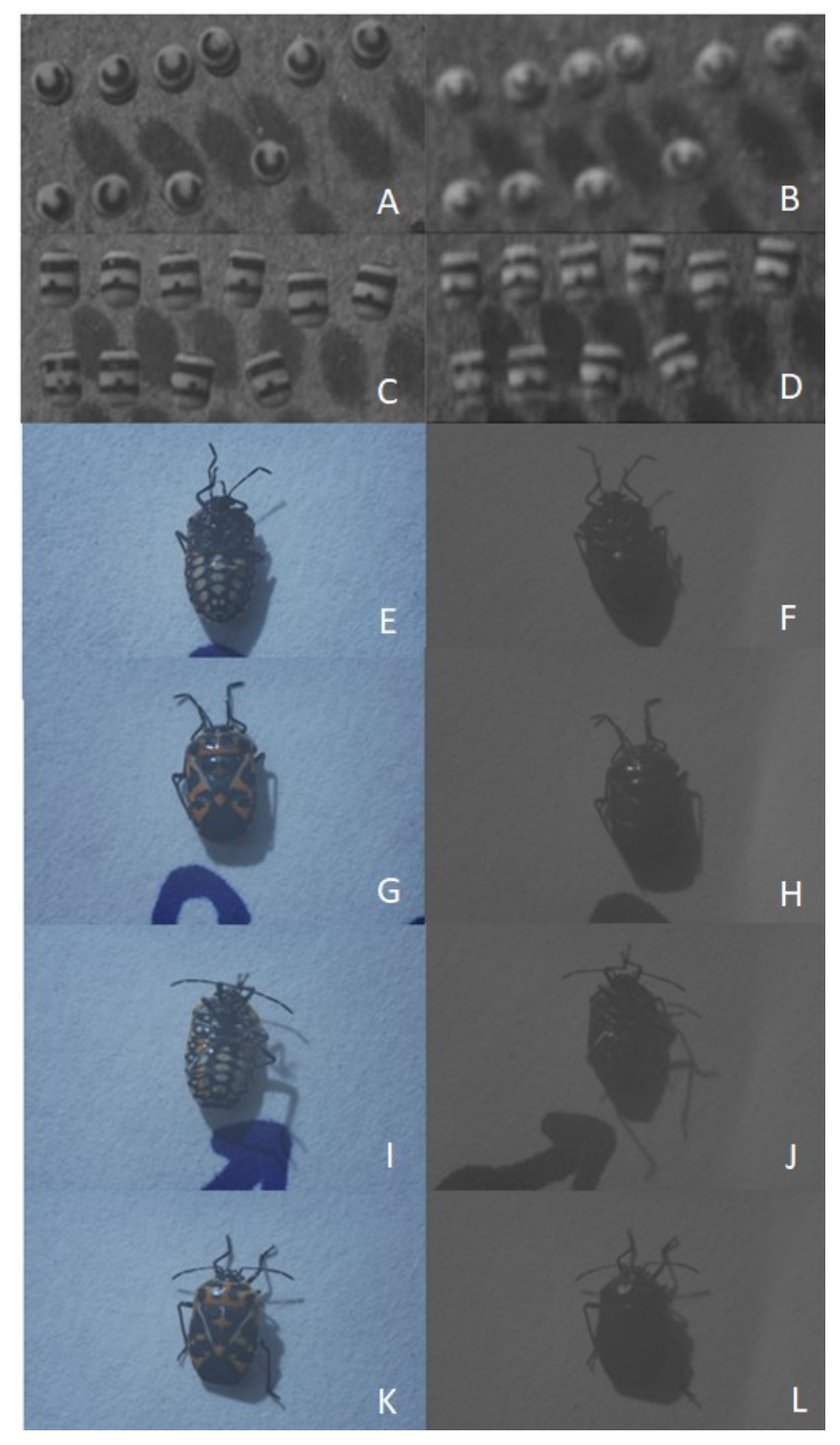

Figure 7. Pictures of eggs and adults taken in the visual (left panels) and ultraviolet (right panels) spectra. Eggs are seen from their top (A-B) and external sides (C-D). The female is seen from her ventral $(\mathrm{E}-\mathrm{F})$ and $\operatorname{dorsal}(\mathrm{G}-\mathrm{H})$ sides. The male is seen from his ventral (I-J) and dorsal (K-L) sides. UV pictures were converted in black and white images so that UV light could be perceived by human eyes on a luminance scale (the brighter the markings, the more UV-reflecting they are). Photo credit: Eric Guerra-Grenier. 


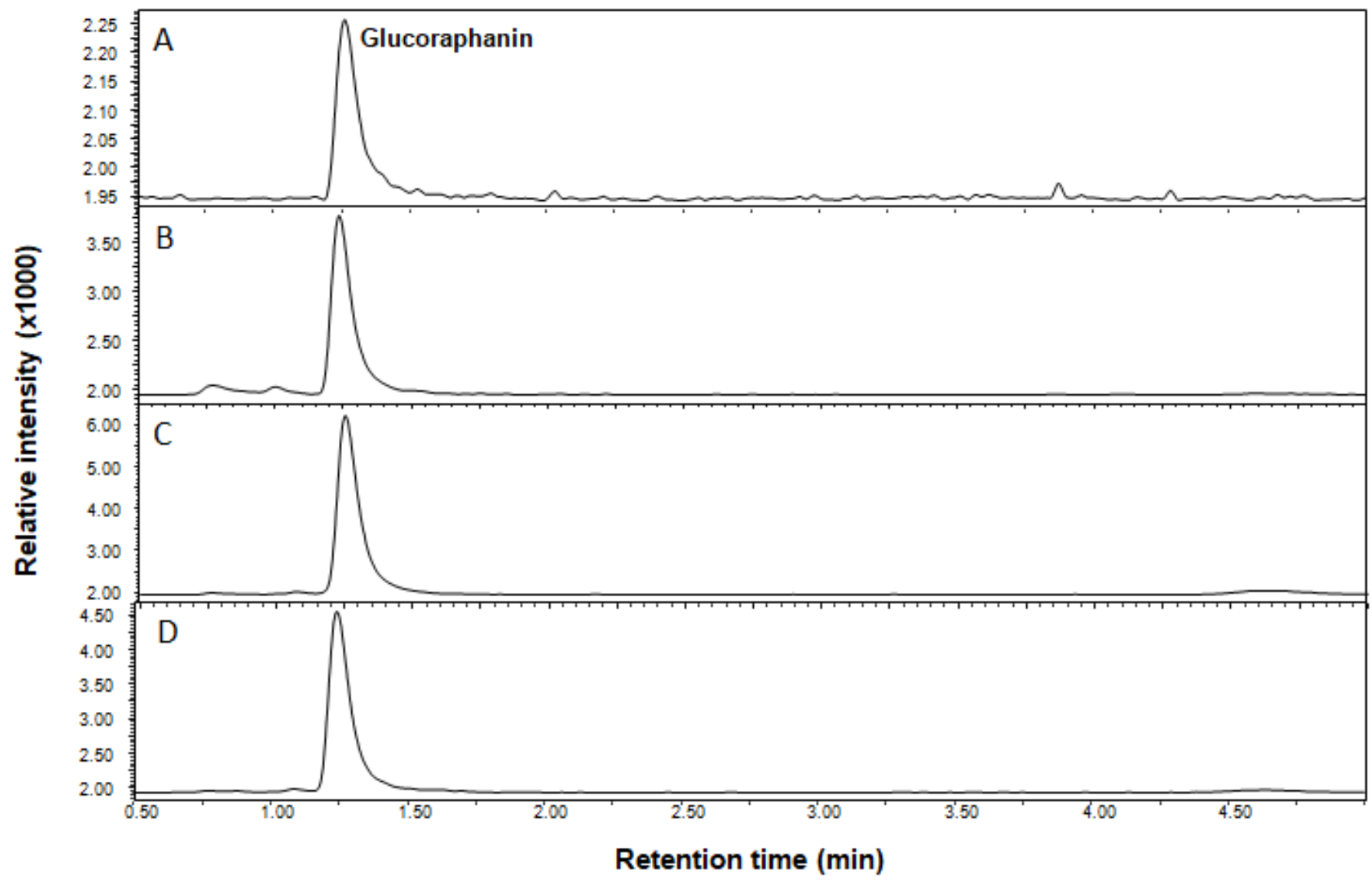

Figure 8. UPLC-ESI/MS negative extracted ion chromatogram of glucoraphanin $(\mathrm{m} / \mathrm{z}=$ 436 (M-H)-). A) Glucoraphanin commercial standard; B) Broccoli flowerets; C) Whole eggs; D) First instars (hatchlings). 


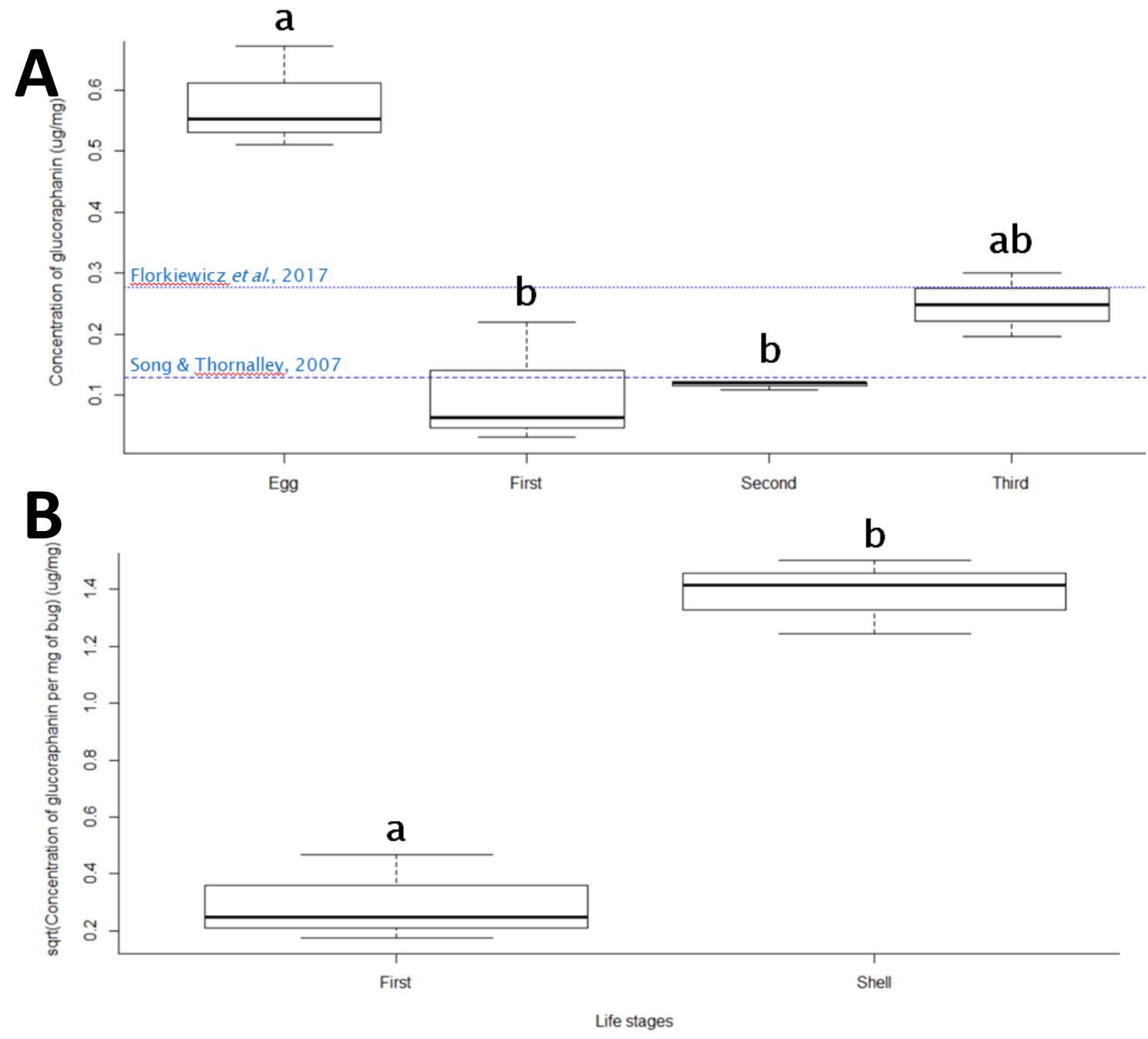

Figure 9. Boxplot representations of glucoraphanin concentrations in various life stages.

A) The concentrations of glucoraphanin $(\mu \mathrm{g} / \mathrm{mg})$ in whole eggs, first, second and third nymphal instars chemical defenses. The blue dotted lines represent concentrations of glucoraphanin in broccoli (reported by Florkiewicz et al. 2017; Song and Thornalley, 2007) as a means of comparison. B) The concentrations of glucoraphanin $(\mu \mathrm{g} / \mathrm{mg})$ in hatchlings and their shells. 
0.0329). Post-hoc comparisons revealed that eggs had significantly higher concentrations than first $\left(\bar{X}_{\text {eggs }}=0.5784, S_{\text {eggs }}=0.0833, \mathrm{M}_{\text {first }}=0.1038, \mathrm{SD}_{\text {first }}=0.1011, \mathrm{Z}=2.6042, \mathrm{p}=\right.$ $0.0046)$ and second instars $\left(\overline{\mathrm{X}}_{\text {second }}=0.1167, \mathrm{~S}_{\text {second }}=0.0073, \mathrm{Z}=2.3778, \mathrm{p}=0.0087\right)$, but did not differ from third instars $\left(\bar{X}_{\text {third }}=0.2481, \mathrm{~S}_{\text {third }}=0.5294, \mathrm{Z}=1.323, \mathrm{p}=0.1288\right)$. Yet, third instars had similar levels of glucoraphanin to first $(Z=-1.4720, p=0.0755)$ and second instars $(Z=-1.2455, p=0.1065)$. Concentrations in the first two nymphal instars did not differ significantly $(Z=-0.2265, \mathrm{p}=0.4104)$. Since hatchlings had significantly less compound than eggs, their concentrations were compared to those of the shells they left behind when hatching (Figure 9b). The analysis revealed that, of all the compound present in the eggs, most of it is laced within the shells $(\mathrm{LM}: \mathrm{F}=88.002, \mathrm{df}=$ $1,4, p<0.001)$, leaving only a small portion of glucoraphanin available for integration by the developing insects.

\section{Tonic immobility in nymphs}

The probability of displaying tonic immobility of a given nymph was strongly influenced by which instar it was in (GLMM: $\left.\chi^{2}=13.0001, \mathrm{df}=2, \mathrm{p}=0.0015\right)$ : hatchlings displayed the behavior more frequently than second $(p=0.0304)$ and third instars $(p=0.0013)$ while the later two instars did not differ in their display frequency $(\mathrm{p}=0.5120)$ (Figure 10a). The probability of displaying TI also slightly reduced the later nymphs were sampled from their clutch of origin (GLMM: $\left.\chi^{2}=3.8653, \mathrm{df}=1, \mathrm{p}=0.0493\right)$ (Figure 10b). The duration of the behavior was shorter in individuals tested later within a clutch compared to those tested earlier (LMM: $\chi^{2}=4.2635, \mathrm{df}=1, \mathrm{p}=0.0390$ ), but was not affected by nymphal instar. The clutch from which nymphs originated was also a key 

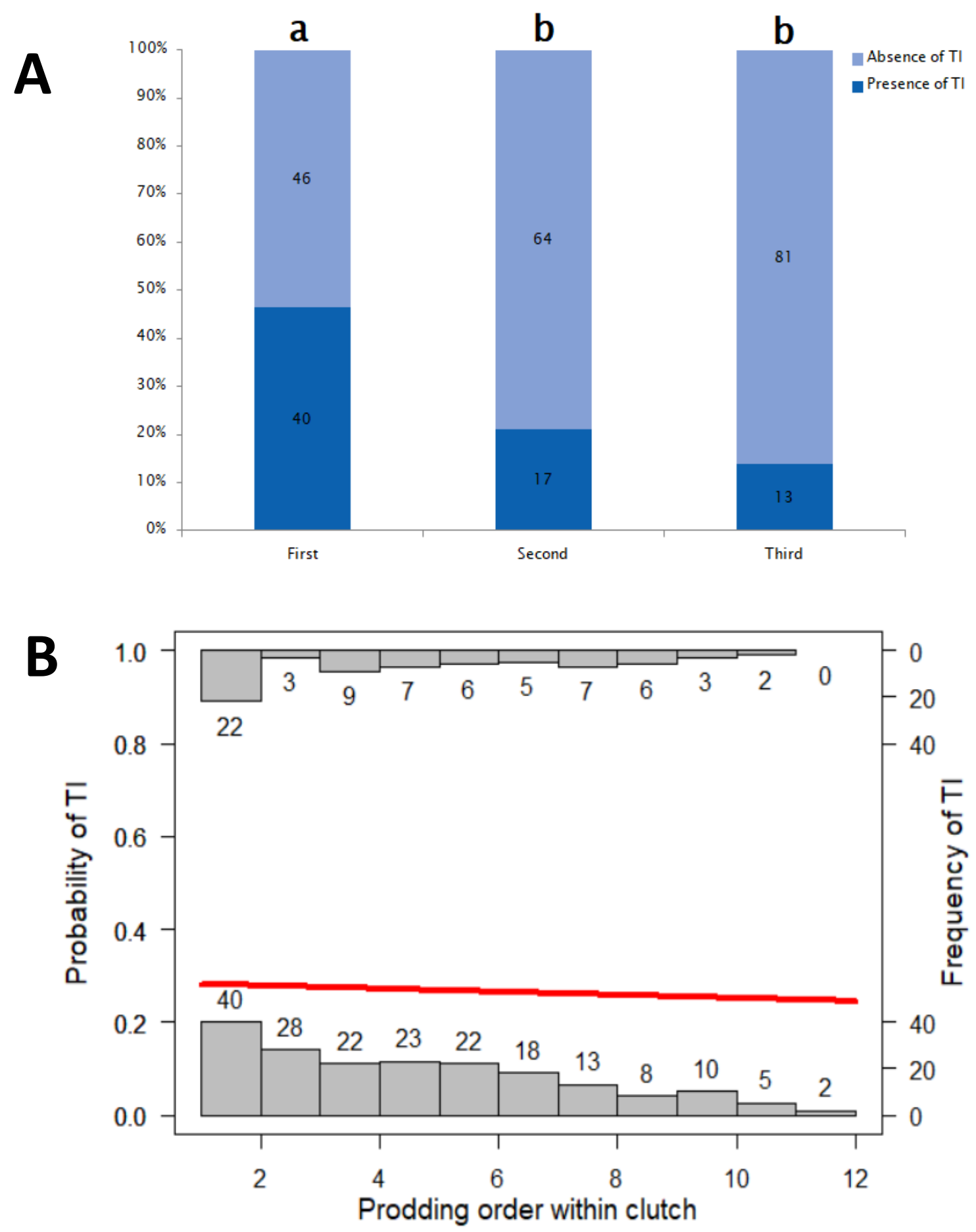

Figure 10. The effects of A) nymphal instars and B) prodding order within a clutch on an individual's probability of entering tonic immobility. 
Table 2. Comparison of the fit of the models testing for the effects of fixed and random factors on A) the presence and B) duration of TI displayed by nymphs. Rows in bold indicate which models best fitted the data based on AIC values. If two or more models shared the lowest $\mathrm{AIC}( \pm 0.1)$, the one with the most degrees of freedom was chosen.

\begin{tabular}{llll} 
A) Presence of TI & & & \\
\hline Model description & Model type & Df & AIC \\
\hline Prodding order & GLM & 2 & 307.39 \\
Instar & GLM & 3 & 283.59 \\
Clutch ID & GLMM & 2 & 283.15 \\
Prodding order + Clutch ID & GLMM & 3 & 282.85 \\
Instar + Prodding order & GLM & 4 & 282.28 \\
Instar + Clutch ID & GLMM & 4 & 276.23 \\
Instar + Prodding order + Clutch ID & GLMM & $\mathbf{5}$ & $\mathbf{2 7 4 . 2 3}$ \\
& & & \\
B) Duration of TI & & & \\
\hline Model description & Model type & Df & AIC \\
\hline Instar + Clutch ID & LMM & 5 & 241.63 \\
Instar & LM & 4 & 240.51 \\
Instar + Prodding order + Clutch ID & LMM & 6 & 240.08 \\
Clutch ID & LMM & 3 & 239.78 \\
Instar + Prodding order & LM & 5 & 239.56 \\
Prodding order + Clutch ID & LMM & $\mathbf{4}$ & $\mathbf{2 3 7 . 6 0}$ \\
Prodding order & LM & 3 & 237.54
\end{tabular}


factor predicting both the probability of displaying TI (Table 2A) and the duration of the behavior (Table 2B), suggesting genetic variation in the way nymphs display tonic immobility.

\section{Discussion}

The aim of this study was to investigate two potential antipredation strategies in eggs and juvenile Murgantia histrionica: chemical protection and tonic immobility. Our results suggest that both strategies are used by the bugs, but also that their use varies across life stages. Given that eggs are completely immobile and are "sitting ducks" to would-be predators, behavioral strategies are unavailable, leaving only chemical protection as a viable defense. This could explain why concentrations in the eggs are much higher than in the young nymphs, in which glucoraphanin levels do not vary significantly among instars. However, levels of compound in the eggs are similar to those of third instars. Given that first and second instars have a significantly lower concentration than eggs, we can speculate that third instars are at an intermediate level, indicating that sequestration probably starts at this stage but has not yet reached the degree seen in adults. Indeed, according to Aliabadi et al. (2002), adults sequester glucosinolates in their tissues at concentrations 20-30 times higher than those found in the gut (i.e. about the same concentration as in cruciferous plants). Our results however demonstrate that concentrations in nymphs are similar to concentrations in broccoli (Song and Thornalley 2007; Florkiewicz et al. 2017, although variation occurs among cultivars as shown by Brown et al. 2002). This may be because it takes time to build up the concentration in body tissues. It may also be because small nymphs of true bugs, including the Harlequin 
cabbage bug, are exposed to different predators than adults and bigger nymphs (mostly invertebrate vs. mostly vertebrate respectively) (Exnerová et al, 2003), and these predators probably have different susceptibilities to mustard oils. Although both vertebrates and invertebrates are usually intolerant to glucosinolates (Halkier and Gershenzon, 2006), such compounds have evolved in plants to limit insect feeding (Louda and Mole, 1991) while they can be beneficial to vertebrates at natural concentrations (Shapiro et al., 1998).

Interestingly, a large proportion of the glucosinolates in the eggs is laced within the shells and is thus not accessible to the bugs for integration before hatching. This could explain why, even though egg predators have seldom been reported, eggs are often attacked by parasitoid wasps of the genera Trissolcus (Platigastridae) and Ooencyrtus (Encyrtidae) (Amarasekare, 2000; Conti et al., 2003; McPherson, 1982; Peri et al., 2016). These endoparasitoids drill through the egg shell with their ovipositor and lay their eggs directly within the host eggs, meaning that they bypass most of the chemical defense. Furthermore, even though the larvae enter in contact with the lower dose of glucosinolates within the eggs, parasitoids are known to be more specialized on their hosts than predators are on their prey and have potentially evolved an increased resistance to the compounds. This of course remains to be tested.

Unlike for chemical protection, Harlequin bug nymphs showed life stage-specific variation in their probability, but not duration, of entering tonic immobility. Indeed, first instars displayed the behavior significantly more frequently than second and third instars. 
As instar-related variation in glucoraphanin content does not occur, we have to reject our hypothesis that TI is present in younger life stages to compensate for the lack of chemical defense. A higher probability of TI in hatchlings could however be explained by variation in life history traits. M. histrionica is not really active until its second instar. Zahn et al. (2008) reported that neonate bugs do not feed and remain aggregated with their siblings; only after the first molt did they start to feed and disperse. In other words, if a ttacked, individuals in their first instars are too small and probably not active enough to successfully flee. TI thus becomes the optimal behavioral strategy, in addition to chemical protection. It is also conserved at a lower degree in second and third instars. Yet again, variation in life history traits could explain the lower frequency in older nymphs: fleeing becomes a safer option as size and speed increase, leading up to an almost zero probability of entering TI in the final nymphal instars and adults (Guerra-Grenier, personal observations).

Regardless of instar, TI use was also influenced by the order in which we prodded individuals of a given clutch. Those tested first had a higher probability of entering tonic immobility than those tested last, and kept the posture for a longer period. This may be because of an alarm cue perceived by the nymphs. Such a cue could be the visual detection of conspecifics being "attacked", but is most likely olfactory in nature. There is a reason why stink bugs are named this way: they release pungent volatile chemicals when disturbed, and these chemicals are known to elicit dispersal in neighboring conspecifics (Ishiwatari, 1974). In Murgantia histrionica specifically, some of these compounds are thiocyanides derived from the glucosinolates they absorb from their host 
plants (Aldrich et al., 1996; Aliabadi et al., 2002). It would make sense for individuals reacting to these chemical cues to engage less frequently and in shorter TI periods if they are stimulated to flee. It should however be noted that ecological factors cannot fully explain the use of TI. Inter-clutch variation in the probability of displaying TI and its duration suggests that there is also a hereditary component to tonic immobility in $M$. histrionica, which is not surprising considering that genetic variation in TI is known to occur in other taxa (Miyatake et al., 2004).

As mentioned in the introduction, TI is sometimes positively correlated with chemical defenses and has been hypothesized to act as a warning display (Miyatake et al., 2009, 2004; Ruxton, 2006). Such a correlation is not apparent in Murgantia histrionica based on our results: the frequency of TI diminishes from first to second and third instar, but glucosinolate levels remain the same across these three life stages. With that said, given that adults have much higher concentrations compared to what we observed in early nymphs (Aliabadi et al, 2002) and that they do not seem to use TI as an antipredation strategy (Guerra-Grenier, personal observation), there is probably a negative correlation between chemical defense and tonic immobility across all life stages, from hatchlings to adults. In this case, TI would not serve as a warning signal but rather simply as an alternative defense strategy, potentially deterring motion-oriented predators. More data on TI and glucosinolate content in fourth and fifth instar as well as in adults need to be collected in order to test for the existence of such a re lationship. 
In addition to the description of their chemical defense, we have demonstrated that $M$. histrionica eggs are most likely highly conspicuous to predators, whether they are UVsensitive or not. Indeed, the white markings of the eggs reflect ultraviolet light, meaning that they appear white (i.e. they reflect all the wavelengths that a given visual system is sensitive to) to any potential predator, regardless of whether they are sensitive to wavelengths between $300-400 \mathrm{~nm}$. Such a color pattern thus contrasts strongly against a leaf background, which usually absorbs UV-light (Gutschick, 1999). In a general sense, it is safe to assume that eggs are aposematic in that they are both conspicuous to would-be predators, and unprofitable; as such, the black and UV-white pattern probably advertises glucosinolate-related unpalatability or toxicity. However, further experiments measuring prey (eggs, but also nymphs) acceptance by ecologically relevant predators over repeated exposures are necessary to confirm that predators indeed learn to avoid consumption of the bugs based on recognition of their color pattern. Such tests should also compare predation levels by chewing vs. piercing-sucking predators to test for the relative importance of the shell (which composes most of the chemical defense) in the learning process. Confirmation of efficacy is also required for the TI strategy: although the posture adopted by Harlequin bug nymphs when disturbed fits with the defining characteristics of TI (Humphreys and Ruxton, 2018), it is still unknown whether it reduces predation success in this species.

Complex color patterns often play a role in multiple defensive and/or communication strategies (Caro et al., 2017, 2016; Marshall, 2000; Tullberg et al., 2005). Specifically for striped black and white patterns, known functions vary from crypsis (e.g. disruptive 
camouflage, countershading, etc.) to warning signals and can interfere with a predator's ability to attack a prey through a dazzling effect (Feltwell, 2016; Izzo et al., 2014; Stevens et al., 2008). Aside from aposematism, the complex M. histrionica egg color pattern may thus have alternative adaptive functions, and future studies should look into those in this species as well as in taxa with similar egg coloration such as Eurydema spp. and Stenozygum spp. (plesiomorphy: Kalender 1999; Samra et al. 2015), but also in Piezodorus spp (convergent evolution: Bundy and McPherson 2000). For example, the stripes and dot may convey an intraspecific signal influencing the ovipositional behaviors of conspecific females. Such a signal could attract other females and encourage the aggregation of offspring, which can in turn allow for cooperative defense through a dilution effect and cooperative feeding reducing the effects of plant defenses per capita. If intraspecific competition is a big issue, the egg color could on the other hand have a deterrent effect and warn conspecific females that laying their eggs in the same area would reduce their fitness. Shapiro (1981a) found evidence of a deterrent signal in the reddish egg color of three pierid butterflies. Another possible function of the color pattern is disruptive camouflage through distance-dependent crypsis. Several organisms, from insects to mammals, are known to have color patterns that make them conspicuous at short range, but cryptic at long range (Barnett and Cuthill, 2014; Caro et al., 2013; Tullberg et al., 2005). It is probable that the stripes and spot of the $M$. histrionica eggs act as a warning signal in close proximity, but from further away they could disrupt the classic egg shape predators seek while foraging. Such a disruptive trait has been described (but not tested) in the eggs of two species of lappet moths, Gastropacha quercifolia (L. 1758) and Epicnaptera Americana (Harr. 1841) (Hinton, 1981). It should 
be mentioned here that parasitoid wasps would unlikely be affected by such a defensive device given their olfactory-based foraging strategy. This would add to our previous explanation as to why known natural enemies of $M$. histrionica eggs are to our knowledge exclusively parasitoids. Finally, the egg color pattern might help in interacting with abiotic factors. For one thing, eggs vary in their proportion of black pigment. This could be an adaptation to help with heat absorption in colder periods. Such a thermoregulatory function has actually been shown in the mobile life stages of the species, where late nymphal instars exposed to colder temperatures will metamorphose into adults with a higher degree of melanisation than those exposed to warmer temperatures (White and Olson, 2014). The fact that the black markings absorb UV radiation while the white markings reflect it suggests that the embryos are probably protected against ionizing radiation. Podisus maculiventris (Say 1832), another stink bug, is known to have evolved selective egg pigmentation as a way to cope with UV radiation (Abram et al., 2015b) and predation (Torres-Campos et al., 2016), a trait that is recycled by its egg parasitoids (Gaudreau et al, 2017). Farnesi et al. (2017) have also shown that higher levels of melanisation in mosquito eggs are inversely correlated to egg desiccation; such a function could also be served by the pigment in the Harlequin bug eggs. 


\title{
CHAP TER 3: UNDERSTANDING THE ROLE OF FREQUENCY-DEPENDENT PREDATION ON THE EVOLUTION OF SELECTIVE EGG PIGMENTATION
}

\begin{abstract}
Color polymorphisms are ubiquitous in nature despite the fact that, at its simplest, theory predicts "winner takes all" scenarios in which the morph with the highest payoff should outcompete the others over evolutionary time. One way around this problem is negative frequency-dependent selection of color phenotypes, in which a certain morph loses its advantage as it increases in frequency within a population, allowing for the selection of competing phenotypes in the current or subsequent generation. One recognized key frequency-dependent selective pressure is predation. The stink bug Podisus maculiventris is known to lay polymorphic eggs that vary in their degree of photoprotective pigmentation: pale eggs are laid on UV-free leaf bottoms while dark eggs are exposed to UV radiation of leaf tops. Previous work has shown that leaf sides also vary in predation intensity, allowing for eggs on the bottom to be more frequently attacked than on the top. Yet, females lay approximately half of their eggs on the top and half on the underside. Here we sought to investigate whether this approximate 50:50 egg morph ratio could be selected by frequency-dependent predation. We developed a replicator dynamics model and looked at how morph frequencies varied over evolutionary time based on their payoff values and likelihood of being attacked. Our results support the contention that females indeed began to exploit UV-irradiated sites because of frequency-dependent predation intensity, biased on leaf undersides. We also suggest that pigmented eggs are seldom found on leaf bottoms, regardless of the cost of applying pigment in UV-free
\end{abstract}


environments, most likely because laying pigmentless eggs on leaf bottoms is the ancestrally dominant strategy.

Key words: Evolutionary game theory, Frequency-dependent selection, Replicator equation, Polymorphism, Egg coloration, Podisus maculiventris

\section{Introduction}

Natural enemies such as predators are known to generate selective pressures affecting prey morphology. Such pressures act strongly on prey coloration and can lead to the evolution of visual antipredation strategies such as camouflage or warning coloration associated with secondary defenses (e.g. toxins, spikes, evasiveness, etc.) (Ruxton et al., 2004). When body coloration is also linked to other adaptive functions such as mating displays or photoprotection, trade-offs between the efficacy of those functions and conspicuousness to predators can lead to color polymorphisms (Allen, 1988, 1989; Nokelainen et al., 2011). The proportions of various morphs within a population are predicted to vary over time because of frequency-dependent selection (Le Rouzic et al., 2015). For example, Olendorf et al. (2006) have suggested that male Trinidadian guppies (Poecilia reticulata Peters, 1859) (Cyprinodontiformes: Poeciliidae) are highly polymorphic in their sexually-selected ornaments because of negative frequencydependent selection by predators, where a rare morph is less targeted and thus has a high reproductive success, leading to that morph's increase in frequency in the following generation. 
The mechanism behind frequency-dependent selection by predators has been theorized to be the low probability of dietary switch among prey types. Indeed, predators are known to sometimes prefer prey types over alternative food sources, depending on their relative frequencies in the environment (Sherratt and Harvey, 1993). By establishing a functional response derived from a Markov process (see also Oaten and Murdoch, 1975; van Leeuwen et al., 2007), van Leeuwen et al. (2013) demonstrated that predators foraging on a given prey type will tend to keep foraging on the same prey over time. This dietary preference is frequency-dependent in the sense that if the preferred prey is frequently encountered in the environment, the probability of a predator switching to an alternative prey is very low. However, if the frequency of that prey item is lowered, predators will tend to switch to a second prey type now more frequently encountered. Interestingly, this model explains fairly well the results obtained by Olendorfet al. (2006).

Another potentially good system to study the effects of frequency-dependent predation on color polymorphism is the selective egg pigmentation by the Spined soldier bug Podisus maculiventris (Say, 1832) (Heteroptera: Pentatomidae). In this species of stink bugs, females can lay eggs of various levels of pigmentation, ranging from pale yellow/white and pigmentless to dark brown/black and heavily pigmented (Abram et al., 2015b). However, when ovipositing on a plant, such as soybean, females usually lay either dark clutches on leaf tops or pale clutches on leaf undersides. Experimental data showed that the eggs are sensitive to ultraviolet (UV) radiation and that exposure to such radiation can cause mortality, but also that heavily pigmented eggs have a much better chance of surviving until hatching than less pigmented eggs (Abram et al, 2015b). In other words, 
the pigment in question acts like sunscreen for eggs laid on leaf tops (i.e. exposed to direct sunlight) and absorbs the harmful wavelengths before they can penetrate the shell and cause damage to the developing embryos. If the eggs are laid under the leaves, they do not require the pigment as the leaves themselves act as parasols and absorb UV rays (Gutschick, 1999). Furthermore, the fitness gained by applying pigment to the eggs not only applies to the stink bugs, but also to parasitoid wasps attacking them (Gaudreau et al., 2017). Following the study by Abram et al. (2015b), Torres-Campos and collaborators (2016) provided evidence that one of the factors driving the evolution of selective egg pigmentation is a higher predation pressure on leaf underside, leading to the exploitation of leaf tops as enemy-free spaces (Jeffries and Lawton, 1984), regardless of UV radiation. Interestingly, parasitism pressure by parasitoid wasps did not differ between leaf sides. The authors also suggested that females keep laying eggs on leaf bottoms because pigment production is probably costly and might affect female survival and fitness if used in excess.

Although the hypotheses put forward by Torres-Campos et al. (2016) to explain the evolution of selective egg coloration in P. maculiventris are valid, they cannot fully explain the maintenance of the dual oviposition strategies: pigmented eggs on top (PT) and non-pigmented eggs on the bottom (NB). Indeed, the data from one of the experiments carried out on soybean plants by Abram et al. (2015b) show that both strategies are employed by females at relatively equal frequencies (i.e. $50 \%$ of the eggs were dark on leaf tops and the other $50 \%$ were pale on leaf undersides). Yet, theory predicts that one strategy should have outcompeted the other over evolutionary time if 1- 
they have different fixed (i.e. frequency-independent) payoffs (Maynard-Smith, 1982) or 2- if the two strategies have equal payo ffs but one initially dominated within a population before the evolution of the other (i.e. if the former is an evolutionary stable strategy; Maynard-Smith, 1972). To have two oviposition strategies at an equilibrium state within a population, a key mechanism maintaining egg color polymorphism in this system must have been overlooked. We here propose that the mechanism in question is frequencydependent selection by predators foraging in a heterogeneous (upperside/lowerside) environment (see for example Murdoch et al., 1975).

The aim of this paper was to investigate whether frequency-dependent predation can explain the maintenance of egg color polymorphism in Podisus maculiventris. To do so, we built a replicator dynamics model (i.e. a mathematical model in which the fitness of the strategies is frequency-dependent and all strategies are present (however rare ) so that possible mutations can be ignored; Nowak and Sigmund, 2004). The form of frequencydependent predation was based on the Markov models proposed by van Leeuwen et al. (2013), adapted to the Podisus system and parametized with experimental data (Abram et al., 2015b; Torres-Campos et al., 2016). We considered leaf sides to be instrumental in distinguishing prey types targeted by predators. Our model thus takes into account frequency-dependent preferences for leaf sides, predation intensity and the payo ff values (= resistance to UV radiation - hypothetical cost of pigment) of each of the strategies. Instead of restricting our investigation to the two main strategies observed in nature (PT and NB), we also considered the two other possibilities that can result from the $2 \times 2$ interaction between leaf sides and pigmentation levels: pigmented eggs on the bottom 
(PB) and non-pigmented eggs on top (NT). This allowed us to test if PB and NT ever had the potential to evolve as well as to tease apart the effects of pigment production costs from the benefits of UV protection. It should be noted that, although egg pigmentation is a continuum, we chose to examine it as a discrete binomial trait (pigmented vs. nonpigmented) as it appears mostly dimorphic in the field.

\section{Methods}

All simulations and analyses were carried out using R 3.3.3 (R Core Team, 2017).

\section{Establishing frequency-dependent predation}

Frequency-dependent predation in the Podisus system depends on the probability of a predator attacking a prey type (i.e. eggs on leaf tops or on leaf bottoms) based on its availability in a prey population. This can be modelled following equations (1) and (2),

$$
\begin{gathered}
R T=\frac{\left(X_{p t}+X_{n t}\right)}{\left(X_{p b}+X_{n b}\right)} \\
F R T=R T \frac{\left(S_{t t} R T+S_{t b}\right)}{\left(S_{t b} R T+S_{b b}\right)}
\end{gathered}
$$

where $\mathrm{X}_{\mathrm{i}}$ is the frequency at which a strategy $i$ is encountered, RT is the ratio of eggs laid on leaf tops, FRT is the ratio of eggs attacked by predators on leaf tops, and $\mathrm{S}_{\mathrm{tt}}, \mathrm{S}_{\mathrm{bb}}$ and $\mathrm{S}_{\mathrm{tb}}$ are the parameters modifying the likelihood of the predator switching from one prey type to another between each attack ( $t$ f for top to top transition, $b b$ for bottom to bottom transition and $t b$ for top to bottom transition). For our model, we chose a set of parameter values such that $\mathrm{S}_{\mathrm{tt}}=1, \mathrm{~S}_{\mathrm{bb}}=2.5$ and $\mathrm{S}_{\mathrm{tb}}=0.05$; these values were chosen in order to obtain prey type fidelity but rare prey switching between top and bottom (see Figure 2 of 
van Leeuwen et al., 2013). Having a value of $S_{b b}$ higher than $S_{t t}\left(\right.$ i.e. $S_{b b}>1$ ) allows for the creation of a bias in favor of foraging on leaf undersides, which is more representative of the relative predation levels observed in nature on leaf tops and leaf undersides (Figure 11). To achieve frequency-independent predation, the value of $S_{t b}$ and $S_{b b}$ have to be changed to 1 so that predators become as likely to change leaf side as they are to keep foraging on the initial prey type.

Establishing the four egg-laying strategies and their payoff values

Even when excluding predation-related costs, the four egg-laying strategies (NB; PT; NT; PB, with probabilities of using each of these strategies summing to 1) lead to different outcomes in terms of mortality and potentially physiological costs to the mothers. This is a simple consequence of the fact that they have different adaptive values. In order to reflect this in the model, payoff values $\left(\mathrm{V}_{\mathrm{i}}\right)$ were attributed to the various strategies. NB has a payoff value of $1\left(\mathrm{~V}_{\mathrm{nb}}=1.00\right.$, i.e. in the absence of predation, the payoff is high) because pigmentless eggs on leaf bottoms do not suffer from ultraviolet radiation and are not costly to the mothers. We attributed a payoff value of 0.8 to $\mathrm{PT}$ eggs $\left(\mathrm{V}_{\mathrm{pt}}=0.80\right)$ since roughly $80 \%$ of the darker eggs survived at high UV intensities in the laboratory experiment done by Abram et al. (2015b). NT has a payoff value of $0.05\left(\mathrm{~V}_{\mathrm{nt}}=0.05\right)$ because survival following exposure to UV radiation without protection is very low, again according to the results of Abram et al. (2015b). We attributed a payoff value of 0.98 to $\mathrm{PB}$ eggs $\left(\mathrm{V}_{\mathrm{pb}}=0.98\right)$ because just like NB eggs, this strategy leaves the embryos fully protected against solar radiation. The difference in payoff values causing $\mathrm{V}_{\mathrm{nb}}>\mathrm{V}_{\mathrm{pb}}$ 


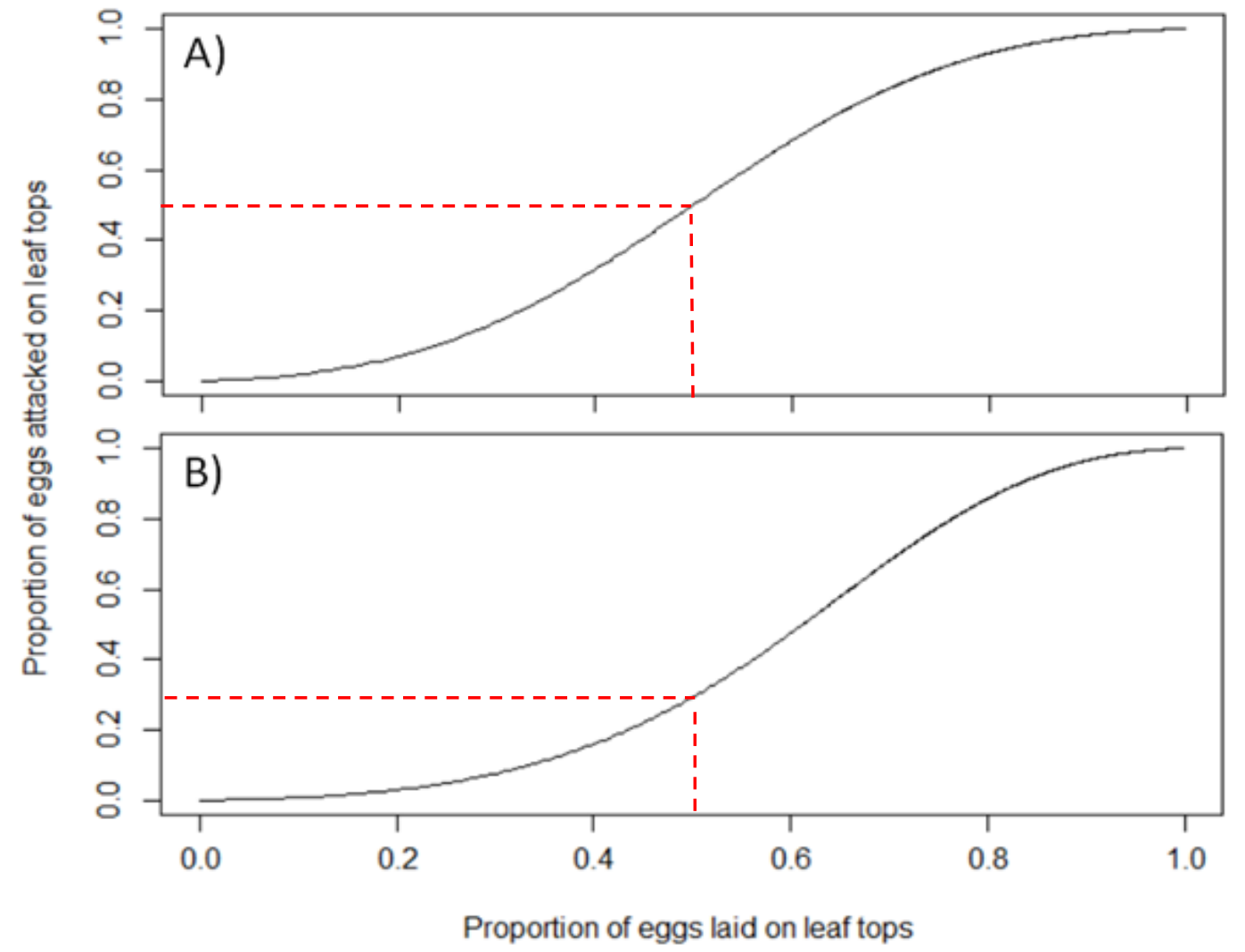

Figure 11. A simulation of frequency-dependent predation on Podisus maculiventris eggs, where predators can either forage on leaf tops (LT) or on leaf bottoms (LB). Proportions of eggs laid or attacked on LB are equal to 1- proportion of eggs laid or attacked on LT respectively. A) FDS using the parameter values in Figure 2 of van Leeuwen et al. (2013): predators are equally likely to keep foraging on leaf tops $\left(S_{t t}=1\right)$ or on leaf bottoms $\left(\mathrm{S}_{\mathrm{bb}}=1\right)$. B) FDS using parameter values optimized using experimental data (Abram et al., 2015b): predators have a preference for leaf bottoms and are more likely to stay under a leaf $\left(S_{b b}=2.5\right)$ than to stay on a leaf top $\left(S_{t t}=1\right)$. For both panels, $\mathrm{S}_{\mathrm{tb}}=0.05$. Dashed lines highlight the proportion of eggs attacked on leaf tops when eggs are laid at a 50:50 top to bottom ratio. 
reflects a hypothetical cost of pigmentation suffered by the mothers, giving a slight advantage to the NB strategy in terms of fitness. We chose a value of 0.98 so that the cost of pigmentation would be minimal as its relevance in nature is still uncertain.

\section{Establishing the replicator model}

Once frequency-dependent predation has been established and the payoff values of the egg-laying strategies are known, it is possible to calculate the fitness of the four strategies following equations (3) to (6),

$$
\begin{gathered}
F_{p t}=V_{p t}-Q\left(\frac{F R T}{1+F R T}\right) \\
F_{n t}=V_{n t}-Q\left(\frac{F R T}{1+F R T}\right) \\
F_{p b}=V_{p b}-Q\left(1-\left(\frac{F R T}{1+F R T}\right)\right) \\
F_{n b}=V_{n b}-Q\left(1-\left(\frac{F R T}{1+F R T}\right)\right)
\end{gathered}
$$

where $\mathrm{F}_{\mathrm{i}}$ is the fitness of a strategy $i$. The parameter Q represents the intensity of the predation pressure in the system. The higher its value, the more likely eggs are to be attacked. If $Q=0$, predators are removed altogether, leaving $F_{i}=V_{i}$.

Fitness values are then integrated into the actual replicator dynamics model in order to establish the selection dynamics, which will predict the fluctuations in relative frequencies of the egg-laying strategies over evolutionary time. Selection dynamics can be calculated using a replicator equation (7), 


$$
\frac{d X_{i}}{d t}=X_{i}\left(F_{i}-\Phi\right)
$$

where $t$ represents evolutionary time and $\Phi=\sum_{i=1}^{n} X_{i} F_{i}$ is the mean fitness of all strategies. $\frac{d X_{i}}{d t}$ thus gives the frequency values of the following time step. We chose the following values as starting frequencies (at $t=0)$ : $\mathrm{X}_{\mathrm{nb}}=0.97 ; \mathrm{X}_{\mathrm{pb}}=\mathrm{X}_{\mathrm{nt}}=\mathrm{X}_{\mathrm{pt}}=0.01$. An initial dominant state was attributed to the NB strategy because it is assumed to be the ancestral phenotype. A non-zero frequency was however needed for the other three strategies so that they would be considered by the model.

Effects of predation intensity, leaf side bias and payoff values on strategy frequencies Although we chose a set of parameter values to best reflect the selective pressures encountered in nature, it is relevant to test for the effect that a range of values would have on the evolution and maintenance of the various egg-laying strategies. Specifically, three factors were explored: predation intensity $(\mathrm{Q})$, predator preference for leaf undersides $\left(\mathrm{S}_{\mathrm{bb}}\right)$ and the payoff values $\left(\mathrm{V}_{\mathrm{i}}\right)$. To do so, we generated contour plots using the Plotly package in $\mathrm{R}$ (https://CRAN.R-project.org/package=plotly). These allowed us to elucidate the relative importance of the leaf side bias compared to overall predation intensity, and to determine whether paying a cost of pigmentation is the reason why pigmented eggs are not observed under leaves in nature. 


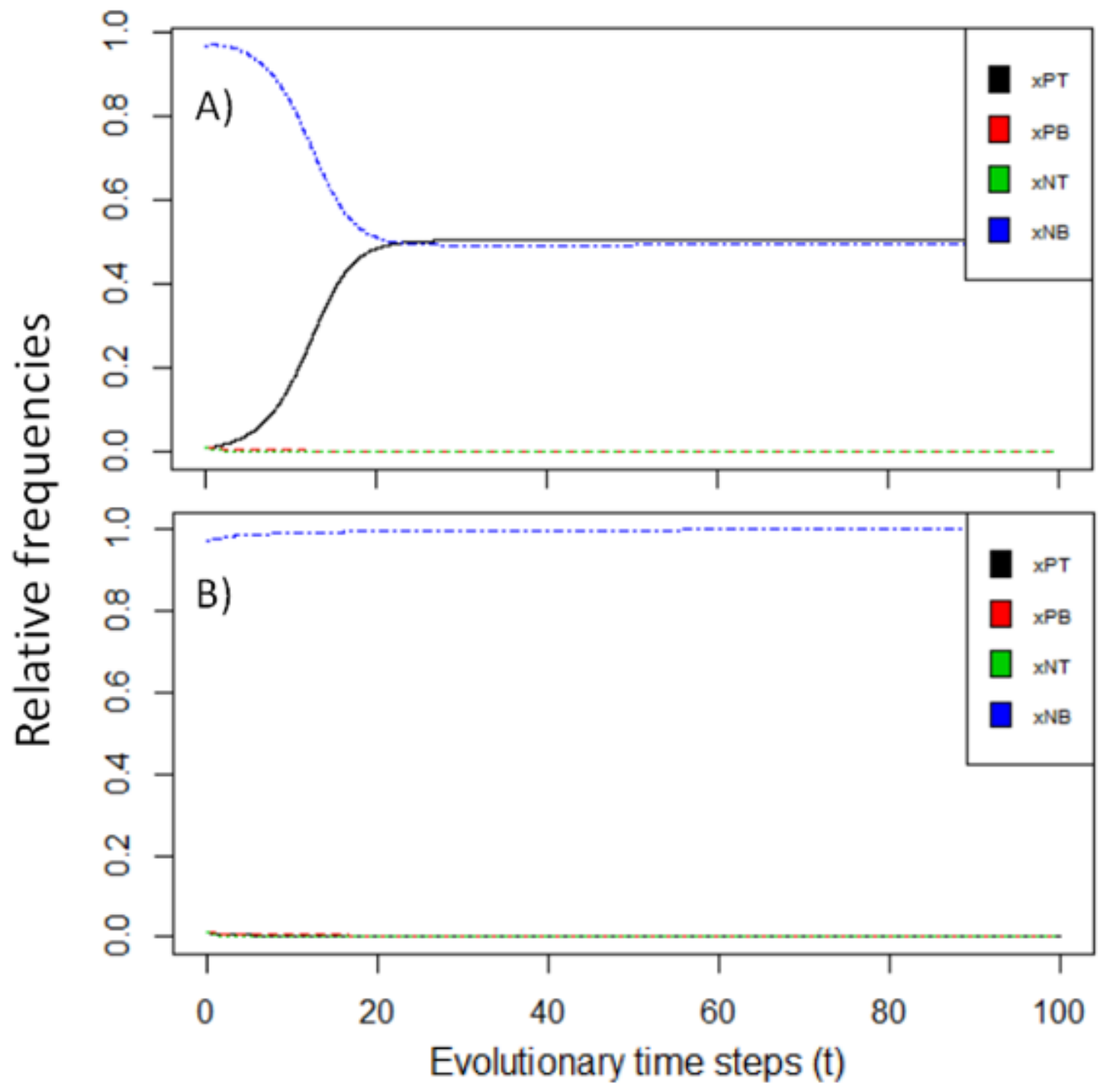

Figure 12. Graphical representation of the variation in frequencies of PT, PB, NT and NB over evolutionary time in a context of frequency-dependent predation $\left(S_{t t}=1, S_{b b}=\right.$ 2.5, $\left.\mathrm{S}_{\mathrm{tb}}=0.05\right)$. A) Predation pressure is relatively high $(\mathrm{Q}=0.5)$, leading to an equilibrium between PT and NB at approximately a 50:50 ratio. B) Predation pressure is low $(\mathrm{Q}=0.05)$, leading to a rapid extinction of $\mathrm{PT}, \mathrm{PB}$ and $\mathrm{NB}$ and a domination of the ancestral NB strategy. 


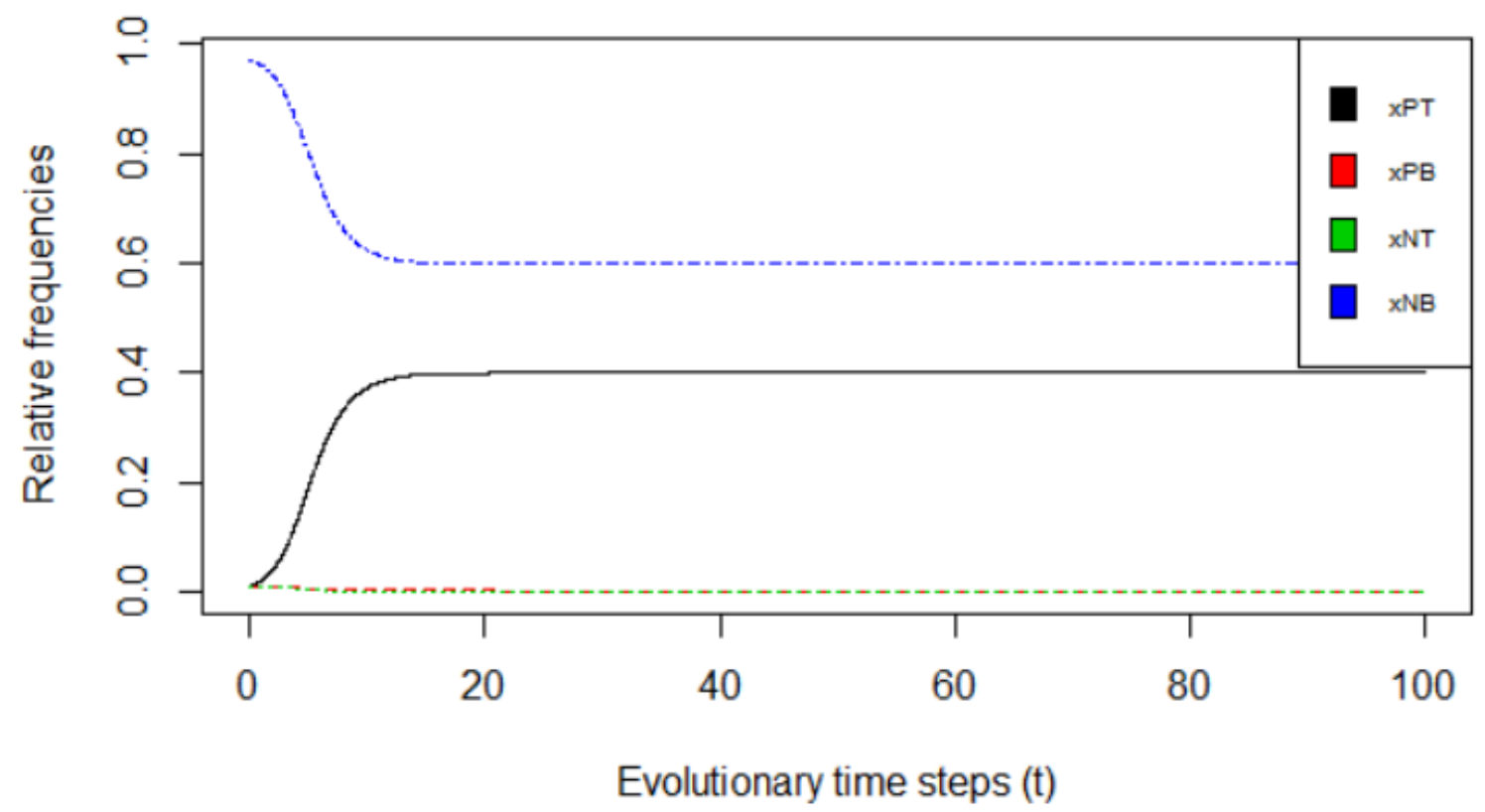

Figure 13. Graphical representation of the variation in frequencies of PT, PB, NT and NB over evolutionary time in a context of frequency-independent predation $\left(\mathrm{S}_{\mathrm{tt}}=\mathrm{S}_{\mathrm{bb}}=\right.$ $\left.\mathrm{S}_{\mathrm{tb}}=1\right)$. Even under very high predation pressure $(\mathrm{Q}=0.99), \mathrm{PT}$ and NB never reach a 50:50 ratio. 


\section{Results}

Our model suggests that, if predators actively foraging for food are present in the system, both PT and NB strategies should evolve and be maintained at relatively equal frequencies over evolutionary time, while PB and NT never truly increase above 0 (Figure 12A). However, under the payoffs assumed, if frequency-dependent predation pressure is excluded from the model and only payoff values are considered, then egg pigmentation never evolves in the first place; NB (the presumed ancestral type) dominates at close to $100 \%$ (Figure 12B). If predation pressure is maintained but rendered frequency-independent, PT and NB can never reach equal frequencies, even at very high predation intensity $(\mathrm{Q}=0.99)($ Figure 13$)$.

Two predation-related factors affected the equilibrium of the four strategies: the intensity of predation pressure $(\mathrm{Q})$ and the foraging preference for leaf undersides $\left(\mathrm{S}_{\mathrm{bb}}\right)$. As the value of Q increases, the proportion of pigmented eggs laid on leaf tops increases as well (Figure 14A). The opposite trend was observed in non-pigmented eggs on the bottom, with their proportion decreasing as the value of Q increased (Figure 14B). Higher values of $\mathrm{S}_{\mathrm{bb}}$ also lead to an increase in the proportion of PT and a decrease of $\mathrm{NB}$, but only when predation pressures were high enough, with $Q \geq 0.3$. Frequency-dependent predation did not affect the proportion of PB and NT eggs (Figure 14C-D).

The lack of dominance of the NT strategy makes sense given its very low payoff value of 0.05. Yet, pigmented eggs on the bottom have a relatively high payoff value of 0.98 

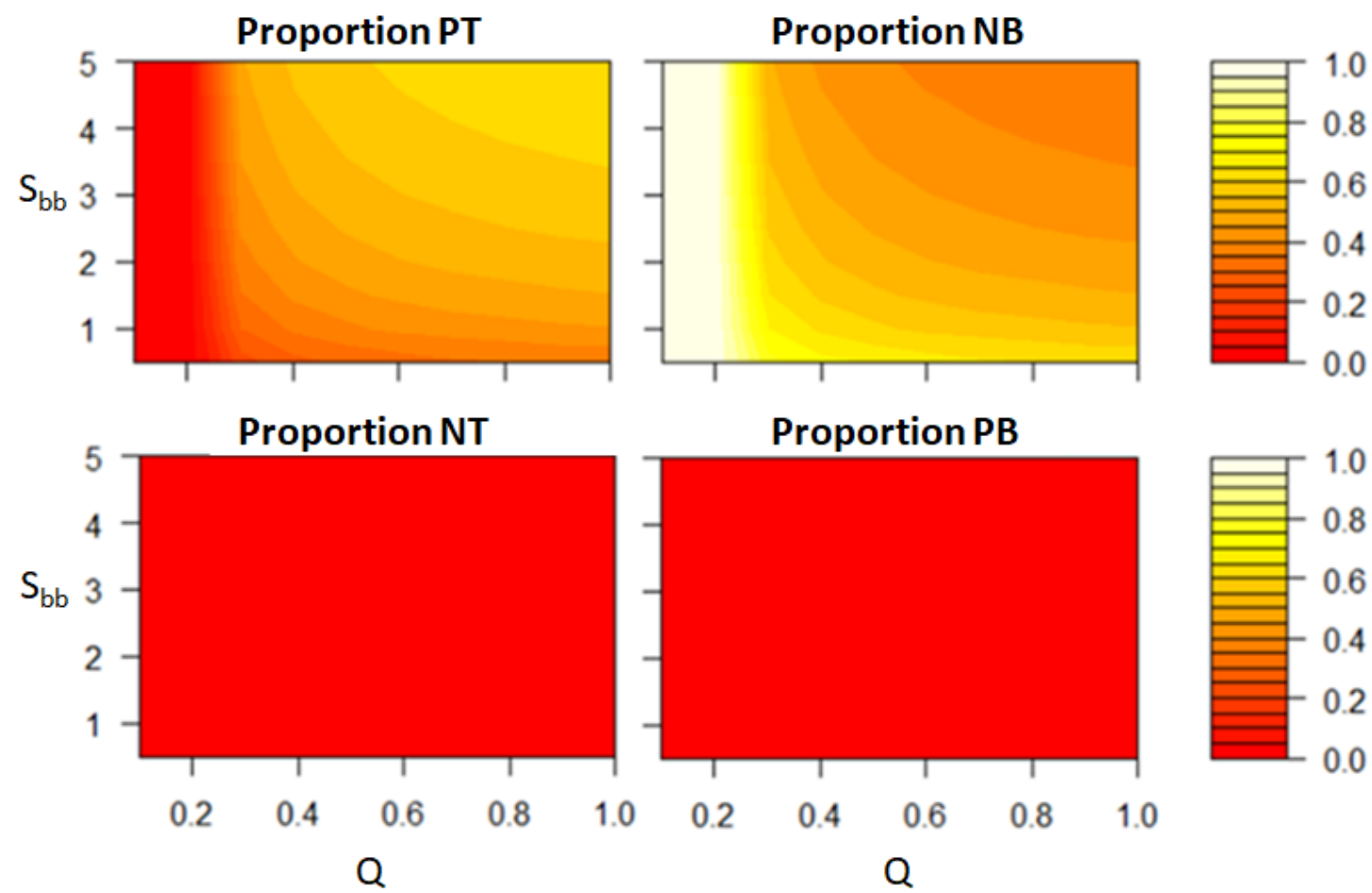

Figure 14. Contour plots showing the effect of the interactions between leaf bottom bias $\left(\mathrm{S}_{\mathrm{bb}}\right)$ and predation intensity $(\mathrm{Q})$ on the proportions of PT (upper left), NB (upper right), NT (lower left) and PB (lower right) eggs within a population. For both panels, $\mathrm{V}_{\mathrm{pt}}=$ $0.80 ; \mathrm{V}_{\mathrm{pb}}=0.98 ; \mathrm{V}_{\mathrm{nb}}=1.00 ; \mathrm{V}_{\mathrm{nt}}=0.05 ; \mathrm{S}_{\mathrm{tt}}=1 ; \mathrm{S}_{\mathrm{tb}}=0.05$. As the value of $\mathrm{Q}$ increases, the proportion of NB eggs decreases. The NB eggs lost are effectively replaced by PT eggs. An increase in the value of $\mathrm{S}_{\mathrm{bb}}$ has a similar effect and leads to an increase in the proportion of $\mathrm{PT}$ and a decrease in the proportion of $\mathrm{NB}$, but only when the value of $\mathrm{Q}$ is high enough. The proportions of PB and NT eggs never significantly increase above zero. 

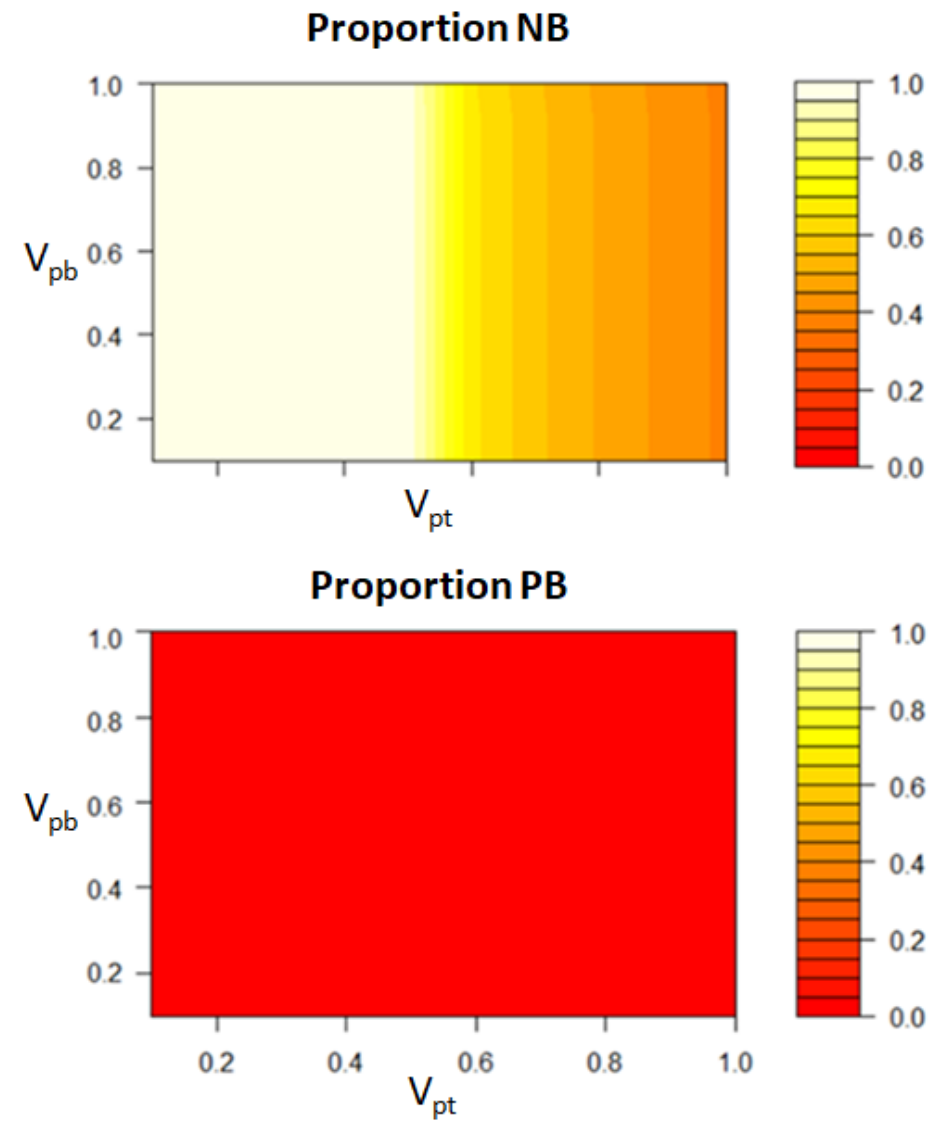

Figure 15. Contour plots showing the effect of the interactions between payoff values of pigmented eggs on leaf bottoms $\left(\mathrm{V}_{\mathrm{pb}}\right)$ and on leaf tops $\left(\mathrm{V}_{\mathrm{pt}}\right)$ on the proportions of NB (upper panel), and PB (lower panel) eggs within a population. For both panels, $\mathrm{V}_{\mathrm{nb}}=$ $1.00 ; \mathrm{V}_{\mathrm{nt}}=0.05 ; \mathrm{S}_{\mathrm{tt}}=1 ; \mathrm{S}_{\mathrm{bb}}=2.5 ; \mathrm{S}_{\mathrm{tb}}=0.05 ; \mathrm{Q}=0.5$. The proportion of NB eggs is unaffected by the value of $\mathrm{V}_{\mathrm{pb}}$ and remaining at 1.0 in any case. NB eggs do decrease in proportion when $\mathrm{V}_{\mathrm{pt}}$ is high enough $\left(\mathrm{V}_{\mathrm{pt}}>0.5\right)$, but they are never replaced by PB eggs. 
compared to PT eggs $\left(\mathrm{V}_{\mathrm{pt}}=0.80\right)$, so why does the PB strategy never appear to be adopted by females (see Discussion for more information)? Even if its payoff is increased to equal that of non-pigmented eggs on the bottom $\left(\mathrm{V}_{\mathrm{pb}}=\mathrm{V}_{\mathrm{nb}}=1.00\right)$, the NB strategy remains dominant (Figure 15). The only strategy that can invade the NB strategy is once again $\mathrm{PT}$, but only when $\mathrm{V}_{\mathrm{pt}} \geq 0.5$.

\section{Discussion}

The aim of this study was to determine whether frequency-dependent selection by predators is sufficient to explain the evolution of selective egg pigmentation in Podisus maculiventris, using a replicator dynamics model. Our results show that approximately equal proportions of pigmented eggs on leaf tops and non-pigmented eggs on leaf undersides can only be achieved when predation intensity is high enough, and if predators forage for prey in a frequency-dependent manner. If selection by predators is frequencyindependent, even the highest possible predation intensity cannot select for a 50:50 NB to PT eggs ratio. Corroborating previous experimental results (Abram et al, 2015b), our model shows that NB and PT are the only two viable egg-laying strategies. NT eggs never evolve because PT has a higher payoff on leaf tops, just like PB eggs never evolve because NB has a higher payo ff on leaf undersides and is ancestrally dominant.

Both a high bias for foraging on leaf undersides and high predation intensity allowed for a reduction of the NB strategy and increased the frequency of PT eggs in the population. Interestingly, the effect of leaf side bias was only noticeable when predation pressures were high enough. This can be explained by the fact that if predators are rare in the field, 
attacks will also be rare, meaning that the threat of predators preferentially foraging on leaf undersides will not be enough to select for a shift in oviposition substrate. It is only when predators decimate enough eggs within the population that their foraging preferences are strong enough to select for egg color polymorphism. This explains why females P. maculiventris do not always lay eggs on leaf undersides.

Another key conclusion that can be drawn from our model is that the cost of pigment production, likely to exist as with similar pigments like melanin (Roff and Fairbairn, 2013), is not sufficient to explain why dark eggs are never encountered on leaf undersides. It is indeed sensible to state that $P$. maculiventris eggs always have an optimal amount of photoprotective pigment regardless of where they are laid. However, even when assuming cost-free pigment production, PB eggs never invaded the NB strategy. This was because of their starting frequencies reflecting the ancestral state of the NB strategy (as argued by Torres-Campos et al. (2016)); eggs are likely to have been ancestrally pigmentless and laid under the leaves before the evolution of selective egg pigmentation. In other words, there is no value in replacing an already effective strategy by a new one, even at equal payoffs. PB eggs could arguably invade small populations by drift even when selectively neutral, but evidence of their existence in natural populations is still lacking. The NB strategy is thus in our opinion a mixed evolutionary stable strategy, at least for eggs laid on leaf bottoms (Maynard-Smith, 1972). This explains why egg pigmentation is selective in $P$. maculiventris. 
Overall, our model provides strong theoretical evidence that FDS by predators is the reason why two egg-laying strategies coexist at approximately equal frequencies in Podisus maculiventris and why one has never outcompeted the other over evolutionary time. More broadly however, our study provides an additional example of color polymorphism selected by frequency-dependent predation. Although applied here only in a species-specific context, we believe that our model can be extended to other systems with polymorphic egg coloration. Just among the Asopinae (e.g. other Podisus spp., Stiretrus spp., Zicrona spp.), pale-dark egg polymorphism can be observed (Abram \& Guerra-Grenier, personal observations). Whether the pigment coating the eggs of those species also protects against UV radiation remains untested, but is very likely given their common evolutionary history (Grazia et al., 2015). Our model could also potentially help explain the evolution of egg jelly color polymorphism in the spotted salamander Ambystoma maculatum (Shaw, 1802) (Caudata: Ambystomatidae) (Ruth et al., 1993), a species in which egg morphs vary in their ability to withstand low oxygen (Hale et al, 2017) and nutrient concentrations (Pintar and Resetarits, 2017) as well as predator attacks (Petranka et al., 1998).

Although this paper looked at the three likely derived egg-laying strategies (PT, NT and PB) as evolving simultaneously, this may not have been the case in nature. Indeed, Torres-Campos et al. (2016) suggested that selective egg pigmentation evolved after the selective oviposition site choice, implying that NT disappeared at some point in favor of PT and PB, only to eventually reappear and replace PB. In such a scenario, the cost of pigmentation may have been the key selective pressure in the evolution of color 
polymorphism. Future work should thus look into this possibility and treat the evolution of the various egg-laying strategies as sequential rather than simultaneous through mutator-replicator models. Furthermore, whilst this study provides theoretical support to the frequency-dependent selection of egg color polymorphism hypothesis, future work should also aim at confirming from an empirical stand point that relevant egg predators such as ants, lacewings, ladybugs and other true bugs (Abram et al., 2015a; Hinton, 1981) do forage in a frequency-dependent manner on $P$. maculiventris eggs. This could be done by exposing predators to various relative frequencies of NB and PT eggs and comparing the proportion of eggs of each phenotype attacked with the functional response established in Figure 11B. 


\section{REFERENCES}

Abram, P.K., Doyon, J., Brodeur, J., Gariepy, T.D., Boivin, G., 2015a. Susceptibility of Halyomorpha halys (Hemiptera: Pentatomidae) eggs to different life stages of three generalist predators. Can. Entomol. 147, 222-226.

Abram, P.K., Guerra-Grenier, E., Després-Einspenner, M.-L., Ito, S., Wakamatsu, K., Boivin, G., Brodeur, J., 2015b. An insect with selective control of egg coloration. Curr. Biol. 25, 2007-2011. https://doi.org/10.1016/j.cub.2015.06.010

Aldrich, J.R., Avery, J.W., Lee, C.-J., Graf, J.C., Harrison, D.J., Bin, F., 1996. Semiochemistry of cabbage bugs (Heteroptera: Pentatomidae: Eurydema and Murgantia). J. Entomol. Sci. 31, 172-182. https://doi.org/10.18474/0749-800431.2.172

Aliabadi, A., Renwick, J.A.A., Whitman, D.W., 2002. Sequestration of glucosinolates by harlequin bug Murgantia histrionica. J. Chem. Ecol. 28, 1749-1762.

Allen, J.A., 1989. Colour polymorphism, predation and frequency-dependent selection. Genet. Life Sci. Adv. 8, 27-43.

Allen, J.A., 1988. Frequency-dependent selection by predators. Phil Trans R Soc Lond B $319,485-503$.

Altig, R., McDiarmid, R.W., 2007. Morphological diversity and evolution of egg and clutch structure in amphibians. Herpetol. Monogr. 21, 1-32.

Amarasekare, P., 2000. Coexistence of competing parasitoids on a patchily distributed host: local vs. spatial mechanisms. Ecology 81, 1286-1296. https://doi.org/10.1890/0012-9658(2000)081[1286:COCPOA]2.0.CO;2 
Bakken, G.S., Vanderbilt, V.C., Buttemer, W.A., Dawson, W.R., 1978. Avian eggs: thermoregulatory value of very high near-infrared reflectance. Science $200,321-$ 323.

Barnett, J.B., Cuthill, I.C., 2014. Distance-dependent defensive coloration. Curr. Biol. 24, R1157-R1158.

Bates, D., Mächler, M., Bolker, B., Walker, S., 2014. Fitting Linear Mixed-Effects Models using lme4. ArXiv14065823 Stat.

Beattie, A.J., 1985. The evolutionary ecology of ant-plant mutualisms. Cambridge University Press.

Bennett, A.T.D., Cuthill, I.C., Norris, K.J., 1994. Sexual selection and the mismeasure of color. Am. Nat. 144, 848-860.

Bernhardt, J.L., 2009. Color changes and development of eggs of rice stink bug (Hemiptera: Pentatomidae) in response to temperature. Ann. Entomol. Soc. Am. $102,638-641$.

Birchard, G.F., 1991. Water vapor and oxygen exchange of praying mantis (Tenodera aridifolia sinen sis) egg cases. Physiol. Zool. 64, 960-972.

Blum, M.S., Hilker, M., 2002. Chemical protection of insect eggs. Chemoecology Insect Eggs Egg Depos. 61-90.

Bond, A.B., 2007. The evolution of color polymorphism: crypticity, searching images, and apostatic selection. Annu Rev Ecol Evol Syst 38, 489-514.

Briscoe, A.D., Chittka, L., 2001. The evolution of color vision in insects. Annu. Rev. Entomol. 46, 471-510. 
Brooke, M. de L., Davies, N.B., 1988. Egg mimicry by cuckoos Cuculus canorus in relation to discrimination by hosts. Nature 335, 630 .

Brown, A.F., Yousef, G.G., Jeffery, E.H., Klein, B.P., Wallig, M.A., Kushad, M.M., Juvik, J.A., 2002. Glucosinolate profiles in broccoli: Variation in levels and implications in breeding for cancer chemoprotection. J. Am. Soc. Hortic. Sci. 127, $807-813$.

Brown, K.S., Francini, R.B., 1990. Evolutionary strategies of chemical defense in aposematic butterflies: cyanogenesis in Asteraceae-feeding American Acraeinae. Chemoecology 1, 52-56.

Bundy, C.S., McPherson, R.M., 2000. Morphological examination of stink bug (Heteroptera: Pentatomidae) eggs on cotton and soybeans, with a key to genera. Ann. Entomol. Soc. Am. 93, 616-624.

Cadet, J., Sage, E., Douki, T., 2005. Ultraviolet radiation-mediated damage to cellular DNA. Mutat. Res. Mol. Mech. Mutagen. 571, 3-17.

Canerday, T.D., 1965. On the biology of the Harlequin bug, Murgantia histrionica (Hemiptera: Pentatomidae). Ann. Entomol. Soc. Am. 58, 931-932. https://doi.org/10.1093/aesa/58.6.931

Carlberg, U., 1986. Phasmida: a biological review (Insecta). Zool. Anz.

Caro, T., Sherratt, T.N., Stevens, M., 2016. The ecology of multiple colour defences. Evol. Ecol. 30, 797-809.

Caro, T., Stankowich, T., Kiffner, C., Hunter, J., 2013. Are spotted skunks conspicuous or cryptic? Ethol. Ecol. Evol. 25, 144-160. https://doi.org/10.1080/03949370.2012.744359 
Caro, T., Walker, H., Rossman, Z., Hendrix, M., Stankowich, T., 2017. Why is the giant panda black and white? Behav. Ecol. 28, 657-667.

Clark, B.R., Faeth, S.H., 1998. The evolution of egg clustering in butterflies: a test of the egg desiccation hypothesis. Evol. Ecol. 12, 543-552.

Clark, J.T., 1976. The eggs of stick insects (Phasmida): a review with descriptions of the eggs of eleven species. Syst. Entomol. 1, 95-105.

Compton, Sg., Ware, A.B., 1991. Ants disperse the elaisosome-bearing eggs of an African stick insect. Psyche (Stuttg.) 98, 207-214.

Conner, W.E., Boada, R., Schroeder, F.C., González, A., Meinwald, J., Eisner, T., 2000. Chemical defense: bestowal of a nuptial alkaloidal garment by a male moth on its mate. Proc. Natl. Acad. Sci. 97, 14406-14411.

Conti, E., Salerno, G., Bin, F., Williams, H.J., Vinson, S.B., 2003. Chemical cues from Murgantia histrionica eliciting host location and recognition in the egg paras itoid Trissolcus brochymenae. J. Chem. Ecol. 29, 115-130.

Cronin, T.W., Bok, M.J., 2016. Photoreception and vision in the ultraviolet. J. Exp. Biol. $219,2790-2801$.

Cuthill, I.C., Allen, W.L., Arbuckle, K., Caspers, B., Chaplin, G., Hauber, M.E., Hill, G.E., Jablonski, N.G., Jiggins, C.D., Kelber, A., 2017. The biology of color. Science 357, eaan0221.

Daloze, D., Braekman, J.-C., Pasteels, J.M., 1994. Ladybird defence alkaloids: structural, chemotaxonomic and biosynthetic aspects (Col: Coccinellidae). Chemoecology $5,173-183$. 
Daloze, D., Pasteels, J.M., 1979. Production of cardiac glycosides by chrysomelid beetles and larvae. J. Chem. Ecol. 5, 63-77.

Damman, H., Cappuccino, N., 1991. Two forms of egg defence in a chrysomelid beetle: egg clumping and excrement cover. Ecol. Entomol. 16, 163-167.

Daniels, J.C., Minno, M.C., Emmel, T.C., Eliazar, P.J., Groce, L.L., 1993. Egg color dimorphism in the endangered Schaus swallowtail butterfly, Papilio Aristodemus Ponceanus, of South Florida. Trop. Lepidoptera 4, 65-66.

Dinno, A., 2017. dunn.test: Dunn's test of multiple comparisons using rank sums.

Doheny-Adams, T., Redeker, K., Kittipol, V., Bancroft, I., Hartley, S.E., 2017. Development of an efficient glucosinolate extraction method. Plant Methods 13, 17.

Dreon, M.S., Ituarte, S., Heras, H., 2010. The role of the proteinase inhibitor ovorubin in apple snail eggs resembles plant embryo defense against predation. PLoS ONE 5, e15059. https://doi.org/10.1371/journal.pone.0015059

Duffey, S.S., Scudder, G.G.E., 1974. Cardiac glycosides in Oncopeltus fasciatus (Dallas)(Hemiptera: Lygaeidae). I. The uptake and distribution of natural cardenolides in the body. Can. J. Zool. 52, 283-290.

Dukas, R., 2008. Evolutionary biology of insect learning. Annu. Rev. Entomol. 53.

Dussourd, D.E., Harvis, C.A., Meinwald, J., Eisner, T., 1989. Paternal allocation of sequestered plant pyrrolizidine alkaloid to eggs in the danaine butterfly, Danaus gilippus. Experientia 45, 896-898. 
Dussourd, D.E., Ubik, K., Harvis, C., Resch, J., Meinwald, J., Eisner, T., 1988. Biparental defensive endowment of eggs with acquired plant alkaloid in the moth Utetheisa ornatrix. Proc. Natl. Acad. Sci. 85, 5992-5996.

Edmunds, M., 1974. Defence in animals: a survey of anti-predator defences. Longman Publishing Group.

Eisner, T., Attygalle, A.B., Conner, W.E., Eisner, M., MacLeod, E., Meinwald, J., 1996. Chemical egg defense in a green lacewing (Ceraeochrysa smithi). Proc. Natl. Acad. Sci. 93, 3280-3283.

Eisner, T., Eisner, M., Rossini, C., Iyengar, V.K., Roach, B.L., Benedikt, E., Meinwald, J., 2000. Chemical defense against predation in an insect egg. Proc. Natl. Acad. Sci. $97,1634-1639$.

Eisner, T., Nowicki, S., Goetz, M., Meinwald, J., 1980. Red cochineal dye (carminic acid): its role in nature. Science 208, 1039-1042.

Eisner, T., Rossini, C., González, A., Iyengar, V.K., Siegler, M.V., Smedley, S.R., 2002. Paternal investment in egg defence. Chemoecology Insect Eggs Egg Depos. 91116.

Endler, J.A., 1983. Natural and sexual selection on color patterns in poeciliid fishes. Environ. Biol. Fishes 9, 173-190.

Exnerová, A., Stys, P., Kristin, A., Volf, O., Pudil, M., 2003. Birds as predators of true bugs (Heteroptera) in different habitats. Biol.-Bratis1. 58, 253-264.

Exnerová, A., Svádová, K., Fousová, P., Fučiková, E., Ježová, D., Niederlová, A., Kopečková, M., Štys, P., 2008. European birds and aposematic Heteroptera: review of comparative experiments. Bull. Insectology 61, 163-165. 
Farnesi, L.C., Vargas, H.C.M., Valle, D., Rezende, G.L., 2017. Darker eggs of mosquitoes resist more to dry conditions: Melanin enhances serosal cuticle contribution in egg resistance to desiccation in Aedes, Anopheles and Culex vectors. PLoS Negl. Trop. Dis. 11, e0006063. https://doi.org/10.1371/journal.pntd.0006063

Feltwell, J., 2016. Black and White in the Wild. RedDoor Publishing.

Ferguson, J.E., Metcalf, R.L., Fischer, D.C., 1985. Disposition and fate of cucurbitacin B in five species of diabroticites. J. Chem. Ecol. 11, 1307-1321.

Fishelson, L., Parsons, J.A., Reichstein, T., Rothschild, M., 1967. Cardenolides (heart poisons) in a grasshopper feeding on milkweeds. Nature 214, 35 .

Florkiewicz, A., Ciska, E., Filipiak-Florkiewicz, A., Topolska, K., 2017. Comparison of Sous-vide methods and traditional hydrothermal treatment on GLS content in Brassica vegetables. Eur. Food Res. Technol. 243, 1507-1517. https://doi.org/10.1007/s00217-017-2860-z

Forsman, A., 2000. Some like it hot: intra-population variation in behavioral thermoregulation in color-polymorphic pygmy grasshoppers. Evol. Ecol. 14, 2538.

Fox, J., Weisberg, S., 2011. An R companion to applied regression. Sage Publications.

Frank, J.H., Curtis, G.A., 1977. On the bionomics of bromeliad inhabiting mosquitoes. IV. Egg mortality of Wyeomyia vanduzeei caused by rainfall. Mosq. News.

Fukatsu, T., Hosokawa, T., 2002. Capsule-transmitted gut symbiotic bacterium of the Japanese common plataspid stinkbug, Megacopta punctatissima. Appl. Environ. Microbiol. 68, 389-396. 
Gaudreau, M., Abram, P.K., Brodeur, J., 2017. Host egg pigmentation protects developing parasitoids from ultraviolet radiation. Oikos 126, 1419-1427. https://doi.org/10.1111/oik.04217

Gilbert, L.E., 1975. Ecological consequences of a coevolved mutualism between butterflies and plants. Coevol. Anim. Plants Univ. Tex. Press Austin 210-240.

González, A., Hare, J.F., Eisner, T., 1999. Chemical egg defense in Photuris firefly “femmes fatales." Chemoecology 9, 177-185.

Grazia, J., Panizzi, A.R., Greve, C., Schwertner, C.F., Campos, L.A., Garbelotto, T. de A., Fernandes, J.A.M., 2015. Stink bugs (Pentatomidae), in: True bugs (Heteroptera) of the Neotropics. Springer, pp. 681-756.

Gutschick, V.P., 1999. Biotic and abiotic consequences of differences in leaf structure. New Phytol. 143, 3-18.

Hale, R.E., Kennedy, C., Winkelman, D., Brown, C., 2017. An advantage of clear over white egg mass morphs in metabolically demanding microhabitats suggests a role of symbiotic algae in the maintenance of a polymorphism in the spotted salamander (Ambystoma maculatum). Evol. Ecol. Res. 18, 637-650.

Halkier, B.A., Gershenzon, J., 2006. Biology and biochemistry of glucosinolates. Annu Rev Plant Biol 57, 303-333.

Hilker, M., 1992. Protective devices of early developmental stages in Pyrrhalta viburni (Coleoptera, Chrysomelidae). Oecologia 92, 71-75.

Hilker, M., Daloze, D., Pasteels, J.M., 1992. Cardenolide glycosides from the adults and eggs of Chrysolina fuliginosa (Coleoptera: Chrysomelidae). Experientia 48, $1023-1027$. 
Hilker, M., Fatouros, N.E., 2015. Plant responses to insect egg deposition. Annu. Rev. Entomol. 60, 493-515.

Hilker, M., Schulz, S., 1991. Anthraquinones in different developmental stages of Galeruca tanaceti (Coleoptera, Chrysomelidae). J. Chem. Ecol. 17, 2323-2332.

Hill, G.E., 1991. Plumage coloration is a sexually selected indicator of male quality. Nature 350, 337.

Hinton, H.E., 1981. Biology of insect eggs. Volume I, Volume II, Volume III. Pergammon Press.

Hoffmeyer, S., 1970. Dispersal of Pachythelia species (Lep.: Psychidae). Entomol. Rec J $\operatorname{Var} 82,33$.

Hothorn, T., Bretz, F., Westfall, P., 2008. Simultaneous inference in general parametric models. Biom. J. 50, 346-363.

Howard, D.F., Blum, M.S., Jones, T.H., Phillips, D.W., 1982a. Defensive adaptations of eggs and adults of Gastrophysa cyanea (Coleoptera: Chrysomelidae). J. Chem. Ecol. 8, 453-462.

Howard, D.F., Phillips, D.W., Jones, T.H., Blum, M.S., 1982b. Anthraquinones and anthrones: occurrence and defensive function in a chrysomelid beetle. Naturwissenschaften 69, 91-92.

Humphreys, R.K., Ruxton, G.D., 2018. A review of thanatosis (death feigning) as an antipredator behaviour. Behav. Ecol. Sociobiol. 72, 22.

Ishiwatari, T., 1974. Studies on the scent of stink bugs (Hemiptera: Pentatomidae): I. Alarm pheromone activity. Appl. Entomol. Zool. 9, 153-158. 
Izzo, A., Walker, H., Reiner Jr, R.C., Stankowich, T., Caro, T., 2014. The function of zebra stripes. Nat. Commun. 5, 3535 .

Jablonski, N.G., Chaplin, G., 2000. The evolution of human skin coloration. J. Hum. Evol. 39, 57-106.

Jacobs, C.G., Rezende, G.L., Lamers, G.E., van der Zee, M., 2013. The extraembryonic serosa protects the insect egg against desiccation. Proc. R. Soc. Lond. B Biol. Sci. $280,20131082$.

Jamie, G.A., 2017. Signals, cues and the nature of mimicry. Proc R Soc B 284, 20162080.

Jeffries, M.J., Lawton, J.H., 1984. Enemy free space and the structure of ecological communities. Biol. J. Linn. Soc. 23, 269-286.

Jones, W.A., 1988. World review of the parasitoids of the southern green stink bug, Nezara viridula (L.)(Heteroptera: Pentatomidae). Ann. Entomol. Soc. Am. 81, $262-273$.

Kalender, Z.S.S.C.Y., 1999. Chorionic sculpturing in eggs of six species of Eurydema (Heteroptera, Pentatomidae): A scanning electron microscope investigation. J Ent $1,27-56$.

Kang, Y., Kulakosky, P.C., Van Antwerpen, R., Law, J.H., 1995. Sequestration of insecticyanin, a blue hemolymph protein, into the egg of the hawkmoth Manduca sexta. Evidence for receptor-mediated endocytosis. Insect Biochem. Mol. Biol. $25,503-510$.

Kawooya, J.K., Keim, P.S., Law, J.H., Riley, C.T., Ryan, R.O., Shapiro, J.P., 1985. Why are green caterpillars green? ACS Publications. 
Kilner, R.M., 2006. The evolution of egg colour and patterning in birds. Biol. Rev. 81, 383. https://doi.org/10.1017/S1464793106007044

Le Rouzic, A., Hansen, T.F., Gosden, T.P., Svensson, E.I., 2015. Evolutionary timeseries analysis reveals the signature of frequency-dependent selection on a female mating polymorphism. Am. Nat. 185, E182-E196.

Li, M., Lin, H., Li, S., Xu, A. -me., Feng, M., 2013. Efficiency of entomopathogenic fungi in the control of eggs of the brown planthopper Nilaparvata lugens Stl (Homopera: Delphacidae). Afr. J. Microbiol. Res. 6, 7162-7167.

Lobdell, C.E., Yong, T.-H., Hoffmann, M.P., 2005. Host color preferences and short-range searching behavior of the egg parasitoid Trichogramma ostriniae. Entomol. Exp. App1. 116, 127-134.

Lognay, G., Hemptinne, J.-L., Chan, F.Y., Gaspar, C.H., Marlier, M., Braekman, J.C., Daloze, D., Pasteels, J.M., 1996. Adalinine, a new piperidine alkaloid from the ladybird beetles Adalia bipunctata and Adalia decempunctata. J. Nat. Prod. 59, $510-511$.

Louda, S., Mole, S., 1991. Glucosinolates: chemistry and ecology. Herbiv. Their Interact. Second. Plant Metab. 1, 123-164.

Ludwig, S.W., Kok, L.T., 2001. Harlequin bug, Murgantia histrionica (Hahn) (Heteroptera: Pentatomidae) development on three crucifers and feeding damage on broccoli. Crop Prot. 20, 247-251. https://doi.org/10.1016/S02612194(00)00150-2

Maan, M.E., Cummings, M.E., 2009. Sexual dimorphism and directional sexual selection on aposematic signals in a poison frog. Proc. Natl. Acad. Sci. 106, 19072-19077. 
Mappes, J., Marples, N., Endler, J., 2005. The complex business of survival by $\begin{array}{llll}\text { aposematism. } & \text { Trends } & \text { Ecol. } & \text { Evol. 20, }\end{array}$ https://doi.org/10.1016/j.tree.2005.07.011

Marchini, D., Marri, L., Rosetto, M., Manetti, A.G., Dallai, R., 1997. Presence of antibacterial peptides on the laid egg chorion of the Medfly Ceratitis capitata. Biochem. Biophys. Res. Commun. 240, 657-663.

Marsh, N., Rothschild, M., 1974. Aposematic and cryptic Lepidoptera tested on the mouse. J. Zool. 174, 89-122.

Marshall, J.N., 2000. Communication and camouflage with the same "bright" colours in reef fishes. Philos. Trans. R. Soc. B Biol. Sci. 355, 1243-1248. https://doi.org/10.1098/rstb.2000.0676

Maynard-Smith, J., 1982. Evolution and the theory of games. Cambridge: Cambridge University Press.

Maynard-Smith, J., 1972. Game theory and the evolution of fighting. Evol. 8-28.

McPherson, J.E., 1982. The Pentatomoidea (Hemiptera) of northeastern North America with emphasis on the fauna of Illinois. SIU Press.

Merle, P. du, Brunet, S., 1991. From green to yellow or yellowish white: egg-color changes in relation to oviposition rank in the fir budworm Choristoneura murinana (Hb.)(Lep., Tortricidae). J. Appl. Entomol. 111, 342-348.

Miyatake, T., 2001. Diurnal periodicity of death-feigning in Cylas formicarius (Coleoptera: Brentidae). J. Insect Behav. 14, 421-432. 
Miyatake, T., Katayama, K., Takeda, Y., Nakashima, A., Sugita, A., Mizumoto, M., 2004. Is death-feigning adaptive? Heritable variation in fitness difference of death-feigning behaviour. Proc. R. Soc. Lond. B Biol. Sci. 271, 2293-2296.

Miyatake, T., Nakayama, S., Nishi, Y., Nakajima, S., 2009. Tonically immobilized selfish prey can survive by sacrificing others. Proc. R. Soc. Lond. B Biol. Sci. rspb. 2009.0558.

Mochi, D.A., Monteiro, A.C., Machado, A.C.R., Yoshida, L., 2010. Efficiency of entomopathogenic fungi in the control of eggs and larvae of the horn fly Haematobia irritans (Diptera: Muscidae). Vet. Parasitol. 167, 62-66.

Moreno, J., Osorno, J.L., 2003. Avian egg colour and sexual selection: does eggshell pigmentation reflect female condition and genetic quality? Ecol. Lett. 6, 803-806.

Murdoch, W.W., Avery, S., Smyth, M.E.B., 1975. Switching in predatory fish. Ecology 56, 1094-1105. https://doi.org/10.2307/1936149

Nahrstedt, A., Davis, R.H., 1986. (R) MandeIonitrile and Prunasin, the sources of hydrogen cyanide in all stages of Paropsis atomaria (Coleoptera: Chysomelidae). Z. Für Naturforschung C 41, 928-934.

Nishida, R., Fukami, H., 1989. Ecological adaptation of an Aristolochiaceae-feeding swallowtail butterfly, Atrophaneura alcinous, to aristolochic acids. J. Chem. Ecol. $15,2549-2563$.

Nishida, R., Rothschild, M., 1995. A cyanoglucoside stored by a Sedum-feeding Apollo butterfly, Parnassius phoebus. Experientia 51, 267-269. 
Nokelainen, O., Hegna, R.H., Reudler, J.H., Lindstedt, C., Mappes, J., 2011. Trade-off between warning signal efficacy and mating success in the wood tiger moth. Proc. R. Soc. Lond. B Biol. Sci. rspb20110880.

Nowak, M.A., Sigmund, K., 2004. Evolutionary dynamics of biological games. science 303, 793-799.

Oaten, A., Murdoch, W.W., 1975. Switching, functional response, and stability in predator-prey systems. Am. Nat. 109, 299-318.

Olendorf, R., Rodd, F.H., Punzalan, D., Houde, A.E., Hurt, C., Reznick, D.N., Hughes, K.A., 2006. Frequency-dependent survival in natural guppy populations. Nature 441, 633-636. https://doi.org/10.1038/nature04646

Opitz, S.E.W., Müller, C., 2009. Plant chemistry and insect sequestration. Chemoecology 19, 117-154. https://doi.org/10.1007/s00049-009-0018-6

Orians, G.H., Janzen, D.H., 1974. Why are embryos so tasty? Am. Nat. 108, 581-592.

Paiero, S.M., Marshall, S.A., McPherson, J.E., Ma, M.S., 2013. Stink bugs (Pentatomidae) and parent bugs (Acanthosomatidae) of Ontario and adjacent areas: A key to species and a review of the fauna. Can. J. Arthropod Identif. 24, $1-183$.

Papaj, D.R., Newsom, G.M., 2005. A within-species warning function for an aposematic signal. Proc. R. Soc. B Biol. Sci. 272, 2519-2523. https://doi.org/10.1098/rspb.2005.3186

Pasteels, J.M., Daloze, D., Rowell-Rahier, M., 1986. Chemical defence in chrysomelid eggs and neonate larvae. Physiol. Entomol. 11, 29-37. 
Pasteels, J.M., Rowell-Rahier, M., Ehmke, A., Hartmann, T., 1996. Host derived pyrrolizidine alkaloids in oreina leaf beetles: physiological, ecological and evolutionary aspects, in: The Biology of Chrysomelidae. Springer, pp. 213-225.

Pawlik, J.R., Kernan, M.R., Molinski, T.F., Harper, M.K., Faulkner, D.J., 1988. Defensive chemicals of the Spanisch dancer nudibranch Hexabranchus sanguineus and its egg ribbons: macrolides derived from a sponge diet. J. Exp. Mar. Biol. Ecol. 119, 99-109.

Peri, E., Salerno, G., Slimani, T., Frati, F., Conti, E., Colazza, S., Cusumano, A., 2016. The response of an egg parasitoid to substrate-borne semiochemicals is affected by previous experience. Sci. Rep. 6, 27098.

Peterson, A., 1962. Some eggs of insects that change color during incubation. Fla. Entomol. 45, 81. https://doi.org/10.2307/3492222

Petranka, J.W., Rushlow, A.W., Hopey, M.E., 1998. Predation by tadpoles of Rana sylvatica on embryos of Ambystoma maculatum: implications of ecological role reversals by Rana (predator) and Ambystoma (prey). Herpetologica 1-13.

Pintar, M.R., Resetarits, W.J., 2017. Persistence of an egg mass polymorphism in Ambystoma maculatum: differential performance under high and low nutrients. Ecology 98, 1349-1360.

Poulton, E.B., 1890. The colours of animals: their meaning and use, especially considered in the case of insects. D. Appleton.

Prohammer, L.A., Wade, M.J., 1981. Geographic and genetic variation in death-feigning behavior in the flour beetle, Tribolium castaneum. Behav. Genet. 11, 395-401. 
Pugalenthi, P., Livingstone, D., 1995. Cardenolides (heart poisons) in the painted grasshopper Poecilocerus pictus F.(Orthoptera: Pyrgomorphidae) feeding on the milkweed Calotropis gigantea L.(Asclepiadaceae). J. N. Y. Entomol. Soc. 191196.

R Core Team, 2017. R: The R project for statistical computing [WWW Document]. URL https://www.r-project.org/ (accessed 5.26.16).

Reichstein, T. von, Von Euw, J., Parsons, J.A., Rothschild, M., 1968. Heart poisons in the monarch butterfly. Science 161, 861-866.

Roff, D.A., Fairbairn, D.J., 2013. The costs of being dark: the genetic basis of melanism and its association with fitness-related traits in the sand cricket. J. Evol. Biol. 26, 1406-1416. https://doi.org/10.1111/jeb.12150

Rothschild, M., 1992. Egg protection by the Atala Hairstreak butterfly (Eumaeus atala florida). Phytochemistry 31, 1959-1960.

Ruth, B.C., Dunson, W.A., Rowe, C.L., Hedges, S.B., 1993. A molecular and functional evaluation of the egg mass color polymorphism of the Spotted salamander, Ambystoma maculatum. J. Herpetol. 27, 306. https://doi.org/10.2307/1565152

Ruxton, G., 2006. Grasshoppers don’t play possum: Behavioural ecology. Nature 440, 880-880. https://doi.org/10.1038/440880a

Ruxton, G.D., Sherratt, T.N., Speed, M.P., 2004. Avoiding attack: the evolutionary ecology of crypsis, warning signals and mimicry. Oxford University Press.

Samra, S., Ghanim, M., Protasov, A., Mendel, Z., 2015. Development, reproduction, host range and geographical distribution of the variegated caper bug Stenozygum 
coloratum (Hemiptera: Heteroptera: Pentatomidae). Eur. J. Entomol. https://doi.org/10.14411/eje.2015.041

Schaffner, U., Müller, C., 2001. Exploitation of the fecal shield of the lily leaf beetle, Lilioceris lilii (Coleoptera: Chrysomelidae), by the specialist parasitoid Lemophagus pulcher (Hymenoptera: Ichneumonidae). J. Insect Behav. 14, 739757.

Shapiro, A.M., 1981a. The pierid red-egg syndrome. Am. Nat. 117, 276-294.

Shapiro, A.M., 1981b. Egg-mimics of Streptanthus (Cruciferae) deter oviposition by Pieris sisymbrii (Lepidoptera: Pieridae). Oecologia 48, 142-143.

Shapiro, T.A., Fahey, J.W., Wade, K.L., Stephenson, K.K., Talalay, P., 1998. Human metabolism and excretion of cancer chemoprotective glucosinolates and isothiocyanates of cruciferous vegetables. Cancer Ep idemiol. Prev. Biomark. 7, $1091-1100$.

Sherrat, T.N., Forbes, M.R., 2001. Sexual differences in coloration of Coenagrionid damselflies (Odonata): a case of intraspecific aposematism. Anim Behav 62, 653660.

Sherratt, T.N., Harvey, I.F., 1993. Frequency-dependent food selection by arthropods: a review. Biol. J. Linn. Soc. 48, 167-186.

Skelhorn, J., Halpin, C.G., Rowe, C., 2016. Learning about aposematic prey. Behav. Ecol. 27, 955-964. https $/ /$ doi.org/10.1093/beheco/arw009

Smedley, S.R., Risteen, R.G., Tonyai, K.K., Pitino, J.C., Hu, Y., Ahmed, Z.B., Christo fel, B.T., Gaber, M., Howells, N.R., Mosey, C.F., Rahim, F.U., Deyrup, S.T., 2017. Bufadienolides (lucibufagins) from an ecologically aberrant firefly (Ellychnia 
corrusca). Chemoecology 27, 141-153. https://doi.org/10.1007/s00049-017$0240-6$

Soler, J.J., Moreno, J., Avilés, J.M., Møller, A.P., 2005. Blue and green egg-color intensity is associated with parental effort and mating system in passerines: support for the sexual selection hypothesis. Evolution 59, 636-644.

Song, L., Thornalley, P.J., 2007. Effect of storage, processing and cooking on glucosinolate content of Brassica vegetables. Food Chem. Toxicol. 45, 216-224. https://doi.org/10.1016/j.fct.2006.07.021

Stallings, D.B., Stallings, V.N., 1986. Variation in egg color in Agathymus estelleae (Lepidoptera: Megathymidae). Entomol. News USA.

Stamp, N.E., 1980. Egg deposition patterns in butterflies: why do some species cluster their eggs rather than deposit them singly? Am. Nat. 115, 367-380.

Stevens, M., 2007. Predator perception and the interrelation between different forms of protective coloration. Proc. R. Soc. B Biol. Sci. 274, 1457-1464. https://doi.org/10.1098/rspb.2007.0220

Stevens, M., Merilaita, S., 2009. Defining disruptive coloration and distinguishing its functions. Philos. Trans. R. Soc. B Biol. Sci. 364, 481-488. https://doi.org/10.1098/rstb.2008.0216

Stevens, M., Yule, D.H., Ruxton, G.D., 2008. Dazzle coloration and prey movement. $\begin{array}{llllll}\text { Proc. } & \text { R. Soc. } & \text { B } & \text { Biol. } & \text { Sci. 275, } 2643 \text {, }\end{array}$ https://doi.org/10.1098/rspb.2008.0877

Stoddard, M.C., Stevens, M., 2011. Avian vision and the evolution of egg color mimicry in the common cuckoo. Evolution 65, 2004-2013. 
Stork, N.E., 2017. How many species of insects and other terrestrial arthropods are there on Earth? Annu. Rev. Entomol.

Torres-Campos, I., Abram, P.K., Guerra-Grenier, E., Boivin, G., Brodeur, J., 2016. A scenario for the evolution of selective egg coloration: the roles of enemy-free space, camouflage, thermoregulation and pigment limitation. R. Soc. Open Sci. 3, 150711. https://doi.org/10.1098/rsos.150711

Troscianko, J., Skelhorn, J., Stevens, M., 2017. Quantifying camouflage: how to predict detectability from appearance. BMC Evol. Biol. 17, 7.

Troscianko, J., Stevens, M., 2015. Image calibration and analysis toolbox-a free software suite for objectively measuring reflectance, colour and pattern. Methods Ecol. Evol. 6, 1320-1331.

Tullberg, B.S., Merilaita, S., Wiklund, C., 2005. Aposematism and crypsis combined as a result of distance dependence: functional versatility of the colour pattern in the swallowtail butterfly larva. Proc. R. Soc. B Biol. Sci. 272, 1315-1321. https://doi.org/10.1098/rspb.2005.3079

Välimäki, P., Kivelä, S.M., Raitanen, J., Pakanen, V.-M., Vatka, E., Mäenpää, M.I., Keret, N., Tammaru, T., 2015. Larval melanism in a geometrid moth: promoted neither by a thermal nor seasonal adaptation but desiccating environments. J. Anim. Ecol. 84, 817-828. https://doi.org/10.1111/1365-2656.12330

van Leeuwen, E., Brännström, Å., Jansen, V.A., Dieckmann, U., Rossberg, A.G., 2013. A generalized functional response for predators that switch between multiple prey species. J. Theor. Biol. 328, 89-98. 
van Leeuwen, E., Jansen, V.A.A., Bright, P.W., 2007. How population dynamics shape the functional response in a one-predator-two-prey system. Ecology 1571-1581. Verhoeven, G.J., Schmitt, K.D., 2010. An attempt to push back frontiers-digital nearultravio let aerial archaeology. J. Archaeol. Sci. 37, 833-845.

Voigt, D., Gorb, S., 2009. Egg attachment of the asparagus beetle Crioceris asparagi to the crystalline waxy surface of Asparagus officinalis. Proc. R. Soc. Lond. B Biol. Sci. rspb20091706.

von Euw, J., Fishelson, L., Parsons, J.A., Reichstein, T., Rothschild, M., 1967. Cardenolides (heart poisons) in a grasshopper feeding on milkweeds. Nature 214, 35.

von Euw, J., Reichstein, T., Rothschild, M., 1971. Heart poisons (cardiac glycosides) in the lygaeid bugs Caenocoris nerii and Spilostethus pandurus. Insect Biochem. 1, $373-384$.

von Nickisch-Rosenegk, E., Schneider, D., Wink, M., 1990. Time-course of pyrrolizidine alkaloid processing in the alkaloid exploiting arctiid moth, Creatonotos transiens. Z. Für Naturforschung C 45, 881-894.

Wallingford, A.K., Kuhar, T.P., Schultz, P.B., Freeman, J.H., 2011. Harlequin bug biology and pest management in brassicaceous crops. J. Integr. Pest Manag. 2, H1-H4. https://doi.org/10.1603/IPM10015

White, A.E., Olson, J.R., 2014. Plasticity of pigmentation and thermoregulation of the harlequin bug, Murgantia histrionica, in response to developmental temperature, in: Integrative and Comparative Biology. Oxford Univ Press inc. journals dept, pp. E368-E368. 
Wickman, P.-O., Karlsson, B., 1987. Changes in egg colour, egg weight and oviposition rate with the number of eggs laid by wild females of the small heath butterfly, Coenonympha pamphilus. Ecol. Entomol. 12, 109-114.

Wiemann, J., Yang, T.-R., Sander, P.N., Schneider, M., Engeser, M., Kath-Schorr, S., Müller, C.E., Sander, P.M., 2017. Dinosaur origin of egg color: oviraptors laid blue-green eggs. PeerJ 5, e3706. https://doi.org/10.7717/peerj.3706

Wiemann, J., Yang, T.-R., Sander, P.N., Schneider, M., Engeser, M., Kath-Schorr, S., Müller, C.E., Sander, P.M., 2015. The blue-green eggs of dinosaurs: How fossil metabolites provide insights into the evolution of bird reproduction. PeerJ Prepr.

Williams, K.S., Gilbert, L.E., 1981. Insects as selective agents on plant vegetative morphology: egg mimicry reduces egg laying by butterflies. Science 212, 467469.

Winters, A.E., Stevens, M., Mitchell, C., Blomberg, S.P., Blount, J.D., 2014. Maternal effects and warning signal honesty in eggs and offspring of an aposematic ladybird beetle. Funct. Ecol. 28, 1187-1196. https://doi.org/10.1111/13652435.12266

Wong, J.W., Meunier, J., Kölliker, M., 2013. The evolution of parental care in insects: the roles of ecology, life history and the social environment. Ecol. Entomol. 38, $123-137$.

Young, C.M., Bingham, B.L., 1987. Chemical defense and aposematic coloration in larvae of the ascidian Ecteinascidia turbinata. Mar. Biol. 96, 539-544. 
Zahn, D.K., Girling, R.D., McElfresh, J.S., Cardé, R.T., Millar, J.G., 2008. Biology and reproductive behavior of Murgantia histrionica (Heteroptera: Pentatomidae). Ann. Entomol. Soc. Am. 101, 215-228. 